Final Technical Report

Exploring Ultrahigh Magnetic Field

Processing of Materials for Developing

Customized Microstructures and

Enhanced Performance

March 2005

Principal Investigator:

Dr. Gerard M. Ludtka

Oak Ridge National Laboratory 


\section{DOCUMENT AVAILABILITY}

Reports produced after January 1,1996 , are generally available free via the U.S. Department of Energy (DOE) Information Bridge.

Web site http://www.osti.gov/bridge

Reports produced before January 1, 1996, may be purchased by members of the public from the following source.

National Technical Information Service

5285 Port Royal Road

Springfield, VA 22161

Telephone 703-605-6000 (1-800-553-6847)

TDD 703-487-4639

Fax 703-605-6900

E-mail info@ntis.fedworld.gov

Web site http://www.ntis.gov/support/ordernowabout.htm

Reports are available to DOE employees, DOE contractors, Energy Technology Data Exchange (ETDE) representatives, and International Nuclear Information System (INIS) representatives from the following source.

Office of Scientific and Technical Information

P.O. Box 62

Oak Ridge, TN 37831

Telephone 865-576-8401

Fax 865-576-5728

E-mail reports@adonis.osti.gov

Web site http://www.osti.gov/contact.html 


\section{FINAL TECHNICAL REPORT}

Project Title:

Award Number:

Project Period:

PI:

Additional Researchers:

Recipient Organization:

Industrial Partners:
Exploring Ultrahigh Magnetic Field Processing of Materials for Developing Customized Microstructures and Enhanced Performance

CPS \#1792; FWP \#CEED001

September 30, 2001-December 31, 2004

Dr. Gerard M. Ludtka

(865) 574-5098

ludtkagm1@ornl.gov

Dr. Roger Jarmillo (ORNL)

Mr. Roger Kisner (ORNL)

Dr. Gail M. Ludtka (ORNL)

Dr. John Wilgen (ORNL)

Oak Ridge National Laboratory

One Bethel Valley Road

P.O. Box 2008

Oak Ridge, TN 37831

Cummins, Inc.

Florida State University 

ORNL/TM-2005/79

\title{
Exploring Ultrahigh Magnetic Field Processing of Materials for Developing Customized Microstructures and Enhanced Performance
}

\author{
Gerard M. Ludtka, Roger Jarmillo, Roger Kisner, \\ Gail M. Ludtka, and John Wilgen
}

March 2005

Prepared by

OAK RIDGE NATIONAL LABORATORY

P.O. Box 2008

Oak Ridge, Tennessee 37831-6283

managed by

UT-Battelle, LLC

for the

U.S. DEPARTMENT OF ENERGY

under contract DE-AC05-00OR22725 


\section{Acknowledgments and Disclaimer}

\section{Acknowledgments}

This report is based upon work supported by the U.S. Department of Energy, Energy Efficiency and Renewable Energy, Industrial Technologies Program, Industrial Materials for the Future, under Award No. DE-FC07-01ID14249.

Research was sponsored by the U.S. Department of Energy, Office of Energy Efficiency and Renewable Energy, Industrial Technologies Program, under contract DE-AC05-00OR22725 with UT-Battelle, LLC.

The high magnetic fields experiments would not have been possible without access to the excellent facilities of the National Science Foundation-funded user facility at the National High Magnetic Field Laboratory of Florida State University in Tallahassee, Florida, made available through Dr. Bruce Brandt and Ms. Merry Ann Johnson. The principal investigator of this project also realizes that the significant accomplishments of this endeavor could not have been achieved except through the dedicated and excellent contributions of the other project members of the Oak Ridge National Laboratory (ORNL) original magnetic processing team, composed of Roger Kisner, John Wilgen, Gail Mackiewicz-Ludtka, Roger Jaramillo, and Don Nicholson. Other staff at ORNL who participated in specific areas of this project are also acknowledged: Sudarsanam Babu, Thomas Watkins, Malcolm Stocks, and J. Winston Lue. In addition, the contributions of Peter Kalu of Florida State University, Roger England of Cummins Inc., and summer FaST Intern Program students Nicholas Bembridge and Pamela Mills of Florida State University are greatly appreciated. The authors wish to thank Dr. Peter Angelini for reviewing the document and Ms. Millie Atchley for preparation of documents.

\section{Disclaimer}

This report was prepared as an account of work sponsored by an agency of the United States Government. Neither the United States Government nor any agency thereof, nor any of their employees, makes any warranty, express or implied, or assumes any legal liability or responsibility for the accuracy, completeness, or usefulness of any information, apparatus, product, or process disclosed, or represents that its use would not infringe privately owned rights. Reference herein to any specific commercial product, process, or service by trade name, trademark, manufacturer, or otherwise, does not necessarily constitute or imply its endorsement, recommendation, or favoring by the United States Government or any agency thereof. The views and opinions of authors expressed herein do not necessarily state or reflect those of the United States Government or any agency thereof. 


\section{Contents}

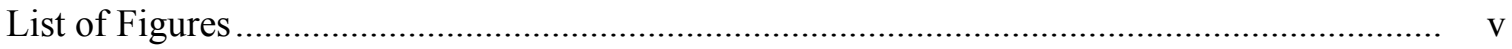

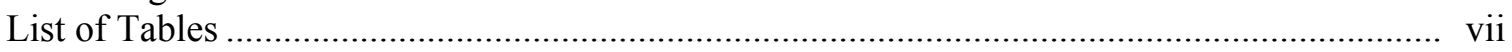

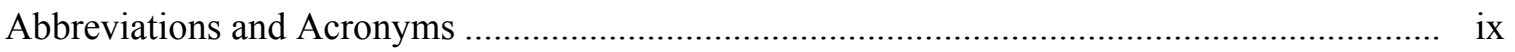

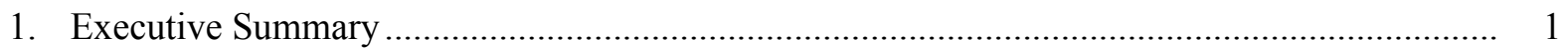

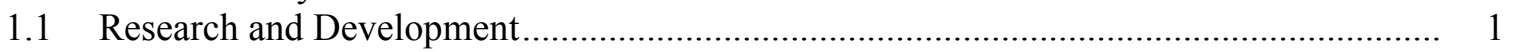

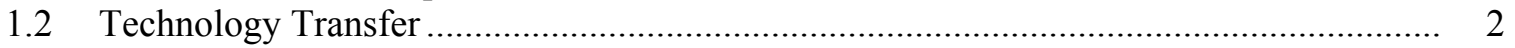

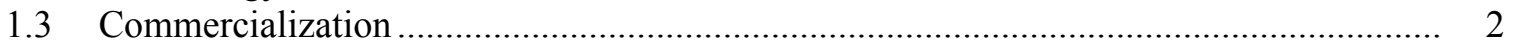

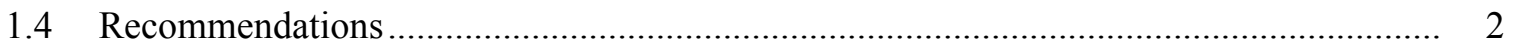

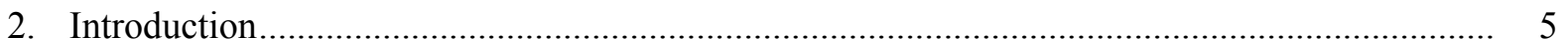

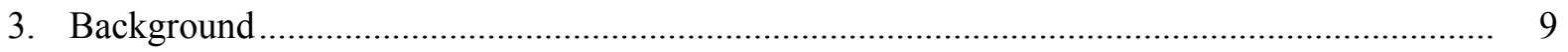

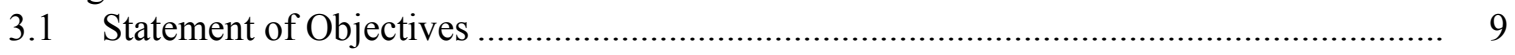

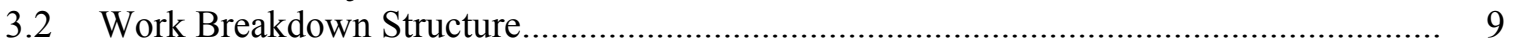

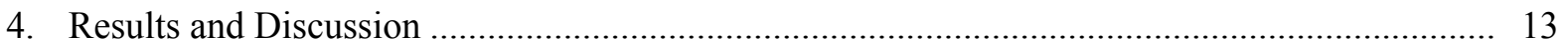

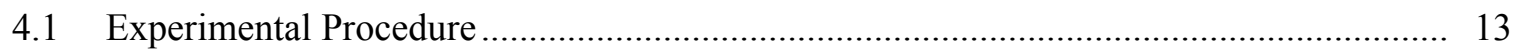

4.2 Modifying Phase Equilibria in Fe-15Ni ................................................................. 13

4.3 SAE 52100 High-Carbon Hypereutectoid Low-Alloy Chromium Steel Investigation...... 17

4.4 SAE 1045 Low-Carbon, Hypoeutectoid Steel Investigation........................................... 22

4.5 Super Bainite High-Strength ( 2.5 GPa) Steel Investigation........................................ 30

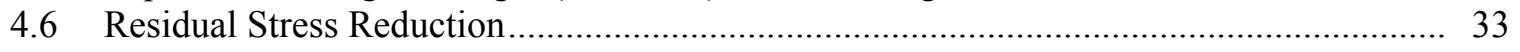

4.7 Energy Savings and Environmental and Economic Benefits to the IMF Program ........... 35

4.8 Alternate Energy Saving Scenarios for Magnetic Processing in the Steel Industry........... 37

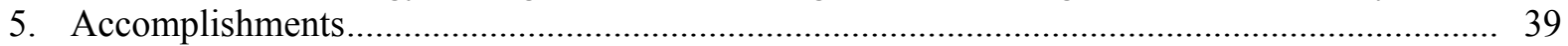

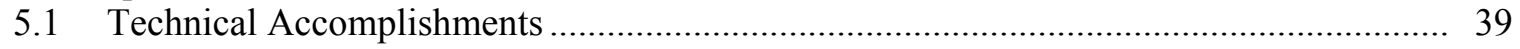

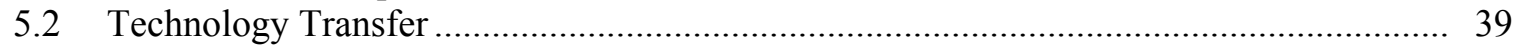

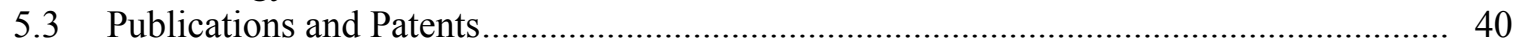

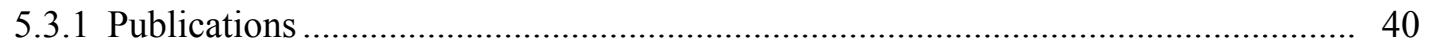

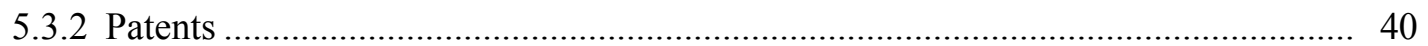

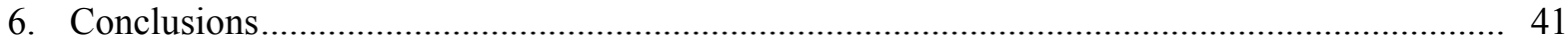

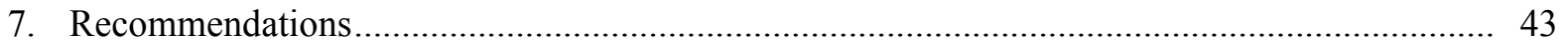

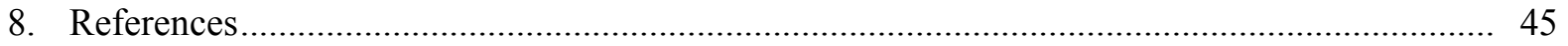

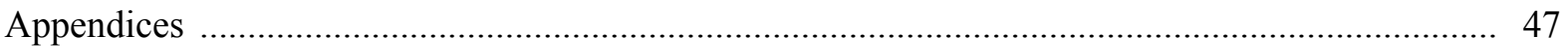

Appendix A: Energy Saving Applications for Magnetic Field Processing of Ferrous Alloys

Appendix B: Publications from the Current Project ........................................................ 57

A.1 In-situ Evidence of Enhanced Phase Transformation Kinetics due to a High Magnetic Field in a Medium Carbon Steel

A.2 Effect of 30-T Magnetic Field on Transformations in a Novel Bainitic Steel

A.3 The Effect of High Magnetic Field Annealing on Enhanced Phase Stability in 85Fe-15Ni 


\section{List of Figures}

4.1 Schematic of experimental apparatus used for heat treatment of specimen within the bore of the magnet

4.2 Iron-rich section of phase diagram showing martensite start-temperature $\left(\mathrm{M}_{\mathrm{S}}\right)$, equal free energy line (dotted line marked $\mathrm{T}_{0}$ ), and decomposition path (horizontal line with arrows) at $500^{\circ} \mathrm{C}$

4.3 Magnetic structure of (a) the ferromagnetic $\alpha$ phase of $\mathrm{Fe}-15 \mathrm{Ni}$ and (b) the paramagnetic $\gamma$ phase in $\mathrm{Fe}-15 \mathrm{Ni}$.

4.4 Free energy curves for $\alpha$ and $\gamma$ phases with and without an applied magnetic field of 30-T strength

4.5 LSD modeling predictions of the shift in phase boundaries under the imposition of a 29-T magnetic field

4.6 The amount of retained austenite in a 52100 alloy steel decreases with increasing magnetic field strength when the field is applied either during or after quench

4.7 Thermal profile and magnetic processing cycle for a 52100 steel showing the 5-min isothermal hold treatment at $740^{\circ} \mathrm{C}$ during which the 30 -T magnetic field was ramped up and maintained until the sample was cooled to ambient temperature.

4.8 Significantly different microstructures evolved at room temperature in the specimen that did not receive any magnetic processing at $740^{\circ} \mathrm{C}$ vs one that was exposed for a short time at this temperature to a $30 \mathrm{~T}$ field

4.9 Application of a 30-T magnetic field during continuous cooling moves the transformation start line in the continuous cooling transformation curve for the 52100 steel upward to higher temperatures and to the left to shorter times as compared with the conventional behavior for this alloy

4.10 Microstructure of a 52100 alloy subjected to continuous cooling at a rate that would result in martensite formation, with and without application of a magnetic field

4.11 Cooling curves for various cooling rates with and without a 30-T magnetic field for the 1045 alloy steel specimens

4.12 Microstructure for 1045 steel specimens cooled at $10^{\circ} \mathrm{C} / \mathrm{s}$

4.13 Continuous cooling path information for the 1045 low-carbon steel alloy for different magnetic field strengths.

4.14 Determination of the transformation temperature shift in the 1045 steel by taking the derivative of the cooling curves, $d T / d t$, and plotting as a function of temperature

4.15 Plot of the experimental transformation temperature shifts

4.16 Plot of the experimentally estimated magnetic contribution to the Gibbs free energy as a function of magnetic field strength.

4.17 Prediction of the pseudobinary phase diagram for 1045 steel for conventional equilibrium and magnetically enhanced equilibrium

4.18 Schematic of a thermal cycling heat treatment cycle about the eutectoid temperature range to achieve austenite phase transformation decomposition

4.19 Schematic of an isothermal magnetic field cycling process showing the magnetic field cycling to achieve austenite decomposition 
4.20 Microstructures for the 1045 alloy steel demonstrating that phase decomposition and reversal equivalent to that obtained from conventional thermal cycling is achieved using isothermal magnetic field processing

4.21 Continuous cooling temperature $\left(1^{\circ} \mathrm{C} / \mathrm{s}\right)$ vs time data for the high-strength bainitic steel alloy for both 0 and 30-T magnetic field conditions.

4.22 Microstructures of the high-strength bainitic steel specimens formed at a cooling rate of $1^{\circ} \mathrm{C} / \mathrm{s}$

4.23 Supporting hardness distribution data for the slow-cooled $\left(1{ }^{\circ} \mathrm{C} / \mathrm{s}\right)$ high-strength bainitic steel for both the "no-field" and 30-T field magnetic processing conditions.

4.24 Prediction of the pseudobinary phase diagram for the tested bainitic steel for both conventional equilibrium and magnetically enhanced equilibrium conditions

4.25 Magnetic processing using a 6-T field altered the residual stresses in 52100 alloy steel samples . 


\section{List of Tables}

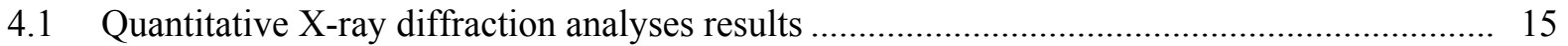

4.2 Enhanced properties in the 52100 alloy after high-field magnetic processing ....................... 18

4.3 Experimentally derived magnetic field contribution to Gibbs free energy ............................ 25

4.4 Projected energy savings for the ultrahigh magnetic field processing project ..................... 36

4.5 Environmental benefits for this project ......................................................................... 37 


\section{Abbreviations and Acronyms}

$\mathrm{A}_{1}$

AISI

ASTM

bcc

CCT

DOE

fcc

HSLA

HTML

IMF

IOF

LSD

$\mathrm{M}_{\mathrm{F}}$

$\mathrm{M}_{\mathrm{S}}$

NHMFL

OIT

ORNL

RA

R\&D

SEM

$\mathrm{T}$

3D

equilibrium eutectoid transformation temperature in steels American Iron and Steel Institute

American Society for Testing and Materials

body-centered cubic

continuous cooling transformation

U.S. Department of Energy

face-centered cubic

high strength low alloy

High Temperature Materials Laboratory

Industrial Materials for the Future

Industries of the Future

local spin density

martensite finish temperature

martensite start temperature

National High Magnetic Field Laboratory

Office of Industrial Technologies

Oak Ridge National Laboratory

retained austenite

research and development

scanning electron microscopy

tesla

three-dimensional 


\section{Executive Summary}

\subsection{Research and Development}

Thermodynamic calculations based on Gibbs free energy in the magnetization-magnetic intensitytemperature (M-H-T) magnetic equation of state space demonstrate that significantly different phase equilibria may result for those material systems where the product and parent phases exhibit different magnetization responses. These calculations show that the Gibbs free energy is changed by a factor equal to $-\mathrm{MdH}$, where $M$ and $H$ are the magnetization and applied field strength, respectively. Magnetic field processing is directly applicable to a multitude of alloys and compounds for dramatically influencing phase stability and phase transformations. This ability to selectively control microstructural stability and alter transformation kinetics through appropriate selection of the magnetic field strength promises to provide a very robust mechanism for developing and tailoring enhanced microstructures (and even nanostructures through accelerated kinetics) with superior properties for a broad spectrum of material applications.

For this Industrial Materials for the Future (IMF) Advanced Materials for the Future project, ferrous alloys were studied initially since this alloy family exhibits ferromagnetism over part of its temperature range of stability and therefore would demonstrate the maximum impact of this novel processing mechanism. Additionally, with these ferrous alloys, the high-temperature parent phase, austenite, exhibits a significantly different magnetization response from the potential product phases, ferrite plus carbide or martensite; and therefore, the solid-state transformation behavior of these alloys will be dramatically influenced by the presence of ultrahigh magnetic fields. Finally, a thermodynamic calculation capability (within ThermoCalc ${ }^{\mathrm{TM}}$ for example) was developed during this project to enable parametric studies to be performed to predict the magnitude of the influence of magnetic processing variables on the phase stability (phase diagrams) in ferromagnetic materials of relevance to the Industries of the Future (IOF).

The new high-payoff industrial processing methodology that could result from this research could lead to the development of alloys and microstructures with superior properties that normally would be impossible to manufacture with conventional thermomechanical processing techniques. Defining phase equilibria thermodynamically in the M-H-T equation of state space (rather than $\mathrm{p}-\mathrm{v}-\mathrm{T}$ ) has not received much investigation. The new classes of alloys with microstructures that can result from this approach, having increased the solid-solution solubility of favorable alloying species, can lead to dramatically improved properties with significant industrial performance. For example, magnetic exposure during continuous cooling was shown to produce ferrite with a higher carbon content and therefore greater hardness. Thus, the process may lead to more energy-efficient, lighter-weight structures in industrial and automotive applications. Similarly, novel microstructure evolution paths and enhanced transformation kinetics may be achieved without the need for further thermal processing or cryogenic heat treatments. This likewise was demonstrated in a study whereby the martensite start temperature was raised $80 \mathrm{~K}$ by the application of a 40-tesla $(\mathrm{T})$ magnetic field during cooling within the magnetic field.

Conceivably, cryogenic processing treatment or the alternate double-temper thermal process to transform any retained austenite to martensite in quenched hypereutectoid steels may be completely eliminated through ultrahigh magnetic field processing, resulting in reduced energy consumption and improved process efficiency. Since essentially all materials (metallic, ceramic, ionic compounds, etc.) exhibit some degree of ferromagnetism or paramagnetism, this investigation has demonstrated a whole new technology for materials processing to develop new classes of materials with novel 
microstructures exhibiting superior properties in support of the vision goals of the IOF effort by the U.S. Department of Energy's (DOE’s) Office of Industrial Technologies (OIT).

The results of this research endeavor clearly demonstrate the dramatic influence that magnetic field processing can have on the resulting microstructure in a broad spectrum of ferromagnetic alloys. This microstructural influence can be observed as changes in the specific phases that make up the final microstructure, in the relative phase stabilities and volume fractions, in the phase solid solubilities, in the transformation temperatures for both equilibrium and metastable transformation products, in the phase decomposition kinetics for both isothermal and continuous cooling thermal processing conditions, and finally in the properties obtained in the resultant microstructures. The goal of this project was to evaluate magnetic processing as a viable and robust new technology for altering phase equilibria and phase transformation kinetics in a ferrous alloy with the goal of developing novel microstructures and properties unattainable through conventional thermomechanical processing approaches. In addition, the potential for future additional significant technological breakthroughs and energy savings have been shown. These findings justify developing a major magnetic processing initiative in the future involving industrial, university, and national laboratory partners to leverage the developments from this project. Further development and commercialization of this technology will provide U.S. industry with a new energy-efficient process and a competitive edge in the global marketplace in the steel, heat-treating, forging, casting, welding, and nanotechnology fields

\subsection{Technology Transfer}

Intellectual property has been generated from this significant research effort. Three inventions are listed in Section 5.3.2. One of these has resulted in a U.S. patent being issued, another patent application has been filed, and a third record of invention has been submitted and is under consideration for formal filing as a patent application.

\subsection{Commercialization}

This project was funded as a Laboratory Call Proposal under the IMF Program. The goal was for ORNL researchers to develop a visionary concept to the stage where sufficient experimental data were available to substantiate future industrial participation in follow-on research and development (R\&D) efforts on specific industrial applications to commercialize this technology. The ORNL researchers on this project are currently developing industrial interest, especially involving a superconducting magnet manufacturer, to pursue collaborations on relevant industrial applications of this magnetic processing technology. The goal is to have an informally organized industrial, university, and laboratory team ready to author and submit proposals to upcoming relevant solicitations that would provide R\&D funding support for this next stage, facilitating successful commercialization of this technology.

Companies who have expressed interest in this technology during this endeavor include American Magnetics, Inc.; Caterpillar, Inc.; Cummins, Inc.; Dana Corporation; Dura-Bar; Hyundai; International Steel Group, Inc. (formerly Bethlehem Steel); Mac Steel; Southwire Company; Stellite Corporation; Stratcor; and Toyota.

\subsection{Recommendations}

This research project has successfully demonstrated for multiple proof-of-principle thrust areas that magnetic processing is a robust tool for customizing the microstructure and enhancing the 
performance of ferromagnetic materials. The principal recommendation of this project team is that the accomplishments and conclusions of this project should be used as the basis for developing appropriate industrial collaborations to enable prototype demonstration facilities for several very specific applications. A secondary recommendation is to initiate proof-of-principle research endeavors on several technology issues. These include

- demonstration of the applicability of magnetic processing for paramagnetic alloy systems;

- extension of ferrous research from solid state applications to solidification processes (casting, welding); and

- pursuit of bulk nanocrystalline microstructure development via isothermal magnetic processing phase transformation reversal. 


\section{Introduction}

Conventional alloying, processing, and heat treating of materials is generally limited to the equilibrium microstructures that can be achieved as defined by a temperature-composition phase diagram or by some metastable microstructures observed and characterized in continuous cooling transformation diagrams (e.g., bainite and martensite in steels) that result from rapid cooling processes such that equilibrium phases cannot form. Similarly, deformation processes may result in non-uniform (inhomogeneous) distributions of the deformation strain throughout the bulk of the material (e.g., strain localization or adiabatic shear), which limits the usefulness of the material in terms of reduced performance (e.g., lowered strain to failure) or frequent annealing cycles between deformation steps in a manufacturing environment. In other applications, powder consolidated materials require rather extensive sintering procedures and cycles (high temperatures, long exposure [sintering] times, applied hydrostatic loads) to produce a product to theoretical density without porosity or reduced performance when compared with wrought product. In solidification processing of materials, casting integrity and performance are often adversely affected by banding/solute segregation and dendrite formation and would benefit tremendously from a more homogeneous, finegrained microstructure. Also, during phase transformations, sometimes defect structures or orientation relationships between parent and product phases (or the lack of orientation relationships) result in some unwanted characteristic (e.g., porosity or distortion) in the final product that the designer would like to eliminate with a processing method. Finally, for some polymorphic materials single-crystal growth attempts from the liquid state yield only multiple-grain specimens at ambient conditions because multiple-phase transformation sequences (with varied nucleation and growth mechanisms) occur upon cooling and negate the single-crystal growth processes (e.g., directional solidification) that are successful at the liquid to high-temperature-phase transformation temperatures prior to cooling.

Research on ferrous alloys [1-7] has clearly shown experimentally that phase stability can be dramatically altered through the application of an ultrahigh magnetic field. This ability to significantly influence the phase stability of parent and product phases provides the ability to tailor and precisely control microstructure for a specific application. Therefore, the simultaneous use of a strong magnetic field and thermal processing promises to be a very robust mechanism to develop uniform and reproducible microstructures in ferrous alloys. This would be especially relevant to hypereutectoid chemistry alloys such as those used in the precision bearing industry (e.g., alloy 52100), where higher carbon levels can result in unwanted retained austenite (RA), which can lead to catastrophic failure while in use. Typically, manufacturing heat-treating operations must then be tailored to eliminate this RA. Eliminating RA usually requires additional processing steps (and therefore higher cost/lower profits) such as a cryogenic treatment immediately upon quenching or a double-temper cycle. An alternative measure - specification of more expensive, higher hardenability grades of the same alloy - to circumvent the unwanted RA issue is not a financially attractive option either.

An applied magnetic field has a direct thermodynamic influence on the chemical potential (Gibbs free energy) of the various phases in a material. This is clearly shown in the following equation for calculating the Gibbs free energy change for iron for the ferrite, $\alpha$, to austenite, $\gamma$, phase transformation in a Fe-C binary alloy in the presence of an applied magnetic field:

$$
\Delta G_{F e}^{\gamma \rightarrow \alpha}=R T\left[\ln a_{F e}^{\gamma}-\ln a_{F e}^{\alpha}\right]+\int_{0}^{H}\left(M_{F e}^{\gamma}-M_{F e}^{\gamma}\right) d H
$$


where $M$ and $H$ are defined as the magnetization and the magnetic intensity, respectively. This effect will be manifested in the $\mathrm{Fe}-\mathrm{C}$ binary equilibrium phase diagram as shifts in the transformation temperatures of the various phases as well as changes in the solubility limits (solvus lines) of the various phases. The main requirement for this proposed magnetic process to be effective is that the parent and product phases need to exhibit different magnetization responses to the applied magnetic field. This property clearly exists for ferrous alloys. Therefore, magnetic fields can be used to drive all of the austenite to transform to martensite upon cooling or immediately after quenching to ambient temperatures. It is likewise conceivable that residual levels of retained austenite could be "dialed in" to precise values for those applications (Hertzian stresses on gear teeth) where small amounts of RA have been found advantageous for improved fatigue performance. Similarly, the application of the high magnetic fields during controlled cooling conditions when metastable conditions exist could be used to refine grain size for those applications mandating a finer and more uniform microstructure. In addition to the thermodynamic effect, other magnetic field characteristics that affect the behavior of ferromagnetic materials include an effective magnetic pressure effect (which can be significant in a large magnetic field gradient) and the Zeeman effect. The latter influences the material at the atomistic level, since it alters discrete energy levels and the orbitals of electrons while a magnetic field is applied. These other characteristics will not be discussed in this report because the thermodynamic effect is the dominant contributing factor to the results obtained in this study.

The new high-payoff industrial processing methodology that could result from this research could lead to the development of alloys and microstructures with superior properties that normally would be impossible to manufacture with conventional thermomechanical processing techniques. Defining phase equilibria thermodynamically in the M-H-T equation of state space (rather than p-v-T) has not received much investigation. The new classes of alloys with microstructures that can result from this approach, having increased the solid-solution solubility of favorable alloying species, can lead to dramatically improved properties with significant industrial performance. For example, magnetic exposure during continuous cooling was shown to produce ferrite with a higher carbon content and therefore greater hardness. Thus, the process may lead to more energy-efficient, lighter-weight structures in industrial and automotive applications. Similarly, novel microstructure evolution paths and enhanced transformation kinetics may be achieved without the need for further thermal processing or cryogenic heat treatments. This likewise was demonstrated in a study whereby the martensite start temperature was raised $80 \mathrm{~K}$ by the application of a 40-T magnetic field during cooling within the magnetic field.

Conceivably, cryogenic processing treatment or the alternate double-temper thermal process to transform any retained austenite to martensite in quenched hypereutectoid steels may be completely eliminated through ultrahigh magnetic field processing, resulting in reduced energy consumption and improved process efficiency. Since essentially all materials (metallic, ceramic, ionic compounds, etc.) exhibit some degree of ferromagnetism or paramagnetism, this investigation has demonstrated a whole new technology for materials processing to develop new classes of materials with novel microstructures exhibiting superior properties in support of the vision goals of the DOE's IMF.

This project was funded as a Laboratory Call Proposal under the IMF Program. The goal was for ORNL researchers to develop a visionary concept to the stage where sufficient experimental data were available to substantiate future industrial participation in follow-on R\&D efforts on specific industrial applications to commercialize this technology. The ORNL researchers on this project are currently developing industrial interest, especially involving a superconducting magnet manufacturer, to pursue collaborations on relevant industrial applications of this magnetic processing technology. The goal is to have an informally organized industrial, university, and laboratory team ready to author and submit proposals to upcoming relevant solicitations that would provide R\&D funding support for this next stage, facilitating successful commercialization of this technology. 
The potential economic benefit of this program can be very significant because of the many ramifications that ultrahigh magnetic field processing can have on many of DOE's Vision Industries. Since all materials exhibit some form of ferromagnetism or paramagnetism, this program may show that magnetic processing can yield unique and novel microstructures with enhanced performance for a broad spectrum of materials impacting the steel, aluminum, chemical, forging, heat treating, metal casting, and welding industries. For instance, it may be possible to eliminate normalization heat treatments for steel product being delivered to forging houses or employed by heat treaters to guarantee consistent and uniform product if magnetic field processing ensures complete transformation to the desired pearlitic microstructure instead of to partial bainitic microstructures that are difficult to machine. This outcome would result in major manufacturing cost savings, reduced scrap, energy savings, and environmental benefits. Similarly, if quenched product for critical applications can be guaranteed to have no retained austenite and have a $100 \%$ martensitic microstructure, subsequent cryogenic treatments or alternate double-temper heat treatments to eliminate retained austenite can be eliminated. Additionally, if novel microstructures can be developed with significantly enhanced performance capabilities, then significant weight reductions can be accomplished with these improved materials, enabling design and use of more lightweight structures in the transportation industries (e.g., the ultralight steel auto body structure).

Considering only the elimination of redundant normalization heat treatment of steels for bar and rod product to ensure that no bainite is present during initial machining operations as a baseline to calculate the potential economic benefit of this program, annual domestic savings would be $\$ 91$ million per year. In terms of energy savings, this translates to $\sim \mathbf{1 4}$ trillion Btu per year. These estimated economic and energy savings are based on eliminating the normalization heat treatment step for only an estimated $20 \%$ of the total tonnage of domestic bar product, equivalent to $\sim 7$ million tons/year. Before the current energy crisis and increased energy costs, a normalization heat treatment cost $\sim \$ 65$ per ton for the heat treatment step. These statistics were provided by one of the industrial partners in a DOE/American Iron and Steel Institute (AISI) project in which ORNL is currently a participant. Additional energy savings of up to $\mathbf{6 8}$ trillion Btu per year, equivalent to an economic impact of $\$ 325$ million per year, could be realized globally if similar calculations were included in the benefit analysis, based on the additional 25 million tons of imported steel per year that is predominantly bar and rod product. 


\section{Background}

The influence of magnetic field processing on microstructure evolution in ferromagnetic materials is a growing research topic [1-7]. High magnetic fields can modify the Gibbs free energy such that phase boundaries in the typical temperature vs composition space become a function of the applied field. This can be explained by the following reasoning. A magnetic flux density of $1 \mathrm{~T}$ augments the free energy by about $5.5 \mathrm{~J} / \mathrm{mole} / \mu_{\mathrm{Bohr}}$ (where $\mu_{\mathrm{Bohr}}$ is defined as a Bohr magneton) and because the ferromagnetic iron moment is $2.2 \mu_{\mathrm{Bohr}}$, the impact on free energy that is anticipated for iron-based materials is $\sim 12 \mathrm{~J} / \mathrm{mole}$ per tesla or $360 \mathrm{~J} /$ mole for a 30 -T magnetic field. This energy compares with energies of mixing, ordering energies, and formation energy differences. One is usually operating near a phase boundary where the free energy difference vanishes, and the objective is to move the phase boundary. Currently available high-magnetic-field magnets have the potential to accomplish this today. Other small energies associated with stacking faults, twinning, short range order, antisite defects, vacancy site preferences, diffusion barriers, elastic constants, etc., can be affected by strong magnetic fields. It is anticipated, then, that phase equilibria, microstructure, and deformation can be modified to a significant degree by available ultrahigh or even high magnetic fields.

The results of this research project, conducted collaboratively using the resources of ORNL and the National High Magnetic Field Laboratory (NHMFL), are presented in this paper. Specifically, the use of magnetic field processing to modify phase equilibria and kinetics in several ferromagnetic materials as well as to eliminate retained austenite in hypereutectoid steels are described and discussed. Experimental results and modeling predictions are presented for the Fe-15Ni alloy system to show that phase stability and solubility can be significantly altered through the presence of a high magnetic field during phase separation. Similarly, the influence of high field magnetic processing on austenite decomposition in several steels is described. These alloys involve the hypoeutectoid 1045 plain carbon steel, the 52100 hypereutectoid low-alloy steel, and a high-strength bainitic steel recently developed by Bhadeshia and coworkers [8,9].

\subsection{Statement of Objectives}

This research endeavor had two main objectives. The principal objective was to evaluate magnetic processing as a viable and robust new technology for altering phase equilibria and phase transformation kinetics in a ferrous alloy with the goal of developing novel microstructures and properties unattainable through conventional thermomechanical processing approaches. The second objective was to develop thermodynamic predictive capability; this task included an evaluation of the influence of an applied magnetic field on the phase equilibria (stability as defined by Gibbs free energy and chemical potential) of ferrous alloys with the ability to extend this capability to more general ferromagnetic, paramagnetic, and diamagnetic materials of relevance to the IOF.

\subsection{Work Breakdown Structure}

The two main objectives of this project involved completion of the following tasks:

\section{Task I: Microstructural Analyses}

This endeavor required a rather thorough characterization of the starting microstructure of the ferrous alloy chosen for this study as well as a similar examination of the same material after exposure to magnetic fields while undergoing either continuous cooling or isothermal transformation treatments. This analysis was required because success in this program was to be measured by the ability of magnetic processing to develop microstructures not achievable with conventional thermomechanical 
processing. The characterization efforts included optical and scanning electron microscopy (SEM) metallography, determination of prior austenite grain sizes, X-ray analyses for measuring phase lattice parameters and detecting any residual phases (such as retained austenite) that might be present, and testing for microhardness.

\section{Task II: Magnetic Field Processing}

These experiments were initially accomplished using the ORNL 6-T superconducting magnet and subsequently with a higher 17- to 20-T superconducting magnet system made available on a daily fee basis by an Oak Ridge superconducting magnet manufacturing firm. The magnetic field exposure was conducted on the ferrous alloy either (1) while it was being austenitized and subsequently transformed upon cooling to a lower isothermal temperature or upon continuous cooling to ambient temperatures at different cooling rates, or (2) after an initial austenitization treatment when the alloy was subsequently exposed to the magnetic field while undergoing similar thermal cycles allowing phase transformation.

The use of different isothermal hold temperatures and cooling rates allowed an evaluation of magnetic processing on both the process of equilibrium microstructure evolution (ferrite + pearlite or carbide + pearlite formation) and the metastable microstructure evolution processes (ferrite + bainite or carbide + bainite formation or martensite formation).

\section{Task III: ThermoCalc ${ }^{\mathrm{TM}}$ Thermodynamic Code Evaluation and Modification}

Task III initially assessed the capabilities of ThermoCalc ${ }^{\mathrm{TM}}$, a commercial thermodynamic phase equilibria prediction code, for incorporating magnetic field processing effects for predicting phase equilibria (essentially phase diagrams in $\mathrm{M}-\mathrm{H}-\mathrm{T}$ space) in ferrous alloys. If this was not a present capability of this code, magnetic field thermodynamic terms were to be incorporated to account for this effect when predicting final phase stability data. In addition, since the magnetic pressure effect also has an influence on the thermodynamics of the plausible phase transformations, this capability was also to be added to the code to account for both effects. Finally, parametric calculations were run to determine the magnetic field processing space needed to achieve specific microstructure modifications.

\section{Task IV: Material Magnetization Response Data for High Magnetic Field Exposures}

Initially, task IV involved reviewing the available literature for magnetization response data for ferrous alloys as a function of applied field strength up to ultrahigh field levels. Generally these data (beyond $\sim 1 \mathrm{~T}$ ) are not available, and so the second aspect of this task was the development of the capability to measure these data at ultrahigh field strengths and to generate a limited, accurate data set for incorporation as input data for the ThermoCalc ${ }^{\mathrm{TM}}$ parametric studies.

\section{Task V: Phase Transformation Kinetic Response Evaluation}

Task $\mathrm{V}$ examined the kinetics of the phase transformation reaction that occurs while cooling through the elevated temperature two-phase austenite + ferrite regime, since this is typical of the intercritical annealing process used by industry during processing of many dual-phase high-strength low-alloy (HSLA) and microalloyed steels.

\section{Task VI: Definition of Additional Industrial Applications of Magnetic Field Processing}

Based on the results of the above tasks plus additional concepts for magnetic processing not included in this current project by the ORNL team, future collaborative R\&D endeavors will be defined for investigation with industrial partners for the purpose of additional technology development, transfer, and commercialization. 


\section{Task VII: Reports}

Quarterly technical reports and a final project summary report (this document) were to be written to document the results of this project. 


\section{Results and Discussion}

\subsection{Experimental Procedure}

A 32-mm-diam-bore magnet at NHMFL with a maximum field strength of $33 \mathrm{~T}$ was used for the experiments. A key component of the experimental work was the ability to heat and cool the specimen while inside the bore of the magnet. A custom-designed induction heating coil, coupled with a gas purge system for atmosphere control and specimen cooling, was fabricated for the experiments. Figure 4.1 is a schematic of the experimental apparatus. The apparatus can heat the steel specimen, located in the center of the bore mid-length, up to $1100^{\circ} \mathrm{C}$ and maintain the high temperature for extended periods of time. The atmosphere is controlled via an argon gas purge. For accelerated cooling, a helium gas quench can be rapidly imposed upon the specimen. Such a system allows for the entire thermal cycle or any portion of it to be exposed to a high magnetic field.

Experiments were performed on a Fe-15 at. \% alloy, a medium carbon 1045 steel with a nominal composition of $0.45 \mathrm{wt} \%$ carbon and $0.8 \mathrm{wt} \%$ manganese, a hypereutectoid SAE 52100 steel, and a bainitic steel. Cylindrical specimens, $8 \mathrm{~mm}$ in diam by $12 \mathrm{~mm}$ long, were machined from the initial stock, which was generally rod with the longitudinal axis aligned with the rod axis.

Temperature measurements were made via a type "S" (Pt-10\%Rh) thermocouple spot-welded on the radial surface at the mid-length of the specimen. Most specimens were heated to $850^{\circ} \mathrm{C}$ (sometimes to $900^{\circ} \mathrm{C}$ for the 52100 alloy and to $1000^{\circ} \mathrm{C}$ for the bainitic steel) using a two-step schedule whereby a rate of approximately $11^{\circ} \mathrm{C} / \mathrm{s}$ was applied to $700^{\circ} \mathrm{C}$, followed by heating at $2.5^{\circ} \mathrm{C} / \mathrm{s}$ to the annealing temperature. A 5-min hold at $850^{\circ} \mathrm{C}$ was performed to fully transform the initial microstructure to austenite. Specimen cooling was controlled by modifying the pressure governing helium gas flow during quench. The slowest cooling rate was obtained by simply turning off the induction heater and allowing the specimen to cool naturally within the argon-purged environment. Faster cooling rates were generated by flowing helium at pressure settings of 5,10 , and 20 psi. The various pressure settings provided a good array of cooling rates for evaluating transformation kinetics.

\subsection{Modifying Phase Equilibria in Fe-15Ni}

The Fe-15Ni (at. \%) alloy is an ideal ferromagnetic alloy system to demonstrate the influence of magnetic field processing on phase equilibria in ferromagnetic materials [10] (i.e., phase volume fraction and solute solubility for each phase). This material also represents an alloy where the solute is present as a substitutional element rather than an interstitial one (e.g., $\mathrm{C}$ in $\mathrm{Fe}$ ) as studied in most 
prior research endeavors in this magnetic-field-processing focus area. The typical temperature vs composition phase diagram in the Fe-rich region of the Fe-Ni phase diagram is shown in Fig. 4.2.

For this experiment, an alloy with an atomic composition of $85 \mathrm{Fe}-15 \mathrm{Ni}$ was prepared from nickel and iron stock of 0.999 purity by arc melting the material in vacuum five times and then drop casting into a 10-mm-diam chilled copper mold in vacuum. The alloy was then homogenized in vacuum for $100 \mathrm{~h}$ at $1100^{\circ} \mathrm{C}$. A small amount was ground into powder; the remainder was cut into 10 -mm-long segments. The powder was made by diamond-wheel grinding and was encapsulated in 10-mm-diam, 10 -mm-long stainless steel tubes that were crimped and sealed by electron discharge machining. All powder capsules and cylinders were annealed together at $700^{\circ} \mathrm{C}$ for $2 \mathrm{~h}$ to obtain the equilibrium $\gamma$ phase and then were quenched in ice salt brine. The bulk cylinders were electropolished. A $10-\mathrm{mm}$ rod and a powder sample were subjected to a 29 -T field for $245 \mathrm{~min}$ at $502^{\circ} \mathrm{C}$. As a control, one of the identically prepared rods and powder samples was annealed for $245 \mathrm{~min}$ at $502^{\circ} \mathrm{C}$ in the ambient field. The samples were rapidly heated from room temperature to $502^{\circ} \mathrm{C}$. They were air cooled at a rate of approximately $100^{\circ} \mathrm{C} / \mathrm{min}$. The field-annealed sample remained in the field until it had cooled to a temperature of $85^{\circ} \mathrm{C}$, at which time the field was turned off.

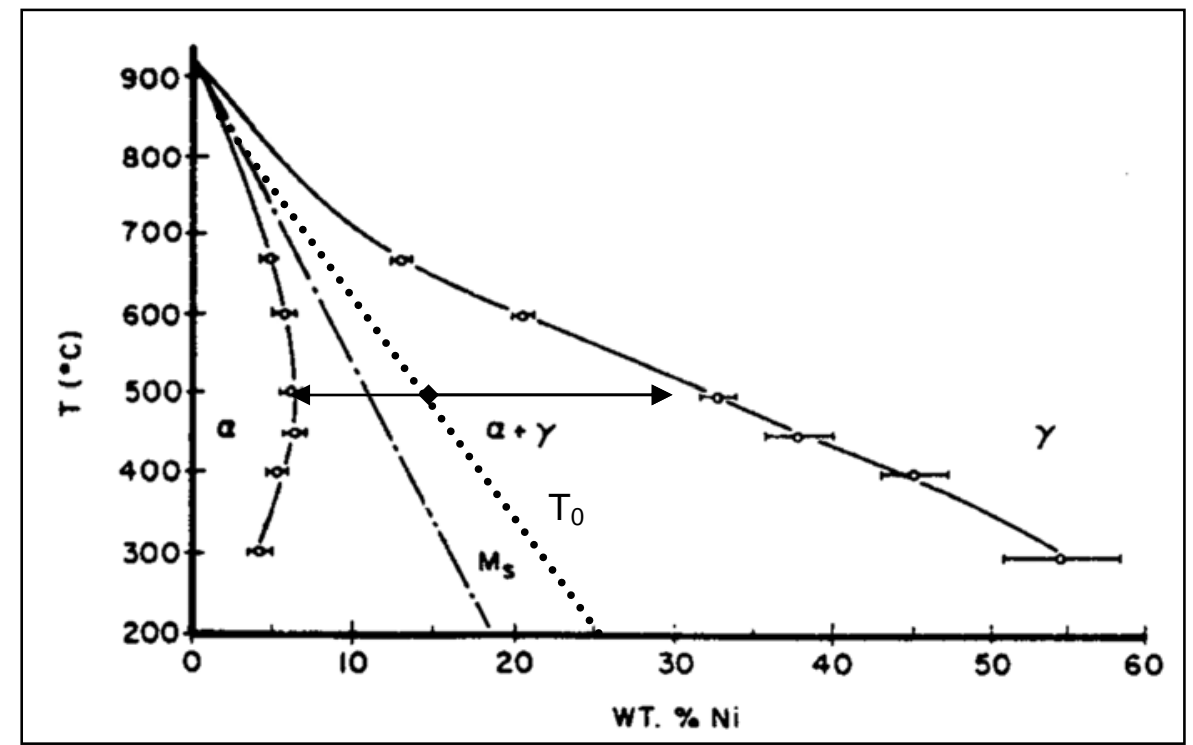

Fig. 4.2. Iron-rich section of phase diagram showing martensite starttemperature $\left(M_{S}\right)$, equal free energy line (dotted line marked $\left.T_{0}\right)$, and decomposition path (horizontal line with arrows) at $500^{\circ} \mathrm{C}$ [ref. 11]. Weight and atomic percentages are nominally the same in the Fe-Ni binary system and are essentially interchangeable for purposes of this paper.

The volume fractions of the $\alpha$ and $\gamma$ phases (body-centered cubic [bcc] phase and face-centered cubic [fcc] phase, respectively) for the powder specimens were determined using $\mathrm{Cu}_{\mathrm{k} \alpha} \mathrm{X}$-ray diffraction from a Philips defractometer with a compensating slit [10]. This analysis yielded the results shown in Table 4.1. These results clearly show that the 29-T magnetic field significantly alters the solubilities and volume fractions for the $\alpha$ and $\gamma$ phases when compared with a specimen that did not receive the high-magnetic-field treatment at $502^{\circ} \mathrm{C}$. Of significant interest is the reduction in the amount of the fcc phase by a factor of 2 and an increase of $\sim 40 \%$ in the nickel solubility of the $\gamma$ phase (from 0.28 to 0.4 atomic fraction $\mathrm{Ni}$ ). The nickel content for the bcc phase was also increased by the presence of the magnetic field during phase decomposition at the isothermal hold temperature. These results are extremely significant because they substantiate the concept of 3D phase diagrams whereby significant 
new and novel alloys could be developed in ferromagnetic alloy systems by processing the materials in the temperature-compositionmagnetic field space.

To supplement these experimental results, modeling efforts were undertaken to predict the influence of magnetic fields on microstructure stability so that this effect on the thermodynamic equilibrium of these alloys could be incorporated into conventional thermodynamic simulation codes. This modeling was accomplished by combining the thermodynamic model of Chuang [12] with local density calculations of the effect of the magnetic field on free energy. The local density calculations were done using real space multiple scattering theory [13]. Because there is only one domain at very high magnetic field strengths, subtle issues associated with domain wall structure and pinning are moot, an especially attractive condition from a modeling standpoint. The predictions for the Fe-15Ni alloy samples are presented below.

For a collinear ferromagnetic material an applied field shifts the Kohn-Sham potential of the majority electrons to lower energy. This shift results in a slight increase of the saturation magnetic moment. As the temperature is increased, ferromagnetic materials become slightly non-collinear due to the thermal excitation of spin waves. Above the Curie temperature the directions of the local moments have no long-range correlation and become increasingly random at higher temperatures. The locally selfconsistent multiple scattering code treats the general case of application of a field to a non-collinear magnetic structure. The additional applied magnetic field contributes to a shift in the local KohnSham potential along the direction of the magnetic moment and a rotation of the moment toward the direction of the applied field. The local magnetic moments calculated for Fe-15Ni in a $30-\mathrm{T}$ field are shown in Fig. 4.3(a) for the $\alpha$ phase and in Fig. 4.3(b) for the $\gamma$ phase. The structures correspond to a temperature of $500^{\circ} \mathrm{C}$ where the $\alpha$ phase is ferromagnetic and the $\gamma$ phase is paramagnetic. The red arrows indicate moments of $2.2 \mu_{\mathrm{Bohr}}$, which are typical of $\alpha \mathrm{Fe}$. The moments in the $\gamma$ phase are smaller and disordered.

Utilizing this information, the free energy curves for the $\alpha$ and $\gamma$ phases were calculated, demonstrating the ability of the local spin density (LSD) approach to predict the change in phase volume fraction and nickel solubility for the Fe-15Ni alloy as a result of the application of a magnetic field at the isothermal hold temperature. These results are shown in Fig. 4.4 for the no-field vs highfield (30-T) conditions. As this graph clearly indicates, the nickel solubilities for both phases will increase with the application of the magnetic field, and a change in the volume fractions of these phases will also result. The shifts in the phase boundaries of the new phase diagram in the temperature-composition-magnetic field (for $H=29 \mathrm{~T}$ ) space are shown in Fig. 4.5.

These specific experimental and modeling results emphasize that applied magnetic fields should be added to the list of thermodynamic variables (in addition to the classically considered ones of temperature, composition, and pressure) considered when phase diagrams and phase equilibria are evaluated to develop microstructures with tailored performance properties. Therefore, the materials scientist is no longer limited to a single binary phase diagram (field strength $=0$ ) but, rather, makes use of a 3D continuum of phase diagrams, an approach that opens a whole new spectrum of thermomechanical-magnetic processing options for optimizing existing alloys or customizing new ones. As demonstrated clearly by these data, the solubility of nickel in the $\gamma$ phase at $\sim 500^{\circ} \mathrm{C}$ is increased significantly (by $>40 \%$ ) by the application of a 29 -T magnetic field during an isothermal hold at this temperature, and this enhanced solubility for this substitutional alloying element was maintained 


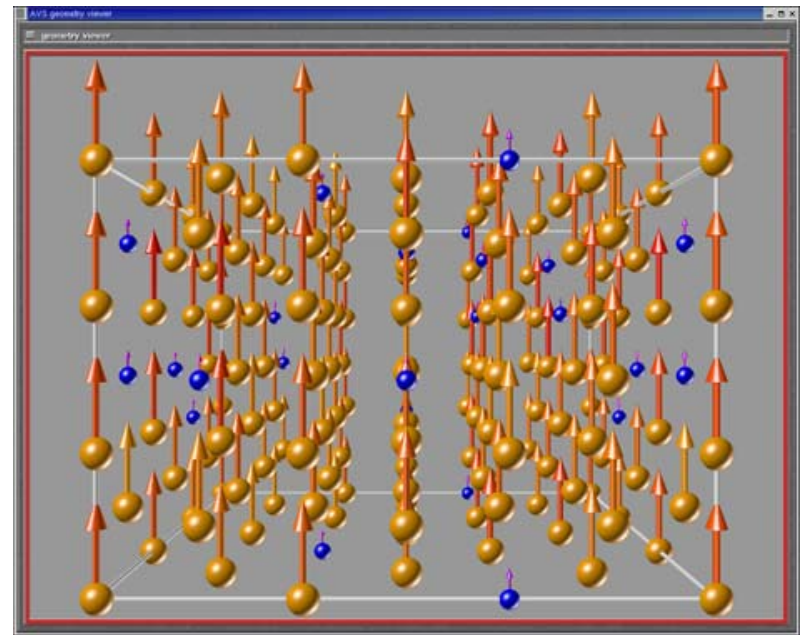

(a)

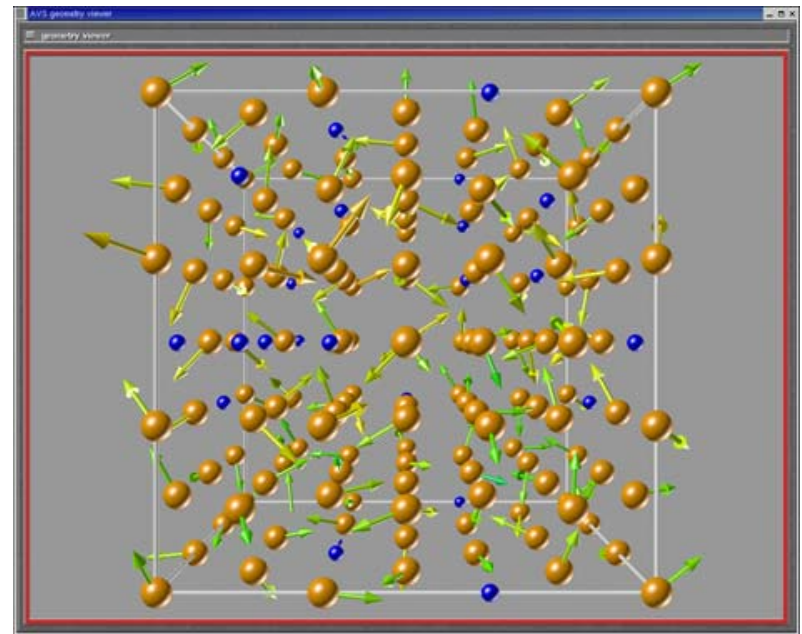

(b)

Fig. 4.3. Magnetic structure of (a) the ferromagnetic $\alpha$ phase of Fe-15Ni and (b) the paramagnetic $\gamma$ phase in Fe-15Ni. Gold spheres indicate iron atoms, and blue spheres indicate nickel.

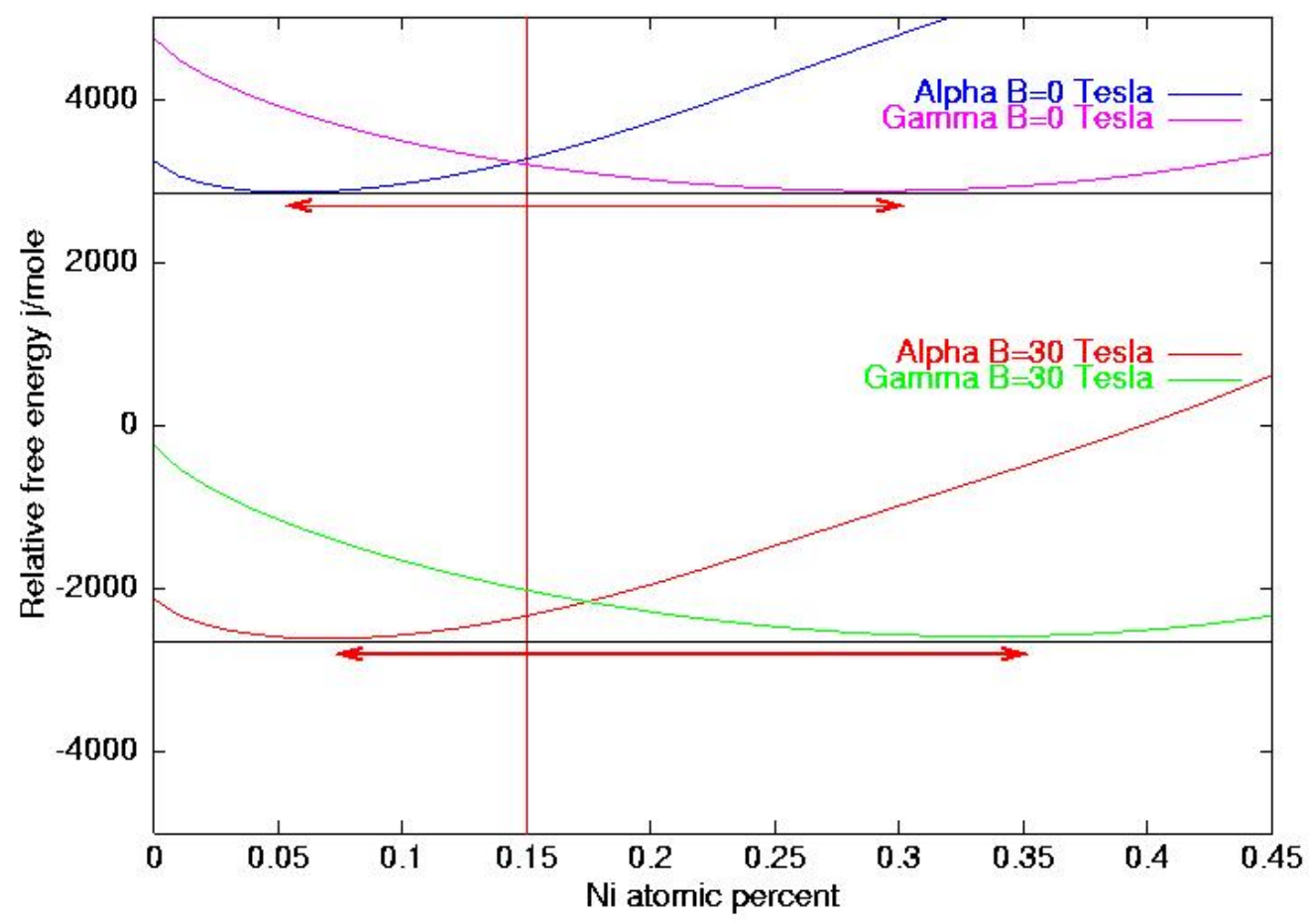

Fig. 4.4. Free energy curves for $\alpha$ and $\gamma$ phases with and without an applied magnetic field of 30-T strength. Arrows indicate the phase concentrations. Curves for these two cases are shifted vertically away from each other an arbitrary amount for clarity of presentation. 


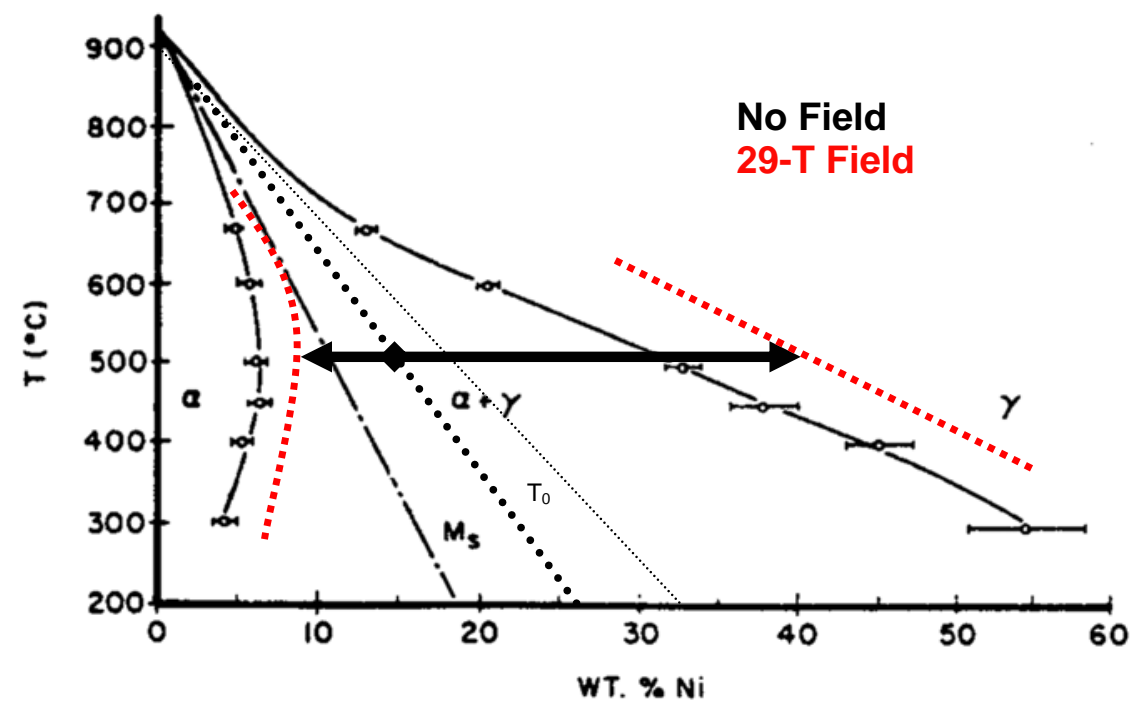

Fig. 4.5. LSD modeling predictions of the shift in phase boundaries under the imposition of a 29-T magnetic field. The dashed red lines indicate the new phase boundaries (solvus lines) exhibiting enhanced Ni solute solid solubility under the influence of the applied field.

at room temperature. The application of high-magnetic-field processing during heat treatment can thus lead to the development of alloys with superior performance in specific engineering applications, materials that are currently impossible to produce without use of magnetic-field processing conditions. The implications too are that novel microstructures can be achieved with current alloys through magnetic processing.

\subsection{SAE 52100 High-Carbon Hypereutectoid Low-Alloy Chromium Steel Investigation}

This section deals with experiments conducted on a 52100 steel under austenitization and rapid helium gas quenching conditions that normally would induce significant retained austenite, as well as isothermal hold experiments to understand the influence of high magnetic fields on austenite equilibrium decomposition.

The retained austenite experiments were performed for two different austenitization temperatures, 850 and $900^{\circ} \mathrm{C}$, with a hold time of $20 \mathrm{~min}$. Under both of these conditions, the material will be in the austenite plus carbide equilibrium phase field, but each will produce a different amount of retained austenite after quenching due to differences in the austenite carbon level developed at these elevated temperatures. This behavior is directly related to the fact that the martensite start temperature, $\mathrm{M}_{\mathrm{S}}$, and finish temperature, $\mathrm{M}_{\mathrm{F}}$, are directly related to the austenite carbon content, and both decrease as the carbon level of the austenite is increased at higher austenitization temperatures.

Various specimens were processed in this manner and were magnetically processed utilizing two separate approaches: (a) during quenching from the austenitization temperature, magnetic fields of 0 , 10, 17, and $30 \mathrm{~T}$ were imposed; and (b) the magnetic fields were imposed at ambient temperature after the specimens were rapidly cooled from the austenitization temperature. Retained austenite values were measured experimentally on all of these samples via an X-ray diffraction technique 
performed according to ASTM specification E 97500 , which defines the industry-accepted procedure for obtaining retained austenite values in steels. The data sets for both processing schemes (Fig. 4.6) show that magnetic field processing decreases the amount of retained austenite that forms during the quench with a magnetic field applied and that the amount of retained austenite formed during the quench without the applied field can be reduced through the application of a magnetic field at ambient temperature after this quench cycle. As anticipated, the higher the magnetic field strength, the greater the reduction in the amount of retained austenite.

Hardness measurements made on several of the specimens for the test conditions described above (Table 4.2) show that in comparison with the hardness value obtained for the specimen that received no magnetic processing, a 5\% increase in hardness was observed for the specimen that received the 30-T exposure during the quench; this increase correlates with less austenite in the final microstructure. A $14 \%$ hardness increase occurred in the sample that received the magnetic exposure at ambient temperature after the quench cycle. A plausible explanation for the higher hardness in this case is that more retained austenite was converted to martensite by the field after the quench, whereas the sample receiving the magnetic exposure during cooling also had a competing reaction involving transformation of some of the austenite to equilibrium or other intermediate phase transformation products. This is supported by the X-ray analyses of the specimens that were magnetically processed during quench, which indicate a gradual loss of tetragonality of the martensite phase as the field strength is increased. Therefore, it is logical to interpret these results with the conclusion that not only is the martensite phase becoming more stable through raising of the $\mathrm{M}_{\mathrm{S}}$ and $\mathrm{M}_{\mathrm{F}}$ temperatures by the applied magnetic field but also that the equilibrium (carbide plus pearlite) and intermediate (carbide + bainite) transformations are similarly becoming more stable and are competing with the martensite transformation when the magnetic field is applied continuously during the rapid quench from the austenitization temperature.

A significant positive ramification of the ability to convert retained austenite formed during a quench cycle by applying a high magnetic field at ambient temperature is that the material will only have to accommodate the strain associated with the phase transformation. One approach used commercially for converting retained austenite is to use a cryogenic treatment, which induces not only the phase transformation strains but also thermal and thermal gradient strains in the material during the subzero cooling process. A thermal gradient of only $100-150^{\circ} \mathrm{C}$ in a specimen can produce plastic strains equivalent to the $0.2 \%$ offset plastic strain used to determine the yield strength in materials. Cracking (even microcracking) is a potential negative result of these cryogenic treatments. Ambienttemperature magnetic processing reduces the probability of damage during the retained austenite conversion process, as no thermal strains will be present. Also, since the strains are less, the 
magnitude of unwanted tensile residual stresses that may result should be reduced or be more compressive.

The second type of experiment run on the 52100 alloy steel was designed to evaluate the influence of an applied magnetic field on phase transformation behavior during a short isothermal hold at a temperature that normally would not result in the development of equilibrium pearlite in the microstructure. The schematic of the thermal and magnetic field application cycle for this experiment is shown in Fig. 4.7. For comparison, a control sample was given the same thermal processing in the absence of a magnetic field to allow for microstructure comparisons.

Figure 4.8 shows the comparison of the microstructures obtained for the 52100 alloy that evolved after only a 5-min hold at $740^{\circ} \mathrm{C}$ for the conditions of without and with an applied magnetic field. The specimen that received no magnetic processing (Fig. 4.8a) exhibits significant martensite formation with only minor evidence of some grain boundary carbide forming during the isothermal hold plus residual spheroidal iron carbide in the matrix that

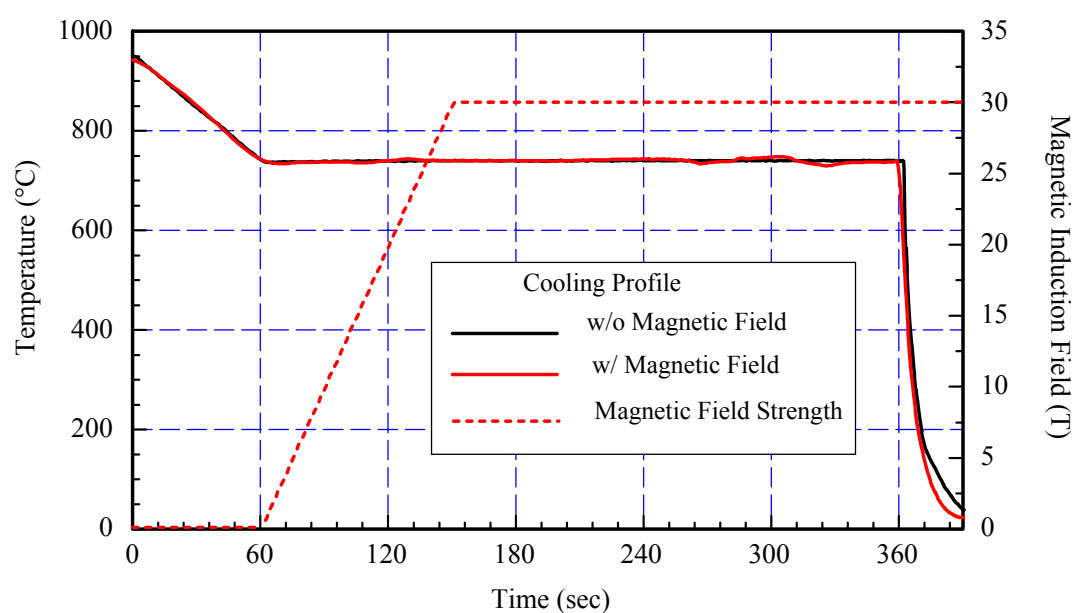

Fig. 4.7. Thermal profile and magnetic processing cycle for a 52100 steel showing the 5 -min isothermal hold treatment at $740^{\circ} \mathrm{C}$ during which the 30-T magnetic field was ramped up and maintained until the sample was cooled to ambient temperature. was not fully dissolved at the austenitization heat-treatment temperature. No pearlite formed under these treatment conditions although the hold temperature of $740^{\circ} \mathrm{C}$ is below value of $754^{\circ} \mathrm{C}$ reported in the literature for the $\mathrm{A}_{\mathrm{C} 1}$ temperature (approximately equal to the eutectoid transformation temperature) of this alloy. With this extremely small undercooling below the transformation temperature, the equilibrium transformation decomposition reaction of $\gamma \rightarrow$ carbide + pearlite would be extremely sluggish and not initiate for rather long hold times. However, when the 30-T magnetic field is applied, the resulting microstructure is all very fine pearlite (Fig. 4.8b). Clearly, the presence of the magnetic field even for very short times dramatically enhances the stability of the equilibrium transformation product and significantly enhances its transformation kinetics by effectively raising the eutectoid temperature (by up to $85^{\circ} \mathrm{C}$, as will be shown Sect. 4.4, on 1045 alloy steel) and thus increasing the degree of undercooling that would stimulate nucleation of the equilibrium transformation.

These results for the 52100 alloy steel demonstrate that the martensite transformation can be driven to further completion (i.e., with less retained austenite) through the application of a magnetic field either during continuously cooling from the austenitization temperature or after quenching at ambient temperature. The hardness data from these retained austenite experiments plus the results of the isothermal hold experiment further indicate that the application of the magnetic field enhances the stability of both the equilibrium and metastable transformation products, since these are ferromagnetic in comparison with the paramagnetic $\gamma$ parent phase. This is directly attributable to the free energy contribution that an applied magnetic field has on the overall free energy change for a phase transformation where the parent and product phases exhibit different magnetic susceptibilities. 


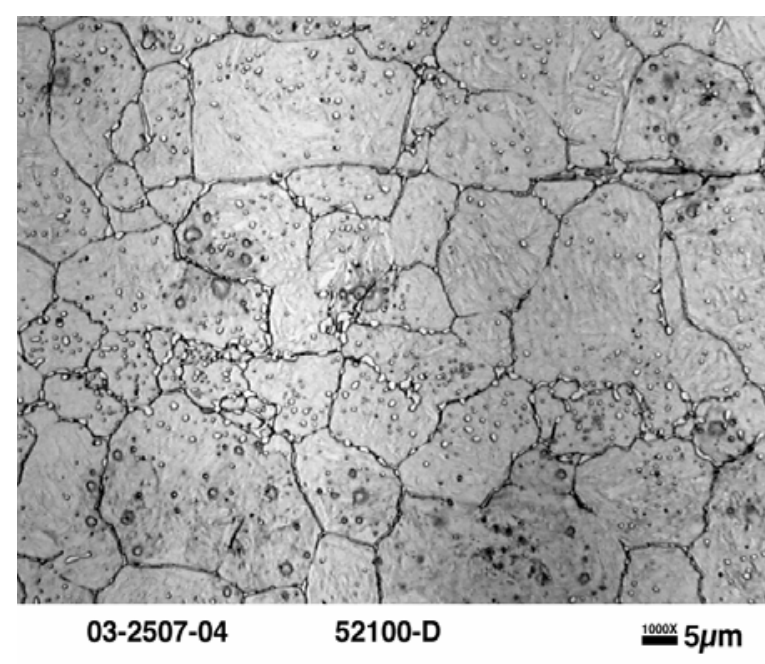

(a) No field

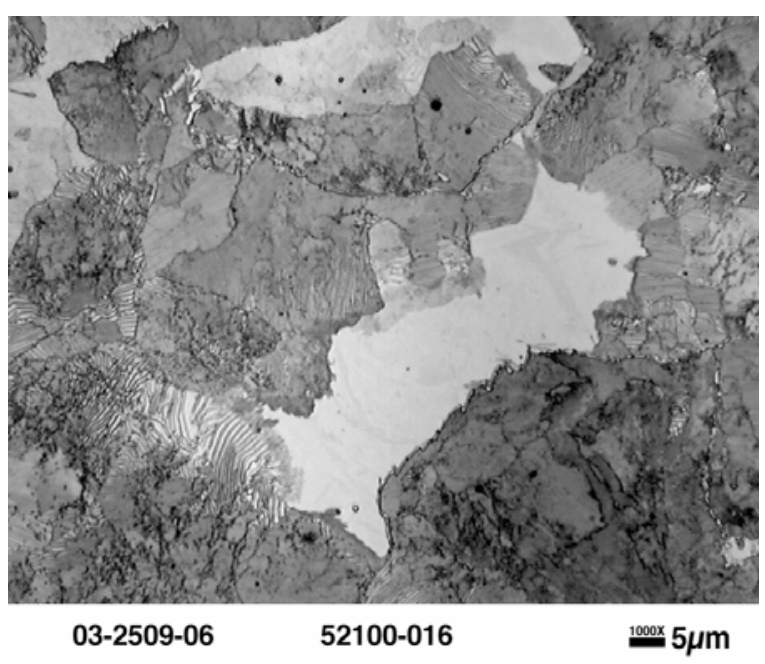

(b) 30-T field

Fig. 4.8. Significantly different microstructures evolved at room temperature in the specimen that did not receive any magnetic processing at $740^{\circ} \mathrm{C}$ (micrograph a) vs one that was exposed for a short time at this temperature to a $\mathbf{3 0} \mathrm{T}$ field (b). The specimen without an applied magnetic field (a) is predominantly martensite (and carbide) with some grain boundary and undissolved spheroidal matrix carbide present; the one with the applied field (b) is very fine pearlite.

However, the $740^{\circ} \mathrm{C}$ isothermal test results indicate that the transformation that will dominate when competing ones are present will be the one that occurs first (upon cooling) or whose transformation temperature (e.g., $\mathrm{A}_{\mathrm{C} 1} \mathrm{vs}_{\mathrm{S}}$ ) is closer to the isothermal hold temperature.

A final set of experiments were run on the 52100 alloy to show that for the same cooling rate, dramatically different microstructures could be achieved in this alloy. The cooling rate chosen was such that martensite would form during continuous cooling of a sample when no magnetic field was applied. The sample cooling profile is shown as the solid black line in Fig. 4.9. A second test was run under identical initial cooling conditions but with the superposition of a 30-T magnetic field; its cooling behavior is indicated by the solid red line in Fig. 4.9. The specimen cooled under the influence of the magnetic field (solid red line) exhibits significant recalescence heating at higher temperatures, an indication that carbide and pearlite are forming. The black line does not show heat evolution (change in slope) until significantly lower temperatures, reflecting no phase change until the martensite transformation occurs. The resulting microstructures obtained in these two tests are shown in Fig. 4.10.

The conventional or normal behavior for this material (i.e., its behavior when it is non-magnetically processed) under the cooling conditions reflected by the microstructure in Fig. 4.10(a) is represented by the solid black line in Fig. 4.9. As can be seen, this process misses the "knee" of the transformation curve and will result in the formation of martensite (plus the remnant carbide stable at the austenitization temperature). However, if the 30-T magnetic field is applied for the same cooling rate, the continuous cooling transformation (CCT) curve is effectively shifted upward and to the left, as demonstrated by the dotted red line in Fig. 4.9(b). For this magnetically enhanced CCT behavior, the specimen will cut through above the knee of the CCT curve and be transformed to pearlite (plus the prior carbide), as observed. This experiment essentially demonstrates that with the same cooling path, the final microstructure that forms upon cooling can be controlled by varying the magnitude of the applied field. Conceivably, the microstructure could be continuously varied from martensite to bainite to pearlite simply by increasing the field strength during the cooling operation. 


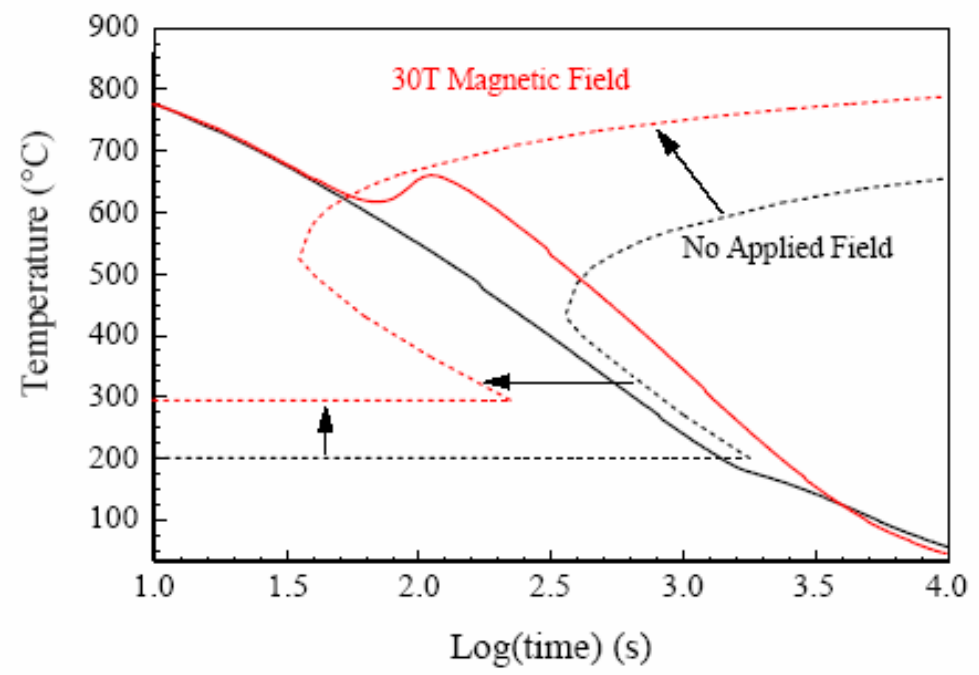

Fig. 4.9. Application of a 30-T magnetic field during continuous cooling moves the transformation start line in the continuous cooling transformation (CCT) curve for the $\mathbf{5 2 1 0 0}$ steel upward to higher temperatures and to the left to shorter times (dotted red line) as compared with the conventional behavior (dotted black line) for this alloy. The solid lines are the cooling paths for the two test specimens with identical initial cooling rates.

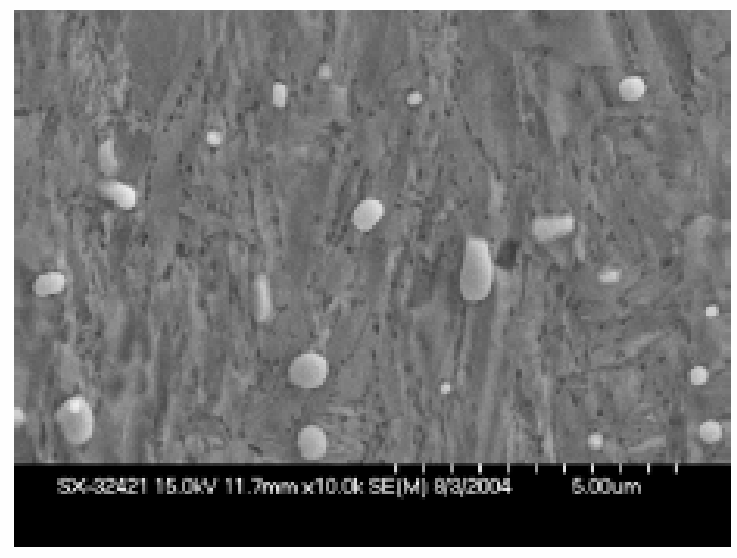

(a) No field

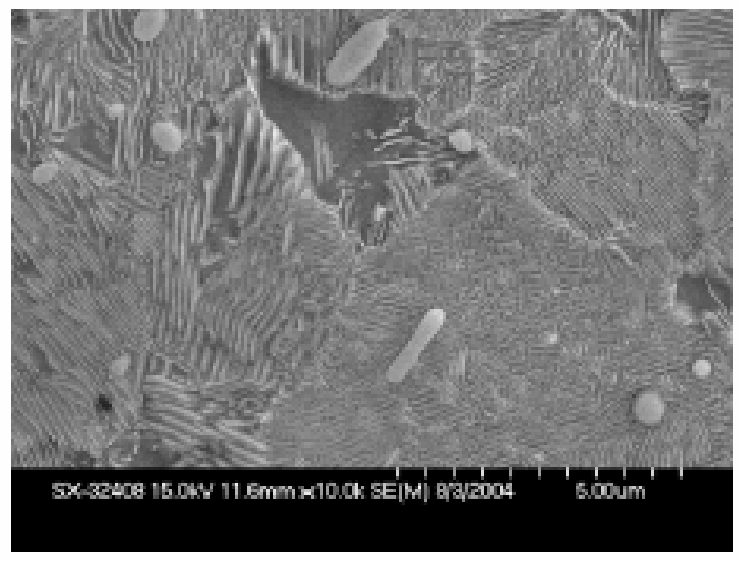

(b) 30-T field

Fig. 4.10. Microstructure of a 52100 alloy subjected to continuous cooling at a rate that would result in martensite formation, with and without application of a magnetic field. Sample (a) shows martensite and remnant carbide; the application of a magnetic field during cooling resulted in the complete transformation to carbide plus pearlite in sample (b). 


\subsection{SAE 1045 Low-Carbon, Hypoeutectoid Steel Investigation}

The experiments performed with the 1045 steel were planned to investigate the influence of different continuous cooling rates on austenite decomposition transformation behavior while a constant 30-T magnetic field was applied, determine the effect of different magnetic field strengths on phase decomposition for a constant cooling rate $\left(\sim 130^{\circ} \mathrm{C} / \mathrm{s}\right)$ condition, estimate the free energy contribution of an applied magnetic field to the overall phase transformation equilibrium, and finally, demonstrate the concept of isothermal, magnetically induced phase transformation decomposition and reversal (isothermal phase transformation reversal cycling).

Figure 4.11 summarizes the influence of an applied constant magnetic field of $30 \mathrm{~T}$ on the austenite phase decomposition in the 1045 alloy for different cooling rates of nominally 55,80 , and $130^{\circ} \mathrm{C} / \mathrm{s}$. The change in slope observed for these controlled cooling experiments is the result of recalescence heating due to the enthalpy of transformation being released for the $\gamma \rightarrow \alpha+$ pearlite transformation during cooling. These results demonstrate that an applied magnetic field of $30 \mathrm{~T}$ significantly increases the temperatures at which transformation is initiated and completed; these temperatures are $\sim 80^{\circ} \mathrm{C}$ higher as compared with the cooling rate data when no field is used. In addition, the times at which phase transformation initiates occur at least $40 \%$ sooner, with greater reductions in initiation time observed for the slower cooling rates. Effectively, these data indicate that the application of a magnetic field raises the austenite decomposition transformation temperature in this ferrous alloy, thereby increasing the supercooling driving force and causing this material to transform more quickly at these higher temperatures.

Related to these cooling experiments under the influence of a 30-T magnetic field is an experiment conducted at a cooling rate of $10^{\circ} \mathrm{C} / \mathrm{s}$ with and without the application of a 30-T field. The purpose of these two runs was to study the potential influence of an applied magnetic field on the volume fraction of the microstructural constituents observed at room temperature. This effect was already demonstrated for the Fe-15Ni alloy, where the solute was a substitutional element. For the 1045 alloy, the solute of interest is carbon, which is an interstitial element and can rapidly diffuse even at low temperatures. The microstructures presented in Fig. 4.12 clearly show the major influence that a high

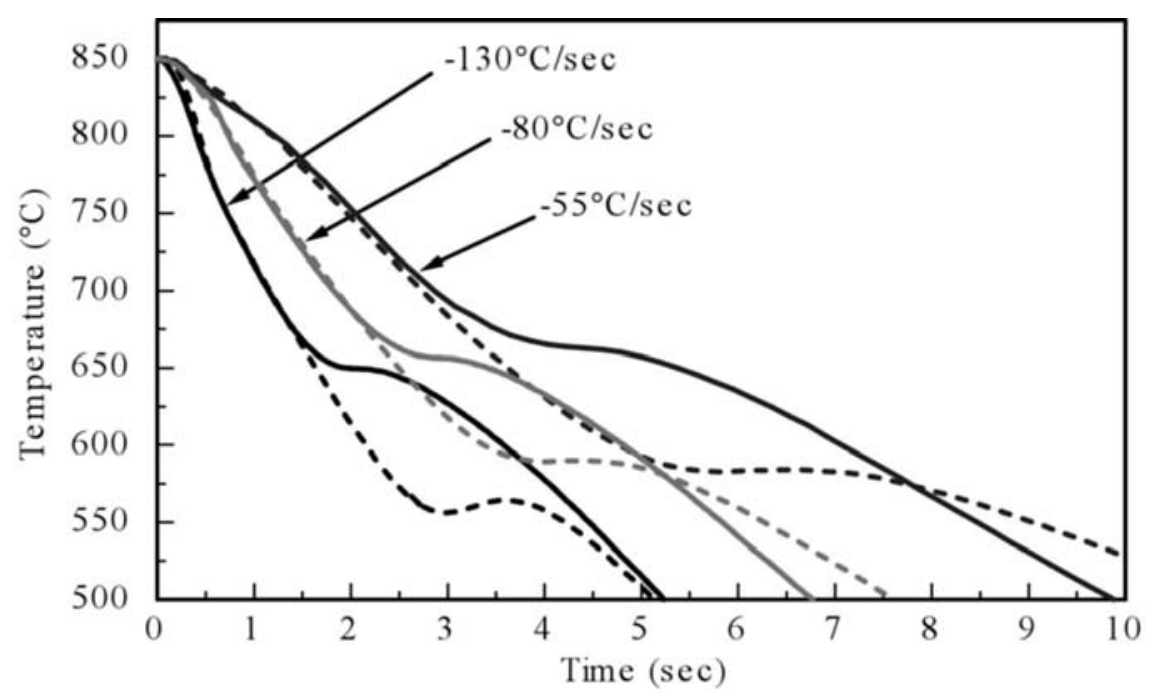

Fig. 4.11. Cooling curves for various cooling rates with (solid line) and without (dashed line) a 30-T magnetic field for the 1045 alloy steel specimens. Specimens were held at $850^{\circ} \mathrm{C}$ for 5 min prior to cooling. 
magnetic field can have on the final distribution of phases in quenched hypoeutectoid steel. For the no-field condition, the volume fraction of proeutectoid ferrite is nominally $40 \%$ (Fig. $4.12 \mathrm{a}$ ) as determined via quantitative metallography. In significant contrast, the volume fraction of proeutectoid ferrite rises to $65 \%$ under the influence of the magnetic field during the continuous cooling cycle (Fig. $4.12 \mathrm{~b}$ ). This represents an $\sim 60 \%$ increase in the volume fraction of proeutectoid ferrite due to the magnetic field. From a microstructural processing perspective, this ability to control the volume fraction of the various constituent phases offers the opportunity to produce steels with enhanced machinability or novel dual-phase HSLA microstructure steels.

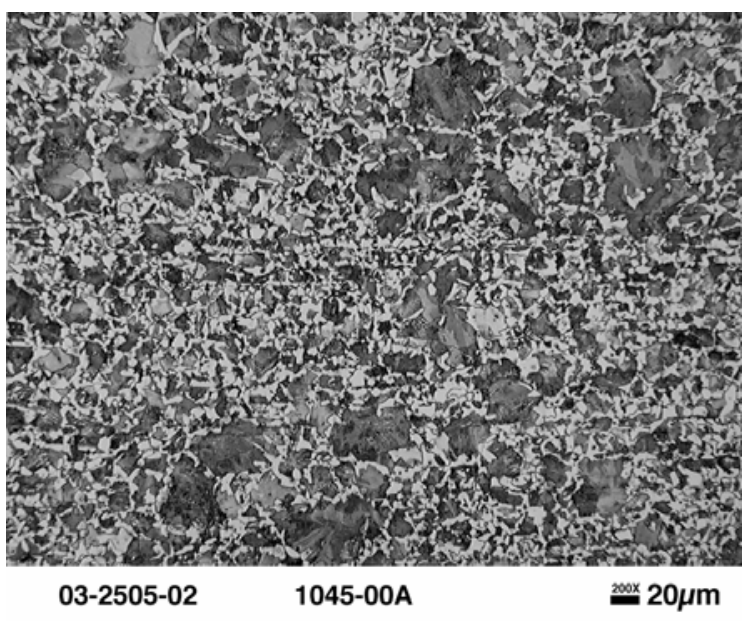

(a) No field

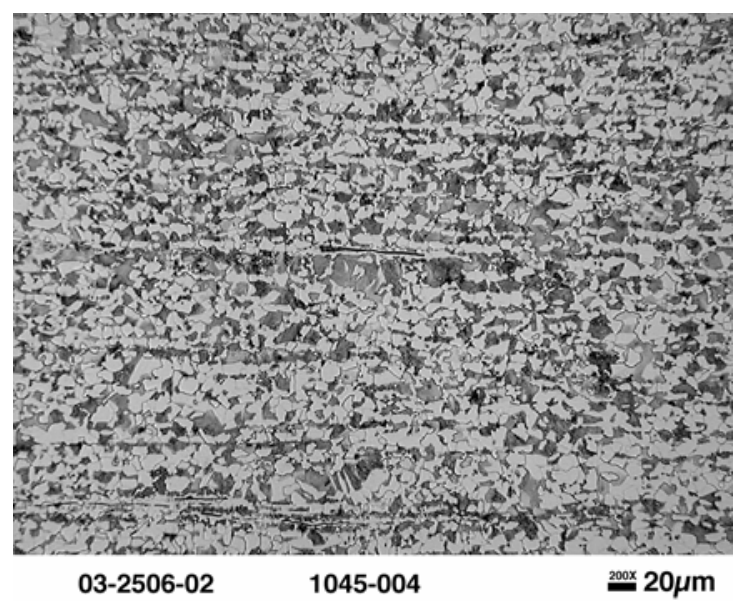

(b) 30-T field

Fig. 4.12. Microstructure for 1045 steel specimens cooled at $10^{\circ} \mathrm{C} / \mathrm{s}$ : (a) $40 \%$ ferrite (light phase) formed without an applied magnetic field, and (b) 65\% ferrite formed with an applied 30-T field (light micrograph, $2 \%$ nital).

The next series of experiments run on the 1045 steel were conducted to determine the shift in the austenite decomposition transformation temperature as a function of magnetic field strength and to obtain an estimate of the Gibbs free energy contribution due to the magnitude of an applied magnetic field. These were determined by conducting identical cooling rate experiments at magnetic field strengths of $0,10,20$, and $30 \mathrm{~T}$ (see Fig. 4.13), applied during the entire cooling cycle from the austenitization temperature. To obtain the shift in transformation temperature between the no-field vs applied-field conditions, the derivatives of the cooling curve data with respect to time, $d T / d t$, were obtained and plotted vs temperature to determine the point at which the greatest rate of change was observed (see Fig. 4.14). This maximum $d T / d t$ point was defined as the transformation initiation temperature for that condition. The shifts in transformation temperature, $T$, between the no-field and the magnetic field strength conditions are also summarized in the middle column of Table 4.3. These $T$ data are plotted vs magnetic field strength in Fig. 4.15. The shift in transformation temperature per tesla of applied field for this alloy is quantified by a slope of $\sim 3^{\circ} \mathrm{C} / \mathrm{T}$. The alloy undergoes a paramagnetic to ferromagnetic transformation during cooling that approximately correlates with the austenite phase decomposition process. 


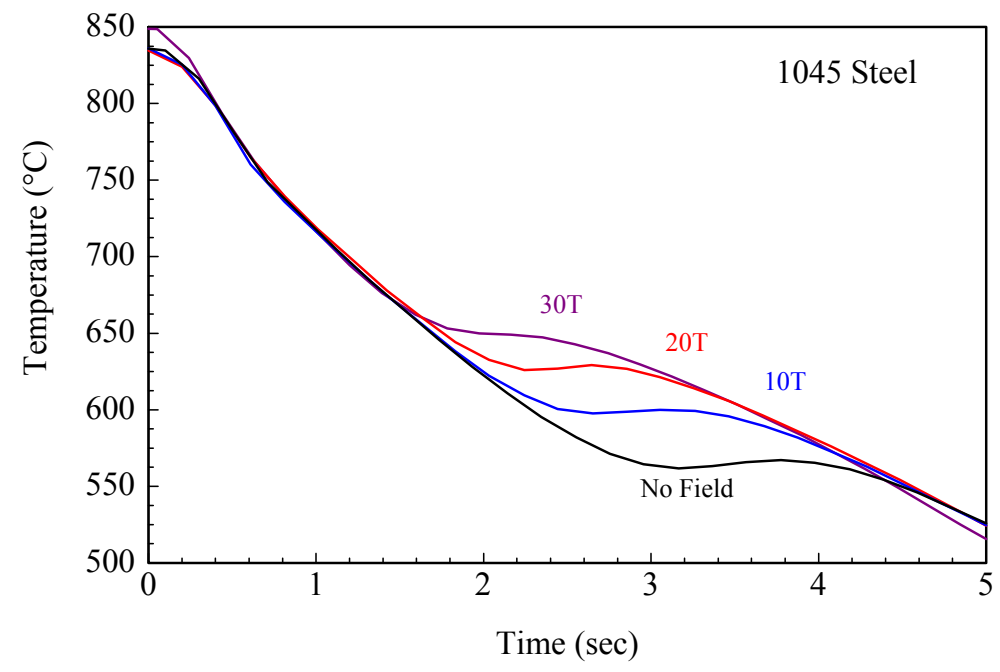

Fig. 4.13. Continuous cooling path information for the 1045 lowcarbon steel alloy for different magnetic field strengths.

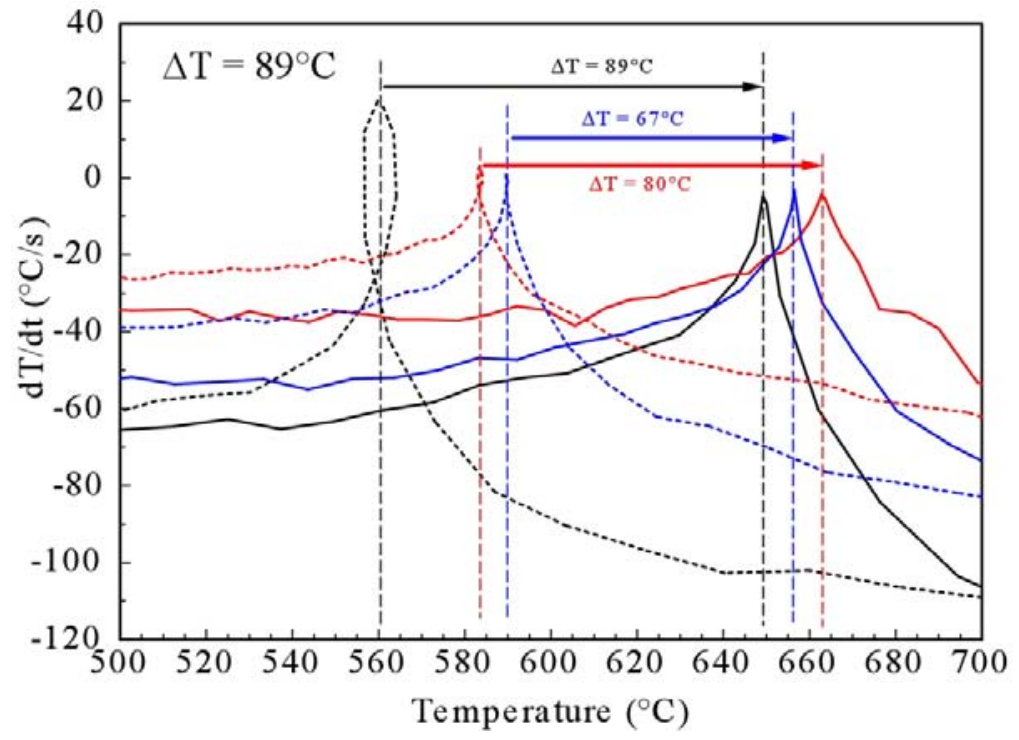

Fig. 4.14. Determination of the transformation temperature shift in the 1045 steel by taking the derivative of the cooling curves, $d T / d t$, and plotting as a function of temperature. The solid curves represent several 30-T magnetic field conditions, while the dashed lines indicate no magnetic field. 
Table 4.3. Experimentally derived magnetic field contribution to Gibbs free energy

\begin{tabular}{ccc}
\hline $\begin{array}{c}\text { Applied } \\
\text { magnetic field } \\
\text { (tesla) }\end{array}$ & $\begin{array}{c}\Delta \mathbf{T}=\mathbf{T}^{\mathrm{B}}-\mathrm{T}^{\mathbf{0}}, \\
\text { transformation temperature shift } \\
\text { due to applied magnetic field } \\
\left({ }^{\circ} \mathbf{C}\right)\end{array}$ & $\begin{array}{c}\Delta \mathbf{G}^{\mathrm{B}, \gamma \rightarrow \alpha}, \\
\text { magnetic free energy } \\
\text { contribution for the } \gamma \rightarrow \mathbf{\alpha} \\
\text { phase transformation } \\
(\mathbf{J} / \mathbf{m o l})\end{array}$ \\
\hline 10 & 35 & 150 \\
20 & 63 & 265 \\
30 & 85 & 360 \\
\hline
\end{tabular}

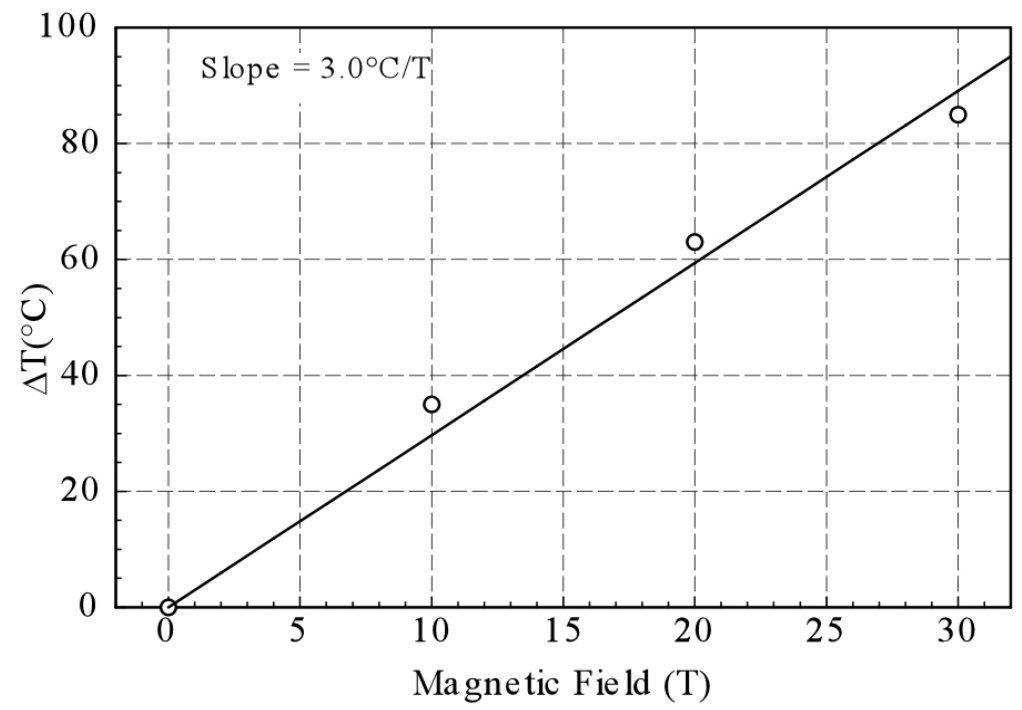

Fig. 4.15. Plot of the experimental transformation temperature shifts (determined via the approach summarized in Fig. 4.12 as a function of magnetic field strengths of $0,10,20$, and $30 \mathrm{~T}$ ).

To obtain an estimate of the Gibbs free energy change for the austenite decomposition transformation due to the presence of the magnetic field, $G^{B}$, the fundamental Gibbs free energy equation serves as the starting point [2]:

$$
G^{\gamma \rightarrow \alpha}=H^{\gamma \rightarrow \alpha}-T S^{\gamma \rightarrow \alpha} .
$$

At equilibrium

$$
S^{\gamma \rightarrow \alpha}=H^{\gamma \rightarrow \alpha} / T_{E},
$$

where $T_{E}$ is the equilibrium phase transformation temperature. Therefore,

$$
G^{\gamma \rightarrow \alpha}=\left(H^{\gamma \rightarrow \alpha} / T_{E}\right)\left(T_{E}-T^{0}\right),
$$

where $T^{0}$ is the transformation temperature for a magnetic field strength equal to zero. When a magnetic field is applied, an additional term, $G^{B}$, must be added to the right-hand side of Eq. 4.3 to account for the free energy change due to the presence of a magnetic field of strength $B$, or 


$$
G^{\gamma \rightarrow \alpha}+G^{B}=\left(H^{\gamma \rightarrow \alpha} / T_{E}\right)\left(T_{E}-T^{B}\right),
$$

where $T^{B}$ is now the transformation temperature under the application of the magnetic field of strength $B$.

From Eq. (4.4) and the experimental transformation cooling curves in Fig. 4.13, an estimate of the contribution of the magnetic field to the Gibbs free energy, $G^{B}$, can be determined for magnetic field strengths of 10, 20, and $30 \mathrm{~T}$, respectively. These results, summarized in Table 4.3, are based on literature values for $H^{\gamma \rightarrow \alpha}$ of $4,200 \mathrm{~J} / \mathrm{mol}$ and for $T_{E}=A_{\mathrm{C} 1}=720^{\circ} \mathrm{C}$. Plotting these data as magnetic free energy contributions, $G^{B}$, vs magnetic field strength gives a slope of $12.6 \mathrm{~J} / \mathrm{mol} / \mathrm{T}$, as shown in Fig. 4.16.

A simple calculation can be done to determine whether these experimentally derived values for the Gibbs free energy contribution by the magnetic field are reasonable. A Bohr magneton, $\mu_{\text {Bohr }}$, is equal to $9.3 \times 10^{-24} \mathrm{~J} / \mathrm{T}$ (on an atom basis). So for a mole of atoms, this yields $\mu_{\mathrm{Bohr}} \times N_{\mathrm{A}}=5.6 \mathrm{~J} /(\mathrm{mol} \cdot \mathrm{T}$ ) where $N_{\mathrm{A}}$ is Avogadro's number $=6.023 \times 10^{23}$ atoms per mole. Since iron has a moment of $2.2 \mu_{\mathrm{Bohr}}$ per atom, this gives the total moment, $m=12.3 \mathrm{~J} / \mathrm{T} / \mathrm{mol}$, which is approximately equivalent to the slope in Fig. 3.14. Therefore, the Gibbs free energy difference between a mole of ferromagnetic iron atoms and non-ferromagnetic atoms in a 30-T field is estimated to be $369 \mathrm{~J} / \mathrm{mol}$, a value in excellent agreement with the value determined experimentally and summarized in Table 4.3.

The experimental results for the 1045 steel clearly estimate the magnitude of the transformation temperature shift as nominally $3^{\circ} \mathrm{C} / \mathrm{T}$ and the contribution of the magnetic field to the Gibbs free energy for the austenite decomposition transformation, ' $G^{B}$, as approximately $12.6 \mathrm{~J} / \mathrm{mol} / \mathrm{T}$. These results also indicate that successively higher magnetic field strengths applied during continuous cooling coincide with higher austenite decomposition transformation temperatures and faster phase transformation initiation times when compared with the results with no magnetic field.

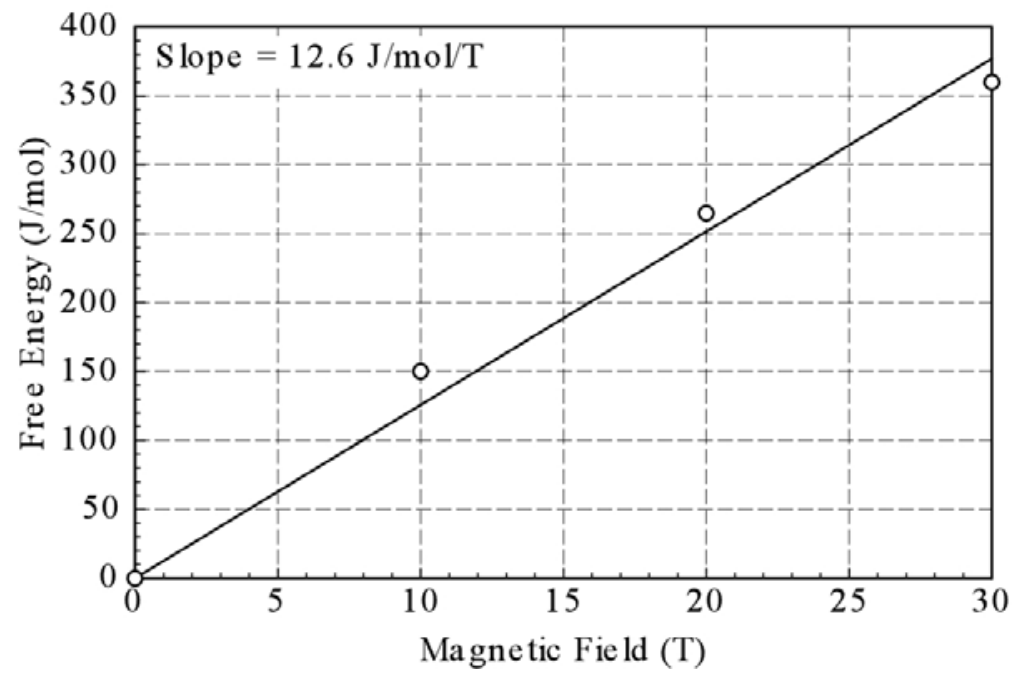

Fig. 4.16. Plot of the experimentally estimated magnetic contribution to the Gibbs free energy as a function of magnetic field strength. 
One major goal of this project was to develop the capability to predict the influence of magnetic field strength on the phase diagram of ferrous alloys. The experimental data for the free energy change due to $1 \mathrm{~T}$ of magnetic field strength provided the essential input required for predictive thermodynamic codes such as the commercially available ThermoCalc ${ }^{\mathrm{TM}}$ program. This software package provides the option of modifying the free energy of any phase; thus, the free energy for the ferrite phase could be modified by inputting the appropriate $G^{B}$ for a given field strength. Figure 4.17 shows the pseudobinary phase diagram predicted by ThermoCalc for both a conventional equilibrium condition and the magnetically enhanced circumstance.

Clearly evident in the predicted phase diagrams is that magnetic fields

1. raise phase transformation temperatures,

2. increase the solubility of carbon in the various phases, and

3. shift critical congruent points such as eutectoid chemistries and temperatures.

This research definitively demonstrates that the materials scientist is no longer limited to just one phase diagram per alloy chemistry when considering alloy development, heat treatment, and thermomechanical processing approaches to optimize microstructure and phase transformation kinetics and to enhance material properties. Magnetic processing now enables a continuum (3D with the added dimension of magnetic field strength, $H$ ) of phase diagrams to be developed for any alloy. Since the thermodynamic dependence of the Gibbs free energy is linear with $H$ [due to the $\int_{0} H_{(M F e} \gamma$ - $\left.M_{F e} \alpha\right) d H$ term in Eq. (2.1)], the only limit to this technology will be the magnetic field strengths available in commercial magnets, which are improving all the time. An implication of these predictions is that magnetic field processing can be used to isothermally transform a material. Applying a high enough magnetic field can shift a sample from being above a phase transformation

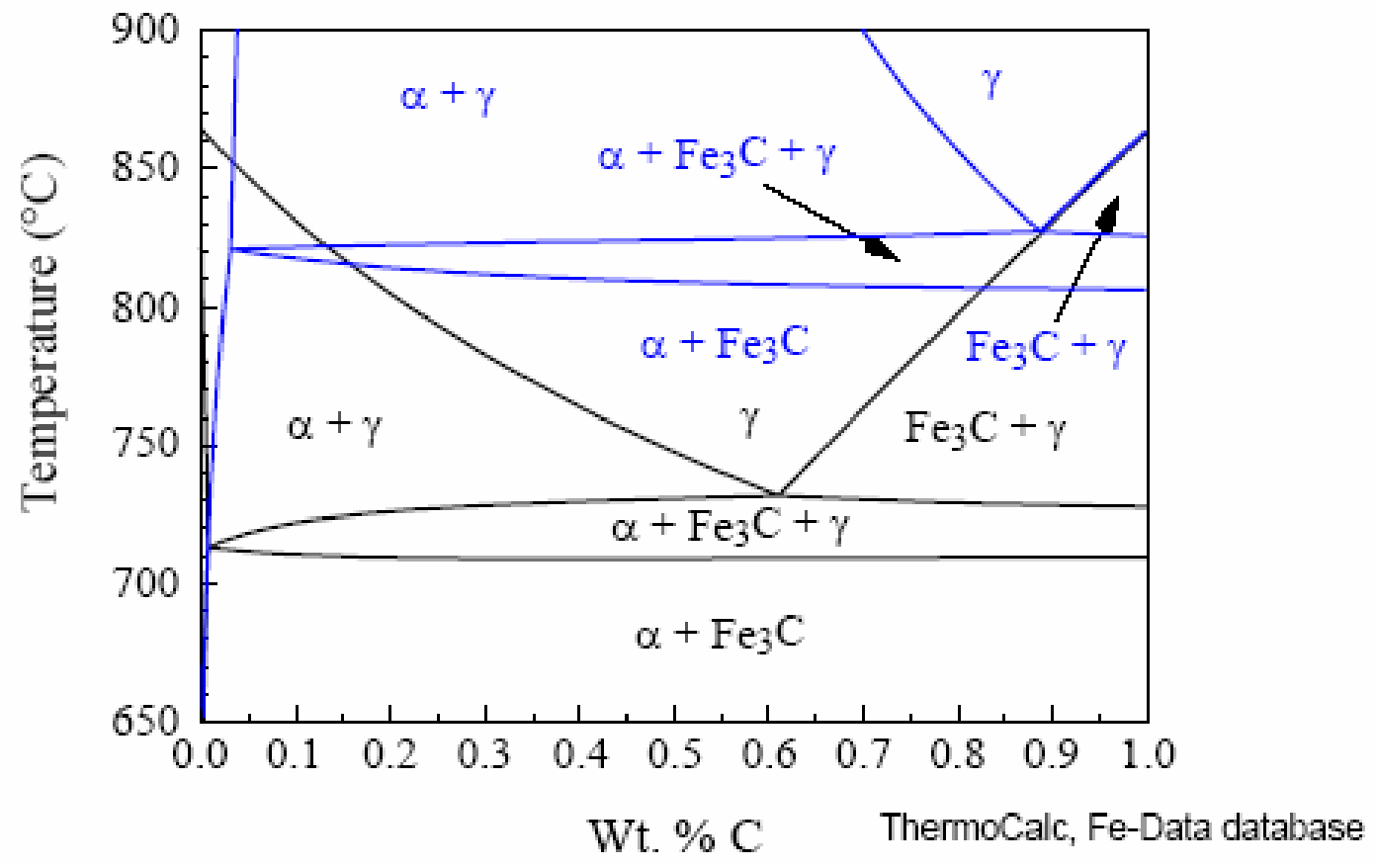

Fig. 4.17. Prediction of the pseudobinary phase diagram for 1045 steel for conventional equilibrium (black lines) and magnetically enhanced equilibrium (blue lines). 
temperature to below the magnetically enhanced phase transformation temperature that would induce phase decomposition. This hypothesis was demonstrated in the set of experiments described below.

One classic method for refining grain size in steels is to cycle the component about the eutectoid $\left(\mathrm{A}_{1}\right)$ temperature, since in steels, equilibrium phase decomposition upon cooling proceeds by multiple nuclei of the transformation product initiating along the prior austenite grain boundaries. This results in the formation of many more distinct grains than originally existed in the steel above the eutectoid temperature. Unfortunately, cooling of large components results in thermal gradients' forming from the surface toward the interior, causing a gradient microstructure to evolve, since deeper locations transform at later times. In addition, thermal strains can result under these thermal gradient conditions, causing residual stress effects. As mentioned in the previous section, since magnetic fields shift transformation temperatures upward, it is conceptually possible to keep a component isothermal and induce phase transformation (decomposition to $\alpha$ + pearlite) of the initial phase (in this case, austenite, $\gamma$, or $\gamma+\alpha$ ) by applying a magnetic field of adequate field strength to magnetically shift the phase transformation temperature upward (there is effectively an $\mathrm{A}_{1}{ }^{\mathrm{H}}$ that is higher than the $A_{1}$ ). An example of a conventional thermal cycling approach that could be used for the 1045 steel is shown in Fig. 4.18.

This figure shows a multiple-cycle approach whereby the material is taken below the eutectoid temperature range $\left(A_{1}\right)$, then above it, and finally below it again. The isothermal magnetic processing treatment that will cause phase transformation reversal comparable with that achieved thermally is indicated in Fig. 4.19. The microstructures obtained after each cycle (or step) graphed in Fig. 4.18 are shown in the top three micrographs presented in Fig. 4.20. In this experiment, after an initial austenitization treatment of $850^{\circ} \mathrm{C}$ the specimen is cooled to $750^{\circ} \mathrm{C}$, which is still above the eutectoid point, and allowed to equilibrate. Without the magnetic field [as seen in the conventional phase diagram (black lines) for this alloy in Fig. 4.17], the alloy is dominantly $\gamma$ with just a little $\alpha$.

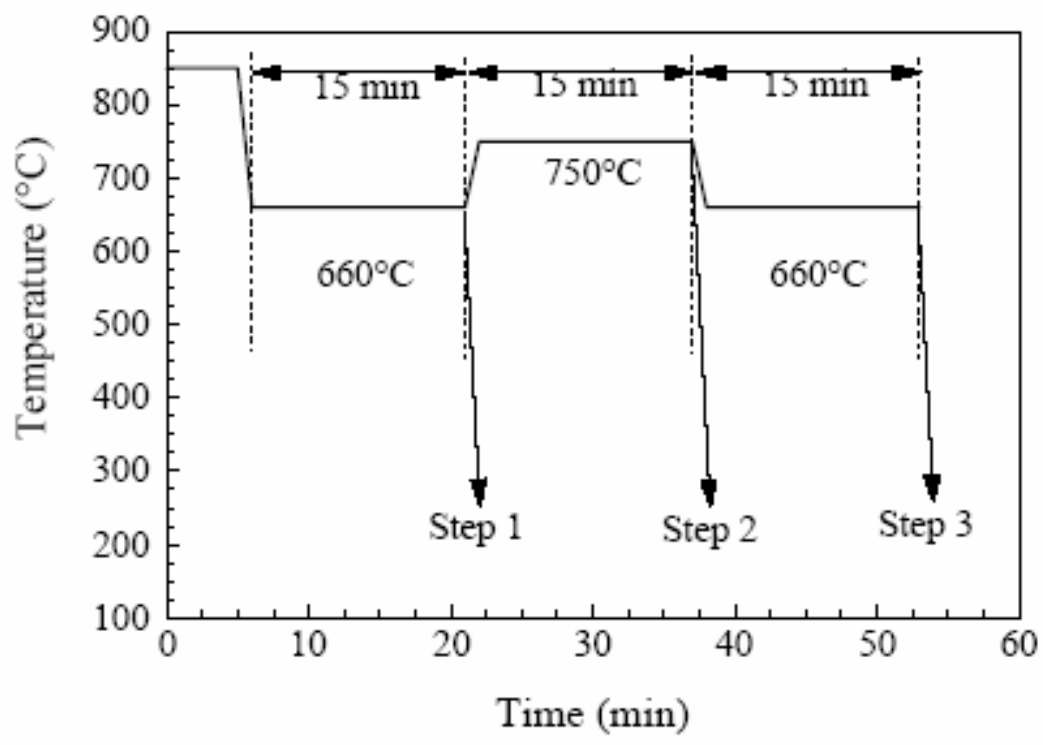

Fig. 4.18. Schematic of a thermal cycling heat treatment cycle about the eutectoid $\left(A_{1}\right)$ temperature range $\left(-710-725^{\circ} \mathrm{C}\right)$ to achieve austenite phase transformation decomposition and reversal back to the parent austenite, followed by a second decomposition cycle. 
However, when a 30-T magnetic field is applied, the calculated magnetically enhanced phase diagram (blue lines in Fig. 4.17) shows that the material is below the new eutectoid temperature range $\left(<\mathrm{A}_{1}{ }^{\mathrm{H}}\right)$ and would be anticipated to decompose to a $\alpha+$ pearlite microstructure during the first cycle (denoted "Step 1" in Fig. 4.19). The microstructures obtained after the various magnetic cycles are shown in the bottom three micrographs of Fig. 4.20.

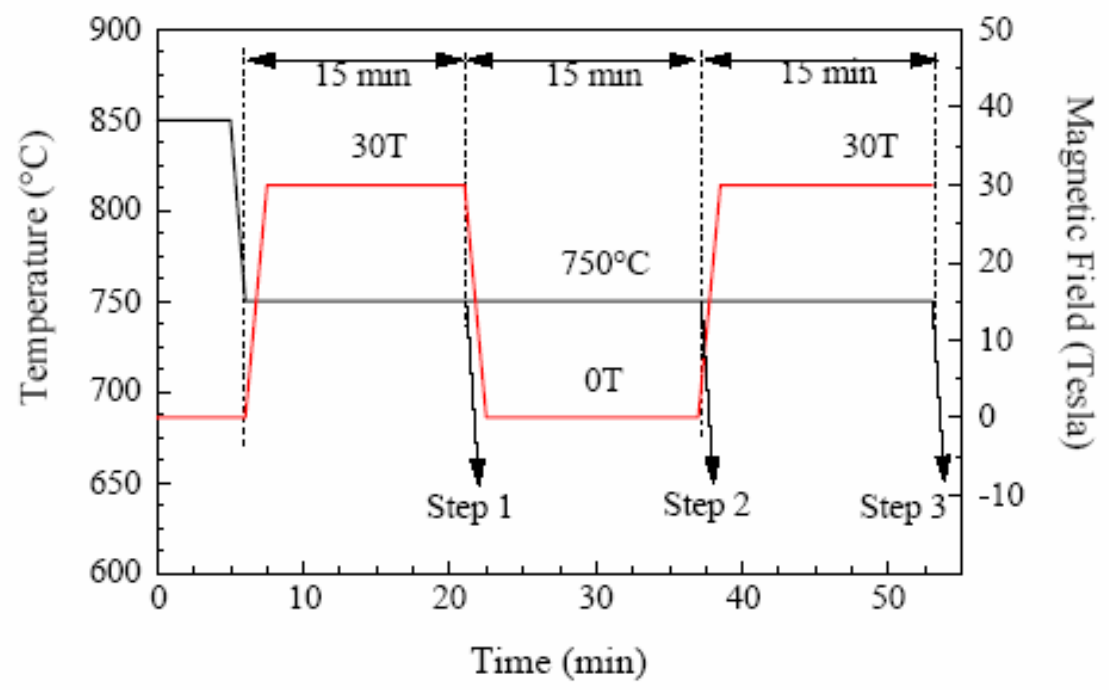

Fig. 4.19. Schematic of an isothermal magnetic field cycling process showing the magnetic field cycling $(0 \mathrm{~T} \rightarrow 30 \mathrm{~T} \rightarrow 0 \mathrm{~T})$ to achieve austenite decomposition and reversal back to the parent austenite, followed by a second decomposition cycle.

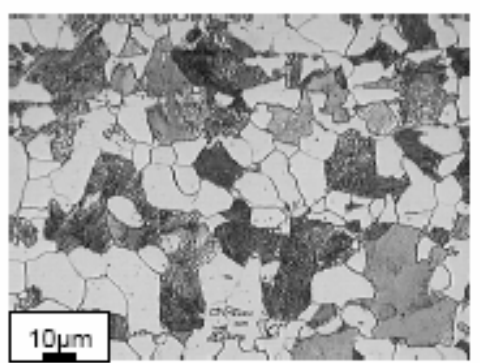

$660^{\circ} \mathrm{C}, 0 \mathrm{~T}$ Step 1

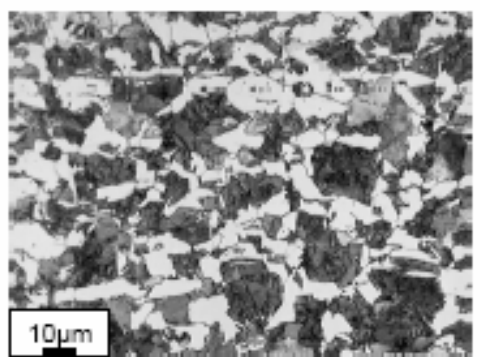

$750^{\circ} \mathrm{C}$, 30T Step 1

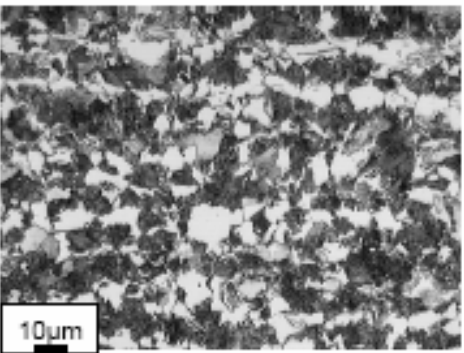

$750^{\circ} \mathrm{C}$, 0T Step 2

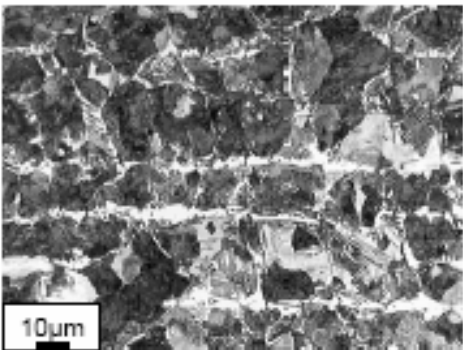

$750^{\circ} \mathrm{C}$, OT Step 2

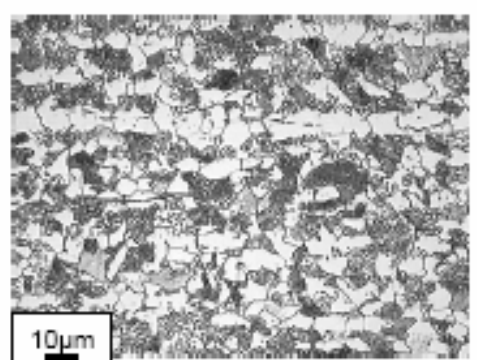

$660^{\circ} \mathrm{C}$, 0T Step 3

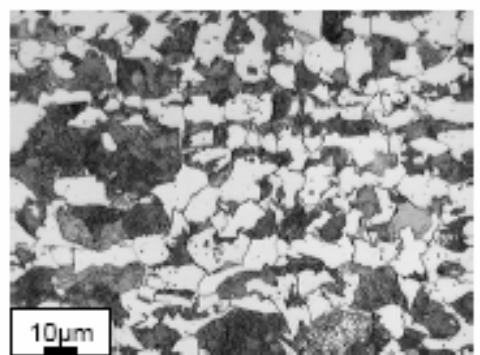

$750^{\circ} \mathrm{C}, 30 \mathrm{~T}$ Step 3

Fig. 4.20. Microstructures for the 1045 alloy steel demonstrating that phase decomposition and reversal equivalent to that obtained from conventional thermal cycling (top three images) is achieved using isothermal magnetic field processing (bottom three images). The thermal and magnetic cycles are defined in Figs. 4.18 and 4.19 , respectively. 
An evaluation of the thermally cycled and magnetically cycled specimen microstructures shown in Fig. 4.20 concluded that for both instances the microstructures obtained could only have been achieved by cycling about a eutectoid temperature. This determination is a major breakthrough for ferrous metallurgy, as bulk samples can be isothermally processed to achieve grain refinement by alternately cycling a magnetic field on and off.

Several major implications can be drawn from this experiment. First, bulk nanocrystalline ferrous microstructures may be viable. Second, since a DC magnetic field completely penetrates a ferrous sample, phase transformation should occur simultaneously everywhere, eliminating microstructure gradient issues. More importantly, because the entire microstructure transforms simultaneously, residual stresses should be reduced, and less distortion should result. Residual stresses generally result from transformations occurring at different times during a sample cooling process resulting in parent austenite phase plastic deformation ahead of the transformation front coupled with the significant volume expansion that occurs when the phase decomposition finally happens locally.

Third, distortion and component cracking should be reduced with the isothermal magnetic phase transformation processes, since this approach decouples the significant thermal gradient strains from the rather large phase transformation strains that exist when thermal processes (cooling) are used to induce phase decomposition. The higher temperatures used in isothermal magnetic cycling processing will enable the material to accommodate phase transformation strains and relieve any residual stresses prior to cooling the component to ambient temperature and dealing with the thermal strain issues separately. This decoupling of phase transformation strain from thermal strain via magnetic processing promises to have a significant impact on reducing manufactured part rejects due to heattreatment-related cracking and distortion. The reduced residual stresses will allow the design engineer greater flexibility in component design by allowing higher design stresses and/or lighter-weight, smaller cross sections, with resulting decreases in energy use (during manufacturing and in the automotive/vehicle industries) and material savings.

\subsection{Super Bainite High-Strength ( 2.5 GPa) Steel Investigation}

The very strong bainitic steel alloys that have been developed recently $[8,9]$ are capable of strengths in excess of $2.5 \mathrm{GPa}$ and exhibit reasonable plasticity before fracture. An example of a chemistry for one of these alloys is Fe-0.78C-1.60Si-2.02Mn-1.01Cr-3.87Co-1.37Al-0.002P-0.002S (wt. \%). A relatively low transformation temperature is required to obtain the very fine bainitic microstructure that develops this attractive property combination of strength and plasticity. Unfortunately, the lengthy processing times required at these low temperatures (e.g., $20 \mathrm{~h}$ at $200^{\circ} \mathrm{C}$ ) can be a drawback in implementing these alloys in a commercial environment. We conducted experiments on the "super bainite" alloy chemistry given above to determine whether the application of a magnetic field during continuous cooling can accelerate the phase decomposition in this alloy such that pearlitic or bainitic transformation products are obtained, rather than martensite.

The cooling curve plots depicted in Fig. 4.21 show evidence that for the two experiments run under the influence of a 30-T magnetic field, super bainitic steel undergoes an elevated transformation decomposition process in contrast to the specimen cooled with no magnetic field applied. These experiments involved heating the bainitic steel initially to $1000^{\circ} \mathrm{C}$ and then cooling it at a rate of $1{ }^{\circ} \mathrm{C} / \mathrm{s}$ down to ambient temperature. For the magnetically processed test runs, the magnetic field was applied at $1000^{\circ} \mathrm{C}$ and during the entire cooling process. 


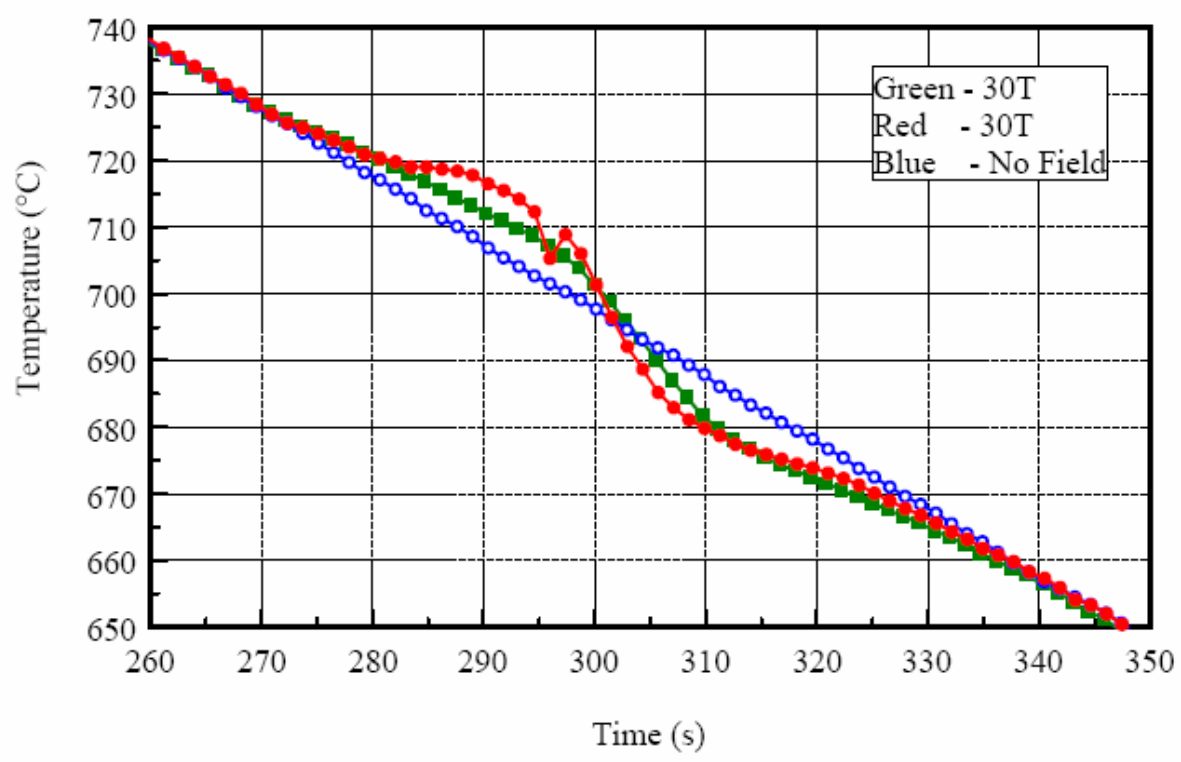

Fig. 4.21. Continuous cooling temperature $\left(1^{\circ} \mathrm{C} / \mathrm{s}\right)$ vs time data for the highstrength bainitic steel alloy for both 0 and 30-T magnetic field conditions.

Figures 4.22(a) and (b) show optical micrographs for specimens processed with no magnetic field and with a 30-T magnetic field, respectively. As anticipated because of the high alloy content of this material, the specimen processed with no magnetic field has a fully martensitic microstructure even for this relatively slow $1{ }^{\circ} \mathrm{C} / \mathrm{s}$ cooling rate. In contrast is the microstructure shown in Fig, 4.22(b), which appears to result from cellular decomposition of the parent $\gamma$ phase, as evidenced by the very irregular grain boundaries in the final transformed product. At the resolution provided by optical metallography, it was not possible to determine whether any other transformation products such as bainite or martensite were present. In order to clearly resolve and identify this microstructure, it was necessary to examine the final microstructure via bright field transmission electron microscopy. Figure 4.22(c) shows the very fine ( $\sim 50-\mathrm{nm}$ lamellae spacing) pearlitic microstructure characteristic of this sample as observed in thin foils made from the specimen processed with the 30-T magnetic field. These results clearly demonstrate that nanocrystalline microstructures are feasible through magnetic processing.

Hardness measurements were made to correlate with the dramatically different microstructures obtained in this super-strength bainitic steel for the no-magnetic field vs 30-T magnetic field processing conditions. Multiple traverses were made across the specimens to obtain hardness distributions for the two conditions; these data are presented in Fig. 4.23. As anticipated, the nomagnetic field condition that resulted in a fully martensitic microstructure has a very well defined high-hardness distribution in the 870-HV range. Similarly, the fully pearlitic condition exhibits a lower hardness distribution at about $480 \mathrm{HV}$. It is important to note that for pearlite this hardness is about double the typical value of $\sim 300 \mathrm{HV}$ achieved in conventional alloys with non-magnetic processing approaches. Therefore, magnetic processing may be the technology breakthrough that will enable achievement of the steel industry goals of developing the next generation of ultrahigh-strength alloys with minimum alloy content. 


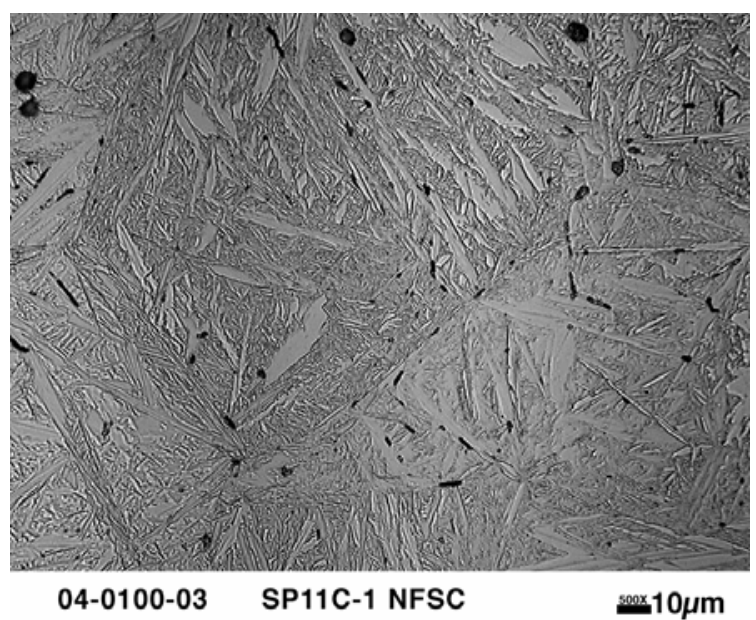

(a)

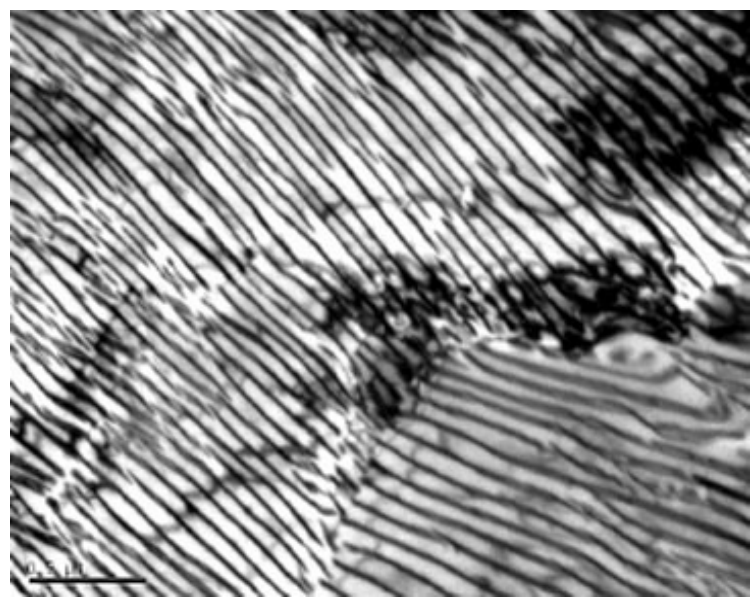

(c)

Fig. 4.23. Supporting hardness distribution data for the slowcooled $\left(1^{\circ} \mathrm{C} / \mathrm{s}\right)$ high-strength bainitic steel for both the "nofield" and 30-T field magnetic processing conditions.

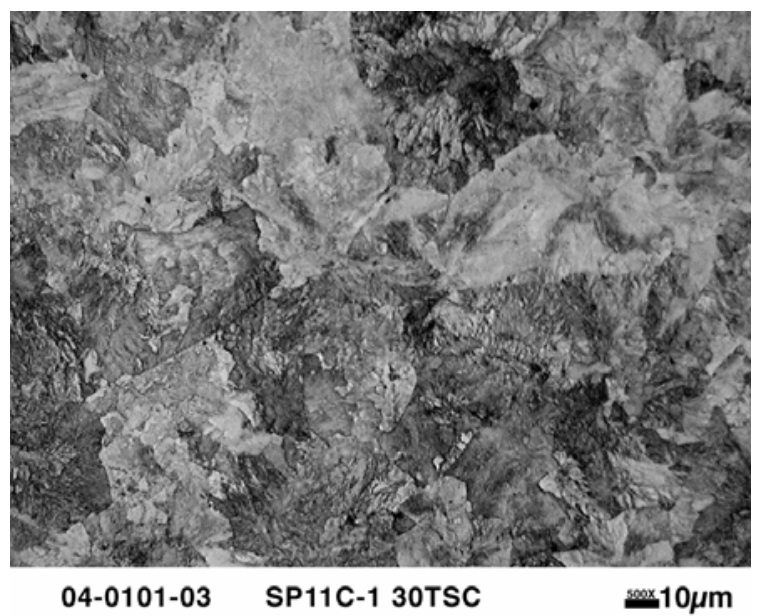

(b)

Fig. 4.22. Microstructures of the high-strength bainitic steel specimens formed at a cooling rate of $1^{\circ} \mathrm{C} / \mathrm{s}$ : (a) optical micrograph of the "no-field" experiment showing the fully martensitic microstructure; (b) optical micrograph of the 30-T experiment showing a microstructure typical of cellular decomposition and no martensite; (c) bright field transmission electron micrograph of the 30-T specimen resolving the very fine pearlite microstructure.

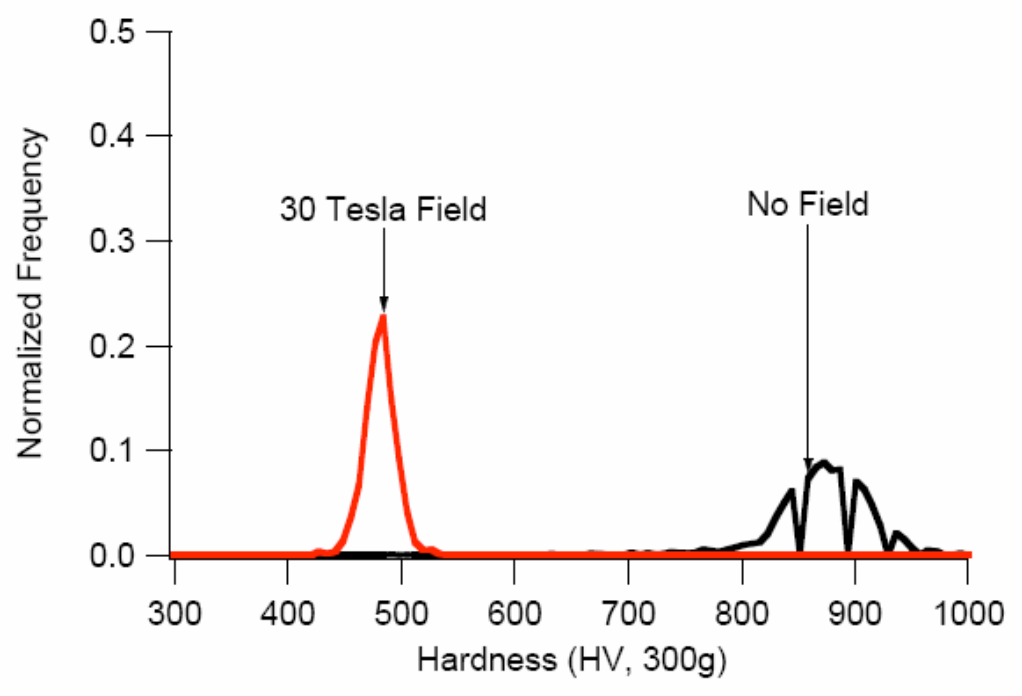


These experiments with super bainite steels further demonstrate that high-magnetic-field processing can dramatically alter the final microstructure and transformation kinetics obtained for a given alloy and thermal processing history (cooling rate). For this specific material, these results suggest that use of the appropriate magnetic-field processing strength and temperature processing parameters during the final low-temperature heat treatment can significantly reduce the time needed to obtain the desired microstructure and properties.

Using the predictive capability developed in this project to show the shift of the phase diagram for this bainitic steel due to magnetic field effects, we calculated pseudobinary phase diagrams (Fig. 24). The typical equilibrium phase diagram is shown in Fig. 4.24(a), and the enhanced phase diagram for the 30-T magnetic field is shown in Fig. 4.24(b). These calculations demonstrate that the phase fields are shifted upward and to the right by the applied magnetic field, which means that the phase transformation temperatures are raised and that phase solubility for carbon is enhanced.
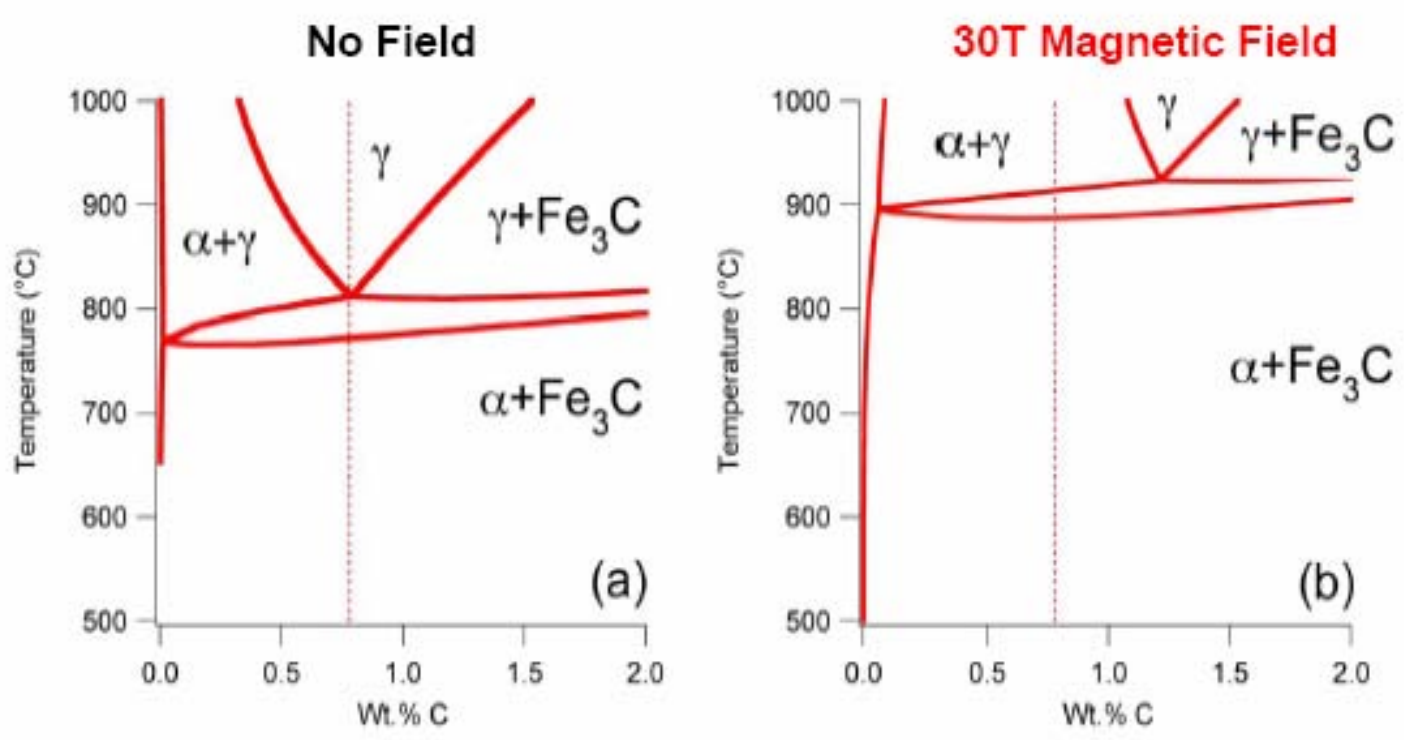

ThermoCalc, Fe-Data database

(a)

(b)

Fig. 4.24. Prediction of the pseudobinary phase diagram for the tested bainitic steel for both (a) conventional equilibrium and (b) magnetically enhanced equilibrium conditions.

\subsection{Residual Stress Reduction}

Data on residual stress reduction were developed in a precursor project to the current one through the ORNL Director's R\&D Seed Money funding initiative. The successes of this initial endeavor led to the development of the concepts presented in the original proposal for this endeavor. The results are presented here to complete the summary of the many benefits of magnetic processing for future R\&D and commercialization endeavors.

As background, residual stresses are nonapplied stresses resulting from a constrained volume change. In metals, these stresses are elastic and are typically the direct result of elastic and plastic strains due to thermal gradient and phase transformation strains in addition to crystallographic anisotropy effects. This experiment explored the hypothesis that magnetic processing can relieve residual stresses 
through enhancing the mobility of the dislocation structure, also known as the magnetoplasticity phenomenon. This can lead to their rearrangement, multiplication, or annihilation, thereby altering the residual stress profile in a material. The abatement of tensile residual stresses through magnetic processing is very beneficial from both a component design and a life expectancy viewpoint, since existing tensile residual stresses typically reduce the design stresses and fatigue life.

To maximize the effects observed in this study, we used the highest field-strength magnetic system at ORNL, a 6-T superconducting system, for magnetic-field processing. These tests were conducted on 25.4-mm-diam by 101.6-mm-long cylindrical samples using a commercial grade of 52100 alloy steel. Because of the high carbon content of this alloy, significant residual stresses and some retained austenite are generated upon quenching to ambient temperatures. Therefore, this alloy is an excellent candidate to show the potential benefits of applying a magnetic field for the purpose of relieving residual stress.

The initial surface axial residual stresses and the percentage of austenite retained for all samples were measured using a TEC X-ray diffractometer at three specific circumferential points $120^{\circ}$ apart at the circular midplane of the samples $50.8 \mathrm{~mm}$ from the flat ends of the samples. Therefore, the plots of these data show three values for each sample to indicate each of the three circumferential values per sample (e.g., Y1-1, Y1-2, and Y1-3 for sample Y1). Chrome K $\alpha$ radiation was used. A $\sin ^{2} \psi$ analysis was employed on the martensitic (211) reflection.

After the initial data were collected on all six of the premagnetically processed samples, two specimens from each lot, tempered samples ("Y") and nontempered samples ("N"), with the most uniform initial residual stress profiles were exposed to the 6-T magnetic field in a Cryomagnetics, Inc., superconducting magnet system located in ORNL's Fusion Energy Division.

A special fixture to hold these specimens exactly in the central bore region of the superconducting magnet was fabricated out of $316 \mathrm{~L}$ stainless steel. The magnetic field was most uniform in the central bore location, eliminating gradient effects. Specimens Y1 and N1 were placed in the magnet system at 0 initial field strength as a safety precaution to eliminate any sample handling and insertion concerns for these initial proof-of-principle experiments. After the bore region was sealed off with a $316 \mathrm{~L}$ plate, the magnetic field was ramped up to $6 \mathrm{~T}$ and held for $1 \mathrm{~h}$ before being slowly discharged to $0 \mathrm{~T}(\sim 1 \mathrm{~h})$ for safe sample removal. Samples Y2 and N2 received 4-h exposures at $6 \mathrm{~T}$ using a similar test cycle. All four magnetically processed samples exhibited remnant magnetization after their cycles, with the nontempered samples $(\mathrm{N})$ showing greater remnant magnetization than did the tempered (Y) samples.

After the magnetic processing experiments, each lot of specimens was clustered together with their untreated counterpart and sent to the TEC residual stress facility at ORNL's High Temperature Materials Laboratory (HTML) to measure residual stresses and retained austenite on all six samples.

The results of these proof-of-principle experiments that compare pre- and post-magnetic processing values for residual stress are indicated in Fig. 4.25. Experimental error for the residual stress measurements is estimated to be $\pm 25 \mathrm{MPa}$. The data in Fig. 4.25 generally indicate that magnetic processing does reduce the magnitude of the quenched-in residual stresses. An anomalous measured increase in residual stress after magnetic processing for one data set, Y2-1, is inconclusive since these values are within the experimental measurement error of $\pm 25 \mathrm{MPa}$ of each other. These limited data do not allow for conclusions about the influence of different magnetic exposure times of 1 and $4 \mathrm{~h}$ at $6 \mathrm{~T}$. While it appears that $1 \mathrm{~h}$ may be just as effective as $4 \mathrm{~h}$, future experiments will be needed to determine if the magnetic processing effect is relatively spontaneous or has some threshold exposure time for its effectiveness. 


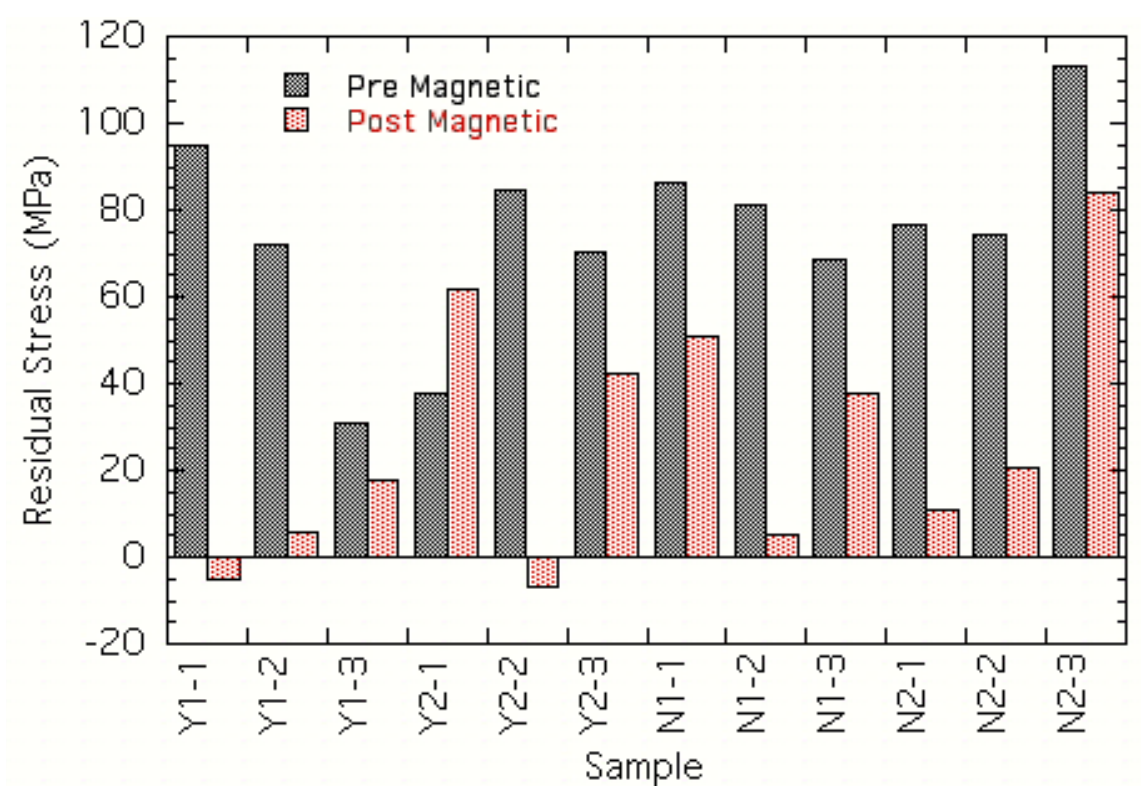

Fig. 4.25. Magnetic processing using a 6-T field altered the residual stresses in $\mathbf{5 2 1 0 0}$ alloy steel samples $(\mathrm{Y}=$ quenched and tempered; $\mathrm{N}=$ quenched and not tempered).

\subsection{Energy Savings and Environmental and Economic Benefits to the IMF Program}

The potential economic benefits of this project can be very large because of the many ramifications that ultrahigh magnetic field processing can have for many of DOE's Vision Industries. Since all materials exhibit some form of ferromagnetism or paramagnetism, this project may show that magnetic processing can yield unique and novel microstructures with enhanced performance for a broad spectrum of materials, impacting the steel, aluminum, chemical, forging, heat treating, metal casting, and welding industries. For instance, normalization heat treatments for steel product being delivered to forging houses or employed by heat treaters to guarantee consistent and uniform product may be able to be eliminated if magnetic field processing ensures complete transformation to the desired pearlitic microstructure instead of the partial bainitic microstructures that are difficult to machine. This will result in major manufacturing cost savings, reduced scrap, energy savings, and environmental benefits. Similarly, if quenched product for critical applications can be guaranteed to have no retained austenite and consist of $100 \%$ martensitic microstructures, subsequent cryogenic treatments or alternate double-temper heat treatments to eliminate retained austenite can be eliminated. Additionally, if currently impossible novel microstructures with significantly enhanced performance capabilities can be developed, then significant weight reductions can be accomplished with these improved materials, enabling design and manufacture of more lightweight structures in the transportation industries (e.g., the UltraLight Steel Auto Body structure).

The estimated energy and environmental savings presented in Tables 4.4 and 4.5 were calculated on the assumption that gas is the sole source of energy for the normalization heat treatment step. An energy savings / environmental benefit Excel spreadsheet was used to calculate these benefit numbers. These tables are copied directly from that spreadsheet and are based on the tonnage figures given in the section below. The calculations were based on a "technology unit year," which defines the embodied energy in the output per year as that from one average steel normalization facility, the 
size of which is $1 / 10$ that of the entire U.S. steel bar and rod industry. Therefore, 10 technology unit years were assumed for the gradual implementation of this technology development for the energy and environmental calculations given below. Additional energy benefits could be claimed if the 25 million tons of imported steel are also included for this calculation.

Considering only the elimination of redundant normalization heat treatment of steels for bar and rod product to ensure that no bainite is present during initial machining operations as a baseline to calculate the potential economic benefit of this program, annual domestic savings would be $\$ 91$ million/year, or an energy savings of $\sim 14$ trillion Btu/year. These values are based on eliminating the normalization heat treatment step for only an estimated $20 \%$ of the total tonnage of domestic bar product, which is $\sim 7$ million tons/year. Before the current energy crisis and increased energy costs, a normalization heat treatment cost $\sim \$ 65 /$ ton for this heat treatment step (statistics provided an ORNL industrial partner in a DOE AISI project). Additional energy savings of up to 68 trillion Btu/year (equivalent to an economic impact of $\$ 325$ million/year) could be realized globally if similar calculations were included in the benefit analysis based on the additional 25 million tons of imported steel per year that is dominantly bar and rod product.

Table 4.4. Projected energy savings for the ultrahigh magnetic field processing project

\begin{tabular}{|c|c|c|c|c|c|}
\hline Impact by year & 2005 & 2010 & 2015 & 2020 & 2025 \\
\hline Units installed & 0 & 1 & 3 & 5 & 8 \\
\hline Market penetration & $5 \%$ & $21 \%$ & $34 \%$ & $61 \%$ & $82 \%$ \\
\hline \multicolumn{6}{|l|}{ Energy metrics } \\
\hline Total primary energy displaced, trillion Btu & $1.61 \mathrm{E}-01$ & 4.59E-01 & $1.12 \mathrm{E}+00$ & $2.09 \mathrm{E}+00$ & $2.98 \mathrm{E}+00$ \\
\hline Direct electricity displaced, billion kWh & $0.00 \mathrm{E}+00$ & $0.00 \mathrm{E}+00$ & $0.00 \mathrm{E}+00$ & $0.00 \mathrm{E}+00$ & $0.00 \mathrm{E}+00$ \\
\hline Direct natural gas displaced, billion $\mathrm{ft}^{3}$ & $1.57 \mathrm{E}-01$ & $4.46 \mathrm{E}-01$ & $1.09 \mathrm{E}+00$ & $2.04 \mathrm{E}+00$ & $2.90 \mathrm{E}+00$ \\
\hline Direct petroleum displaced, million barrels & $0.00 \mathrm{E}+00$ & $0.00 \mathrm{E}+00$ & $0.00 \mathrm{E}+00$ & $0.00 \mathrm{E}+00$ & $0.00 \mathrm{E}+00$ \\
\hline Direct coal displaced, million short tons & $0.00 \mathrm{E}+00$ & $0.00 \mathrm{E}+00$ & $0.00 \mathrm{E}+00$ & $0.00 \mathrm{E}+00$ & $0.00 \mathrm{E}+00$ \\
\hline Feedstock energy displaced, trillion Btu & $0.00 \mathrm{E}+00$ & $0.00 \mathrm{E}+00$ & $0.00 \mathrm{E}+00$ & $0.00 \mathrm{E}+00$ & $0.00 \mathrm{E}+00$ \\
\hline Renewable energy used, trillion Btu & $0.00 \mathrm{E}+00$ & $0.00 \mathrm{E}+00$ & $0.00 \mathrm{E}+00$ & $0.00 \mathrm{E}+00$ & $0.00 \mathrm{E}+00$ \\
\hline Waste energy displaced, trillion Btu & $0.00 \mathrm{E}+00$ & $0.00 \mathrm{E}+00$ & $0.00 \mathrm{E}+00$ & $0.00 \mathrm{E}+00$ & $0.00 \mathrm{E}+00$ \\
\hline \multicolumn{6}{|l|}{ Cost } \\
\hline Energy-cost savings, million $\$ / y r$ & 4.47E-01 & $1.34 \mathrm{E}+00$ & $3.35 \mathrm{E}+00$ & $6.64 \mathrm{E}+00$ & $9.45 \mathrm{E}+00$ \\
\hline Non-energy cost savings, million $\$ / y r$ & $0.00 \mathrm{E}+00$ & $0.00 \mathrm{E}+00$ & $0.00 \mathrm{E}+00$ & $0.00 \mathrm{E}+00$ & $0.00 \mathrm{E}+00$ \\
\hline
\end{tabular}


Table 4.5. Environmental benefits for this project

\begin{tabular}{lccccc}
\hline \multicolumn{1}{c}{ Environmental metrics $^{\mathbf{a}}$} & $\mathbf{2 0 0 5}$ & $\mathbf{2 0 1 0}$ & $\mathbf{2 0 1 5}$ & $\mathbf{2 0 2 0}$ & $\mathbf{2 0 2 5}$ \\
\hline CO displaced, MMT & $2.90 \mathrm{E}-06$ & $8.25 \mathrm{E}-06$ & $2.01 \mathrm{E}-05$ & $3.77 \mathrm{E}-05$ & $5.36 \mathrm{E}-05$ \\
$\mathrm{CO}_{2}$ emissions displaced, MMT TCE & $2.34 \mathrm{E}-03$ & $6.65 \mathrm{E}-03$ & $1.62 \mathrm{E}-02$ & $3.04 \mathrm{E}-02$ & $4.32 \mathrm{E}-02$ \\
Other greenhouse emissions displaced, MMT TCE & $2.93 \mathrm{E}-07$ & $8.32 \mathrm{E}-07$ & $2.03 \mathrm{E}-06$ & $3.80 \mathrm{E}-06$ & $5.41 \mathrm{E}-06$ \\
$\mathrm{SO}_{2}$ displaced, MMT & $6.61 \mathrm{E}-06$ & $1.88 \mathrm{E}-05$ & $4.58 \mathrm{E}-05$ & $8.59 \mathrm{E}-05$ & $1.22 \mathrm{E}-04$ \\
$\mathrm{NO}_{x}$ displaced, MMT & $1.71 \mathrm{E}-05$ & $4.86 \mathrm{E}-05$ & $1.18 \mathrm{E}-04$ & $2.22 \mathrm{E}-04$ & $3.16 \mathrm{E}-04$ \\
Particulates displaced, MMT & $0.00 \mathrm{E}+00$ & $0.00 \mathrm{E}+00$ & $0.00 \mathrm{E}+00$ & $0.00 \mathrm{E}+00$ & $0.00 \mathrm{E}+00$ \\
VOCs displaced, MMT & $1.61 \mathrm{E}-07$ & $4.59 \mathrm{E}-07$ & $1.12 \mathrm{E}-06$ & $2.09 \mathrm{E}-06$ & $2.98 \mathrm{E}-06$ \\
\hline
\end{tabular}

${ }^{a}$ MMT = million metric tons; TCE $=$ total carbon equivalent

\subsection{Alternate Energy Saving Scenarios for Magnetic Processing in the Steel Industry}

Appendix A presents schematically several scenarios in the steel manufacturing/fabrication cycle where magnetic processing may provide significant energy savings and product enhancement. (The steel manufacturing flowline diagrams are from the AISI WEB site, http://www.steel.org/learning/ flowline/index.htm.) These scenarios are not discussed further in this document but do provide concepts for future program development activities for the magnetic processing technology. 


\section{Accomplishments}

\subsection{Technical Accomplishments}

This project has successfully accomplished and significantly exceeded its goals. This effort has demonstrated and documented the following properties and advantages of ultrahigh magnetic field processing of ferromagnetic materials:

- Dramatically shifts phase equilibria and enhances phase solubilities

- Implications: New (3D) phase diagrams that open up a whole new avenue for major alloy development activities (one of the most significant breakthroughs in materials research); additional "new" phases can now exist in "equilibrium"

- Increases phase transformation kinetics

- Benefits: Major energy savings ramifications, enhanced process flexibility, and improved efficiency

- Produces novel microstructures with enhanced performance

- Will enable development currently "impossible" microstructures with unique properties

- Applicable to bulk nanomaterial development efforts (magnetically cycling about a transformation temperature for grain refinement while still being isothermal)

- Provides a totally new and unique processing (thermomechanical-magnetic) methodology for designing and engineering new materials and processing approaches

— Enhanced "materials by design" flexibility

— Residual stress relief for component life extension and improved manufacturability

\subsection{Technology Transfer}

Intellectual property has been generated as a result of this significant research effort. Three inventions are listed in Section 5.3.2. One of these has resulted in the issuance of a U.S. patent; another patent application has been filed, and a third record of invention has been submitted and is under consideration for formal filing as a patent application.

This project was funded as a Laboratory Call Proposal under the IMF Program; therefore, the goal was for ORNL researchers to develop a visionary concept to the stage where sufficient experimental data were available to substantiate future industrial participation in follow-on R\&D efforts on specific industrial applications to commercialize this technology. The ORNL researchers on this project are currently developing industrial interest, especially involving a superconducting magnet manufacturer, to pursue collaborations on relevant industrial applications of this magnetic processing technology. The goal is to have an informally organized industrial, university, and laboratory team ready to author and submit proposals to upcoming relevant solicitations that would provide R\&D funding support for this next stage, facilitating successful commercialization of this technology.

Companies who have expressed interest in this technology during this endeavor include American Magnetics, Inc.; Caterpillar, Inc.; Cummins, Inc.; Dana Corporation; Dura-Bar; Hyundai; International Steel Group, Inc. (formerly Bethlehem Steel); Mac Steel; Southwire Company; Stellite Corporation; Stratcor; and Toyota. 


\subsection{Publications and Patents}

This research has contributed to the refereed literature, as three publications have already appeared in technical journals, a fourth is in press, and several others are in preparation. The three published papers are included in Appendix B after the initial listing of publications published, in press, or in preparation. Below is a list of the publications and patents that have come from this project.

\subsubsection{Publications}

1. G. M. Ludtka et al., "In-situ Evidence of Enhanced Phase Transformation Kinetics due to a High Magnetic Field in a Medium Carbon Steel," Scripta Materialia 51 (2004) 171-174.

2. D. M. Nicholson et al., "The Effect of High Magnetic Field Annealing on Enhanced Phase Stability in 85Fe-15Ni," Journal of Applied Physics 95, No. 11 (June 2004) 6580-6582.

3. R. A. Jaramillo, S. S. Babu, G. M. Ludtka, R. A. Kisner, J. B. Wilgen, G. Mackiewicz-Ludtka, D. M. Nicholson, S. M. Kelly, M. Murugananth, and H.K.D.H. Bhadeshia, "Effect of 30 Tesla Magnetic Field on Transformations in a Novel Bainitic Steel," Scripta Materialia 52 (2005) 461466 .

4. G. M. Ludtka et al., "Exploring Ultrahigh Magnetic Field Processing of Materials for Developing Customized Microstructures and Enhanced Performance," Proceedings of the International Workshop on Materials Analysis \& Processing in Magnetic Fields, ed. H. J. Schneider-Muntau and H. Wada, National High Magnetic Field Laboratory of Florida State University, Tallahassee Florida, March 16-19, 2004, in press.

5. G. M. Ludtka et al., "Novel Microstructures and Enhanced Properties Obtained in a 52100 Alloy Steel via Ultra High Magnetic Field Processing," Metallurgical and Materials Transactions A, in preparation.

6. R. A. Jaramillo et al., "Investigation of Austenite Decompositions in High-Carbon High-Strength Fe-C-Si-Mn Steel under 30 Tesla Magnetic Field," Proceedings of the TMS Conference on SolidSolid Phase Transformations in Inorganic Materials 2005, to be held May 29-June 3, 2005, Phoenix, AZ, in preparation.

7. R. A. Jaramillo et al., "Investigation of Phase Transformation Kinetics and Microstructural Evolution in 1045 and 52100 Steel under Large Magnetic Fields," Proceedings of the TMS Conference on Solid-Solid Phase Transformations in Inorganic Materials 2005, to be held May 29-June 3, 2005, Phoenix, AZ, in preparation.

\subsubsection{Patents}

"Method for Residual Stress Relief and Retained Austenite Destabilization," G. M. Ludtka, U.S. Patent No. 6,773,513 issued August 10, 2004.

"Magnetic Field Processing for Customizing Microstructures and Properties in Materials," G. M. Ludtka, R. A. Kisner, G. Mackiewicz-Ludtka, J. Wilgen, R. A. Jaramillo, and D. M. Nicholson, Invention Disclosure ID 0916, S-99 666, March 2001, submitted October 26, 2004.

"Induction Heating and Rapid Quenching of Material in a High Magnetic Field Environment," R. A. Kisner, J. Wilgen, G. M. Ludtka, and R. A. Jaramillo, Invention Disclosure DOE \# S-105,091, submitted November 11, 2004. 


\section{Conclusions}

The results of this research endeavor clearly demonstrate the dramatic influence that magnetic field processing can have on the resulting microstructure in a broad spectrum of ferromagnetic alloys. This microstructural influence can be observed as changes in the specific phases that make up the final microstructure, in the relative phase stabilities and volume fractions, in the phase solid solubilities, in the transformation temperatures for both equilibrium and metastable transformation products, in the phase decomposition kinetics for both isothermal and continuous cooling thermal processing conditions, and finally in the properties obtained in the resultant microstructures. The excellent agreement obtained between the LSD and ThermoCalc phase diagram calculations and the experimental results for the contribution of the magnetic field to the Gibbs free energy for the Fe$15 \mathrm{Ni}, 1045,52100$, and bainitic alloy steel systems validate the ability to predict the observed changes in the temperature-composition-magnetic field space such that modeling endeavors can now drive future research efforts to maximize magnetic field processing for a specific alloy family.

For structural materials, this research project has demonstrated or concluded the following:

- 3D phase diagrams (temperature-magnetic field-composition) exist.

- No longer limited to a single-phase diagram per alloy family

- Magnetic fields accelerate austenite decomposition during continuous cooling.

- Increase transformation temperatures

- Decrease time to transformation initiation and completion

- Magnetic field processing accelerates austenite decomposition kinetics during isothermal transformation.

- Reduces retained austenite in SAE 52100

- Eliminates cracking issues caused by cryogenic cooling, since magnetic processing to convert retained austenite is performed under ambient temperatures and thus eliminates thermal contraction strain

- Magnetic field cycling causes isothermal transformation reversal

- Separates phase transformation strains from component cooling thermal gradient strains to eliminate thick part/cross section cracking or reduce residual stress

- Potential method to make bulk nanocrystalline steels

- The phase transformation temperature shift by a magnetic field is $\sim 3^{\circ} \mathrm{C} / \mathrm{T}$.

- The $\Delta \mathrm{G}$ shift due to magnetic fields is $\sim 12.6 \mathrm{~J} / \mathrm{mol} / \mathrm{T}$.

- Magnetic processing enhances substitutional solute solid solubility.

- Enables new alloy development options

- Eliminates expensive $M_{s}$-raising alloy additions as the $M_{s}$ can be magnetically increased [eliminates, e.g., cobalt in the ferrous alloy HP9-4-20 ( 9 Ni, $4 \mathrm{Co}, 0.20 \mathrm{C})$ ]

- Magnetic processing can yield novel microstructures with enhanced and/or superior performance (e.g., optimized super-strength bainitic steels; new generation elevated-temperature, highstrength, and creep-resistant alloys).

- Thermo-magnetic-mechanical processing opportunities exist.

— Enhanced processing tools for the materials scientist and engineer 
- Optimized heat treatment and deformation processing can incorporate magnetic processing as a new parameter.

- Bulk structural nanocrystalline materials appear viable.

- Enhanced texture development may be feasible.

- Residual stress reduction has been shown

- Component life extension

- Retained austenite destabilization/reduction has been achieved.

- Increased solid solubility, making possible novel alloys for superior strength and elevatedtemperature creep resistance, is a result of magnetic processing.

- In welding science, control of final microstructure and stresses may be demonstrated in the near future.

- Bulk amorphous ferromagnetic alloys may result.

- Magnetic quenching can instantly lower temperatures by tens of degrees.

With the successful completion of this technology feasibility demonstration research phase, future projects will be developed to include a superconducting magnet manufacturer and appropriate industrial partners. This route will ensure the development and demonstration of materials-processing magnet systems with thermal processing capability for several prototype applications. Since this technology has never been implemented in industry, the initial impediment to commercialization will be this establishment of robust and energy-efficient superconducting magnet systems for industrial use. Currently, superconducting magnet systems are generally limited by available bore size (and therefore the component size that can be processed) and maximum field strength. As this technology is accepted, improved superconducting magnet materials and systems will evolve and drive system design to larger bore diameters and field strengths.

The supporting intellectual property has been established to convey the concepts of this magnetic processing technology to potential users through patents and patent disclosures (see Sect. 5.3.2). In addition, literature publications have been prepared, with some appearing in print already (Appendix B), so that the fundamental concepts and the experimental demonstration of the magnetic processing technology can receive broad visibility within the technical and commercial communities. Crucial to the acceptance of this technology will be the thorough characterization of the physical and mechanical performance (strength, fatigue, wear, etc.) characteristics of magnetically processed vs conventionally processed materials. 


\section{Recommendations}

This research project has successfully demonstrated for multiple proof-of-principle thrust areas that magnetic processing is a robust tool for customizing the microstructure and enhancing the performance of ferromagnetic materials. The principal recommendation of this project team is that the accomplishments and conclusions of this project should be used as the basis for developing appropriate industrial collaborations to enable prototype demonstration facilities for several very specific applications. A secondary recommendation is that proof-of-principle research endeavors should be initiated on several technology issues. These include

- demonstration of the applicability of magnetic processing for paramagnetic alloy systems;

- extension of ferrous research from solid state applications to solidification processes (casting, welding); and

- pursuit of bulk nanocrystalline microstructure development via isothermal magnetic processing phase transformation reversal. 


\section{References}

1. Choi, J-K., Ohtsuka, H., Xu, Y., Choo, W-Y. Scripta Mater. 43 (2000) 221.

2. Enomoto, M., Guo, H., Tazuke, Y., Abe, Y. R., Shimotomai, M., Metall. Mater. Trans. 32A (2001) 445.

3. Liu, W., Ou, D. R., Zhou, H. H., Tang, G. Y., Wu, F., J. Mater Res. 16 (2001) 2280.

4. Joo, H. D., Kim, S. U., Shin, N. S., Koo, Y. M., Mater. Lett. 43 (2000) 225.

5. Lee, K. J., Scripta Mater. 40 (1999) 735.

6. Ludtka, G. M., Jaramillo, R. A., Kisner, R. A., Nicholson, D. M., Wilgen, J. B., MackiewiczLudtka, G., Kalu, P. K., Scripta Mater. 51 (2004) 171-174.

7. Ou, D. R., Zhou, H. H., Tang, G. Y., Zhu, J., Mater. Sci. Technol. 19 (2003) 87.

8. Cabellero, F. G., Bhadeshia, H.K.D.H., Mawella, K. J. A., Jones, D. G., Brown, P., Mater. Sci. Technol. 18 (2002) 279.

9. Garcia-Mateo, C., Cabellero, F. G., Bhadeshia, H.K.D.H., ISIJ Int. 43 (2003) 1821-1825.

10. Nicholson, D. M., Kisner, R. A., Ludtka, G. M., Sparks, C. J., Petit, L., Jaramillo, R. A., Mackiewicz-Ludtka, G., Wilgen, J. B., Sheikh-Ali, A., Kalu, P. K., J. Appl. Phys. 95, No. 11 (2004) 6580-6582.

11. Zhang, J., Williams, D. B., Goldstein, J. I., Metall. Mater. Trans. 25A (1994) 1639.

12. Chuang, Y-Y., Chang, Y. A., Schmid, R., Lin, J-C., Metall. Mater. Trans. 17A (1986) 1361.

13. Wang, Y., Stocks, G. M., Shelton, W. A., Nicholson, D. M., Phys. Rev. Lett. 75 (1995) 2867. 
Appendices 


\section{Appendix A: Presentation}

Energy Saving Applications for Magnetic Field Processing of Ferrous Alloys 


\section{Energy Saving Applications for Magnetic Field Processing of Ferrous Alloys}

Magnetic Processing Would Be Effective at Locations A, $B$, and $C$ Shown in the Current Steel Process Flowline (continued on next slide)

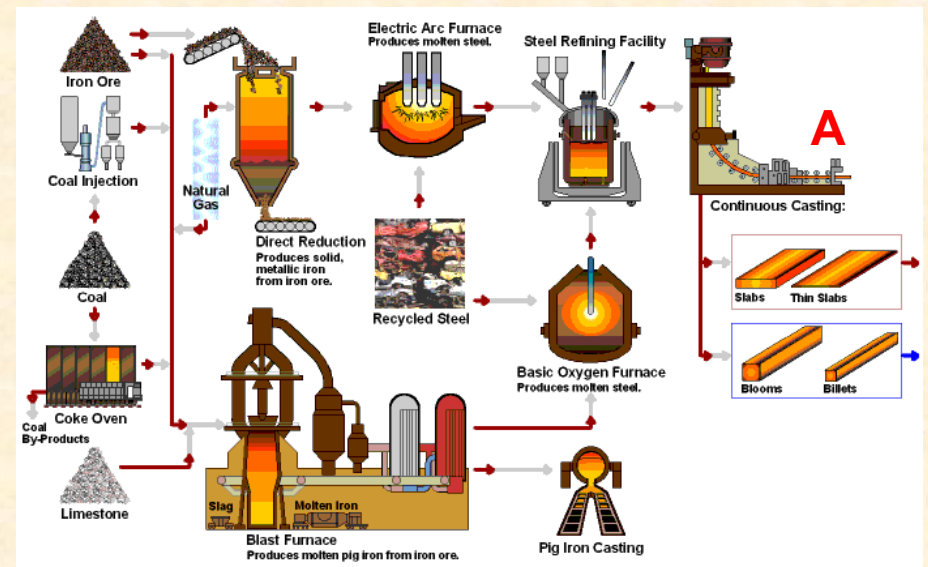

OAK RIDGE NATIONAL LABORATORY 
Magnetic Processing Would Be Effective at Locations A, $B$, and C Shown in the Current Steel Process Flowline (cont. from previous slide)

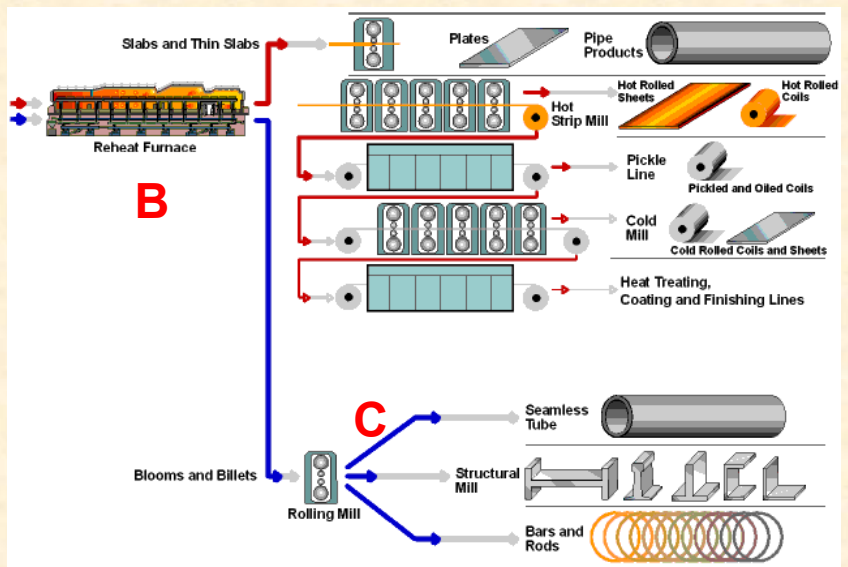

C (by enduser)

OAK RIDGE NATIONAL LABORATORY

\section{Magnetic Process A, 15T Superconducting (SC) magnet}

- Elimination of final normalization/annealing step used by bar \& rod steel manufacturers to improve machinability for end users.

Typical Normalization

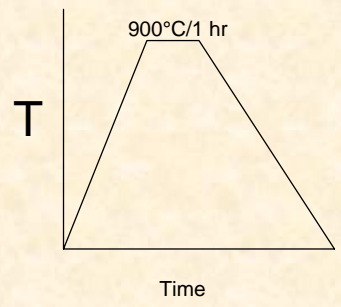

Typical Annealing cycle

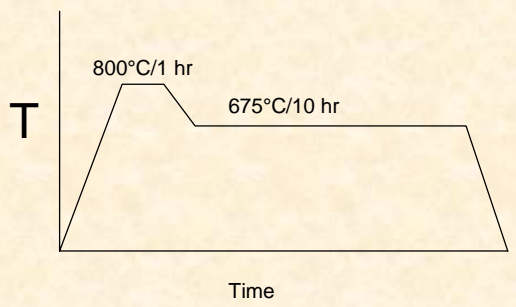

OAK RIDGE NATIONAL LABORATORY 


\section{Magnetic Process A (cont.)}

- Insert 15 T SC magnet at Point A in the steel flowline to eliminate the need for either of these 2 cycles

- Magnetic processing increases

- the volume fraction of ferrite obtained when compared with conventional processing therefore enhancing machinability (energy savings via higher throughput)

- Phase transformation kinetics

\section{Magnetic Process A Energy Savings}

- Total U.S. bar \& rod production is $\sim 8 \mathrm{M} \mathrm{T/yr}$

- Assume $50 \%$ market penetration (4M T/yr)

- Energy savings of 7T BTU/yr in U.S. for Process A

- End users redo normalization heat treatments to ensure proper microstructure to protect tooling life, therefore, this can also be eliminated doubling the energy savings to $14 \mathrm{~T} \mathrm{BTU/yr}$

- Worldwide energy savings would be $\sim 68 \mathrm{~T}$ BTU/yr based on $\sim 35 \mathrm{M} \mathrm{T} / \mathrm{yr}$ of bar \& rod product produced globally 


\section{Magnetic Process B, 15T Superconducting (SC) magnet}

- Significant reduction in energy use for the Spheroidization processing of hypo- and hypereutectoid steels to achieve maximum softness for cold formability before final heat treatment

Current Process

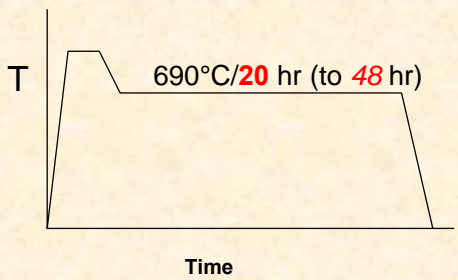

OAK RIDGE NATIONAL LABORATORY

Energy Efficient Magnetic Process B

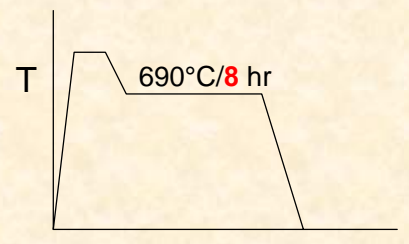

Time

\section{Magnetic Process B (cont.)}

- Insert 15 T SC magnet at Point B in the steel flowline to dramatically reduce the spheroidization process cycle time and energy consumption

- Based on existing magnetic processing research results, dramatically enhanced transformation/spheroidization kinetics are anticipated 


\section{Magnetic Process B Energy Savings}

- Process cycle time is anticipated to be reduced by $60 \%$

- Estimated tonnage impacted by process: 4M T/yr

- Anticipated energy savings per ton is estimated to be comparable to that per ton for process $A$, therefore,

- Energy savings estimate of 7T BTU/yr for magnetic process $B$

\section{Magnetic Process C, \\ $<$ l0T Superconducting (SC) magnet}

- Energy savings through propertyperformance enhancement

- Demonstrated on a 1035 steel by applying a 1 $T$ field during the quench resulting in a $21 \%$ improvement in flow stress after tempering

- Applicable to hypoeutectoid (lath martensite forming) steels

- E.g., SAE 1020, 1040, 4120, 4620, 5120, 5140, 8620,8820 , etc. grade steels 


\section{Magnetic Process C (cont.)}

- Estimated impact on 20M T/yr of steel

- Energy savings achieved through

- Superior material performance of existing steel grades

- Less material required for an application so less material has to be made or heat treated

- Fuel savings via lighter weight steel vehicles

- Use superconducting magnets

- No energy consumption to use these once the SC magnet is initially charged to the required field strength

- Very advantageous for continuous processes

\section{Major Energy Savings Ramification of Magnetic Process C}

- The Ultra Light Steel Auto Body (ULSAB) Program estimates a $36 \%$ weight savings if higher strength steels are used

- Current steels however exhibit too much property variability to make this goal a reality

- Magnetic processing potentially can yield more consistent, superior performance even in existing alloys

- Assuming only half of this weight savings is achieved via magnetic processing to develop more uniform, superior steel grades would save $1.02 \times 10^{12}$ gallons of gasoline per year

- This is a potential energy savings of 1.42 Quads per year. 



\section{Appendix B: Publications}

A.1 In-situ Evidence of Enhanced Phase Transformation Kinetics due to a High Magnetic Field in a Medium Carbon Steel
A.2 Effect of 30-T Magnetic Field on Transformations in a Novel Bainitic Steel
A.3 The Effect of High Magnetic Field Annealing on Enhanced Phase Stability in $85 \mathrm{Fe}-15 \mathrm{Ni}$ 


\title{
In situ evidence of enhanced transformation kinetics in a medium carbon steel due to a high magnetic field
}

\author{
G.M. Ludtka ${ }^{\text {a }}$, R.A. Jaramillo ${ }^{\text {a,* }}$, R.A. Kisner ${ }^{\text {b }}$, D.M. Nicholson ${ }^{\text {c }}$, J.B. Wilgen ${ }^{\text {b }}$, \\ G. Mackiewicz-Ludtka ${ }^{\text {a }}$, P.N. Kalu ${ }^{\text {d }}$ \\ ${ }^{a}$ Metals and Ceramics Division, Oak Ridge National Laboratory, P.B. 2008, Oak Ridge, TN 37831, USA \\ ${ }^{\mathrm{b}}$ Engineering Science and Technology, Oak Ridge National Laboratory, Oak Ridge, TN 37831, USA \\ ${ }^{c}$ Computer Science and Mathematics, Oak Ridge National Laboratory, Oak Ridge, TN 37831, USA \\ ${ }^{\mathrm{d}}$ FAMU-FSU, College of Engineering and National High Magnetic Field Laboratory, Tallahassee, FL 32310, USA
}

Received 28 January 2004; received in revised form 23 March 2004; accepted 24 March 2004

Available online 20 April 2004

\begin{abstract}
A medium carbon steel was cooled from $850{ }^{\circ} \mathrm{C}$ at various rates with and without a 30-T magnetic field. Due to the magnetic field, the onset of thermal recalescence associated with the release of latent heat showed $70-90{ }^{\circ} \mathrm{C}$ increase, indicating acceleration in austenite decomposition. The relative shift was cooling rate dependent. Microstructural examination revealed increased ferrite content and corroborated temperature measurements.
\end{abstract}

(C) 2004 Acta Materialia Inc. Published by Elsevier Ltd. All rights reserved.

Keywords: Steels; Phase transformation kinetics; Magnetic field; Austenite decomposition

\section{Introduction}

Several researchers [1-4] have shown that the application of a high magnetic field can modify the Gibbs free energy of the $\mathrm{Fe}-\mathrm{C}$ system such that the austenite/ferrite phase boundary becomes a function of the applied field. Because the magnetic susceptibilities of ferrite and austenite are substantially different, the magnetization of the material coupled with the applied field strength alters the free energy and, therefore, phase stabilities. Calculations for pure Fe by Choi et al. [1] suggest that the Ae3 temperature is increased over $50{ }^{\circ} \mathrm{C}$ by a $30-\mathrm{T}$ magnetic field and the Ael temperature for the $\mathrm{Fe}-\mathrm{C}$ binary increased by approximately $30{ }^{\circ} \mathrm{C}$. Experimental validation has been limited to steels transformed in magnetic fields of $10 \mathrm{~T}$ or less and quantitative metallography served to verify the effect. Choi et al. [1] cooled a $0.44 \% \mathrm{C}-0.23 \% \mathrm{Si}-1.24 \% \mathrm{Mn}$ steel at $5{ }^{\circ} \mathrm{C} / \mathrm{min}$ and reported a $10 \%$ increase in ferrite volume fraction due to a

\footnotetext{
3940.

${ }^{*}$ Corresponding author. Tel.: +1-865-576-3768; fax: +1-865-574-

E-mail address: jaramillora@ornl.gov (R.A. Jaramillo).
}

10-T magnetic field. Enomoto et al. [2] performed detailed quantitative metallography on a $0.39 \% \mathrm{C}$ steel that had been isothermally transformed at $750{ }^{\circ} \mathrm{C}$. Depending upon hold time, their analysis indicates a $5-10 \%$ increase in ferrite volume fraction for a 7.5-T magnetic field. While these studies validate the magnetic field effect, it is difficult to deduce the quantitative changes in transformation kinetics due to a magnetic field. In this work, steel cylinders were exposed to a 30-T magnetic field during cooling. Temperature measurements provided a quantitative measure of the shift in transformation kinetics due the magnetic field.

Thermocouple measurements were used to monitor the temperature behavior of a steel specimen undergoing phase transformation during continuous cooling with and without a magnetic field. Because release of latent heat associated with austenite decomposition is readily observed in temperature measurements [5], a phase transformation can be associated with specific times and temperatures during cooling. Therefore, for a given cooling rate, the shift in recalescence provides a relative measure of the effect of a high magnetic field on transformation kinetics. The enhancement of transformation kinetics associated with the magnetic field was 
reinforced by phase volume fractions observed in the resulting microstructure.

\section{Experimental procedure}

A $32 \mathrm{~mm}$ diameter bore resistive magnet with a $33 \mathrm{~T}$ maximum field strength at the National High Magnetic Field Laboratory (NHMFL) was used for experiments. A key component of the experimental work was the ability to heat and cool the specimen while inside the bore of the magnet. A custom designed induction heating coil coupled with a gas purge system for atmosphere control and specimen cooling was fabricated for experiments. Fig. 1 is a schematic of the experimental apparatus. The apparatus locates the specimen in the center of the bore mid length and can heat the steel specimen up to $1100{ }^{\circ} \mathrm{C}$ and maintain the high temperature for extended periods of time. Atmosphere is controlled via an argon gas purge. For accelerated cooling, a helium gas quench can be rapidly imposed upon the specimen. Such a system allows for the entire thermal cycle or any portion of it to be exposed to a high magnetic field.

Experiments were performed using a medium carbon 1045 steel with a nominal composition of 0.45 wt.\% carbon and 0.8 wt. $\%$ manganese. A $13 \mathrm{~mm}$ diameter rod was received in the annealed and furnace-cooled condition. Cylindrical specimens, $8-\mathrm{mm}$ diameter $\times 12-\mathrm{mm}$ long, were machined from the rod with the longitudinal axis aligned with the rod axis.

Temperature measurements were made via a type "S" ( $\mathrm{Pt}-10 \% \mathrm{Rh})$ thermocouple spot-welded on the radial surface at the mid-length of the specimen. All specimens were heated to $850{ }^{\circ} \mathrm{C}$ using a two-step schedule where a rate of approximately $11{ }^{\circ} \mathrm{C} / \mathrm{s}$ was applied to $700{ }^{\circ} \mathrm{C}$, followed by heating at $2.5^{\circ} \mathrm{C} / \mathrm{s}$ to the annealing temperature. A 5 min hold at $850{ }^{\circ} \mathrm{C}$ was performed to fully transform the initial microstructure to austenite. For cooling with a magnetic field, the ramping of the field

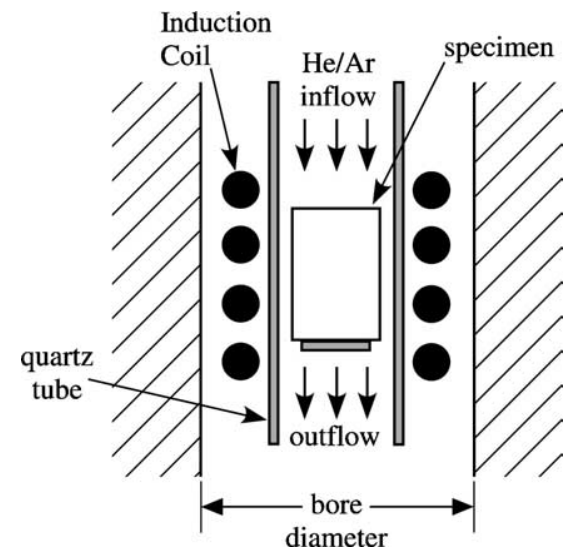

Fig. 1. Schematic of experimental apparatus used for heat treatment of specimen within the bore of the magnet.
Table 1

Helium quench pressure and the associated cooling rate

\begin{tabular}{lc}
\hline Helium gas pressure $(\mathrm{Pa})$ & Measured cooling rate $\left({ }^{\circ} \mathrm{C} / \mathrm{s}\right)$ \\
\hline 0 & 10 \\
35 & 55 \\
70 & 80 \\
140 & 130 \\
\hline
\end{tabular}

Cooling rate is an average of the rate between 850 and $700{ }^{\circ} \mathrm{C}$.

was initiated at the midpoint of the 5 min hold at 850 ${ }^{\circ} \mathrm{C}$. A time of $1.5 \mathrm{~min}$ was required for the field to reach $30 \mathrm{~T}$. Specimen cooling was controlled by modifying the pressure governing helium gas flow during quench. Table 1 provides a list of helium gas pressures used and the associated cooling rates. The reported cooling rates are an average of the rates measured between 850 and $700{ }^{\circ} \mathrm{C}$.

A slow cooling rate of $10{ }^{\circ} \mathrm{C} / \mathrm{s}$ was obtained by simply turning off the induction heater and allowing the specimen to cool "naturally" within the argon purged environment. Additional cooling rates of 55,80 and $130{ }^{\circ} \mathrm{C} / \mathrm{s}$ were generated by flowing helium at 35,70 and $140 \mathrm{~Pa}$, respectively.

\section{Results and discussion}

Temperature histories for the $10{ }^{\circ} \mathrm{C} / \mathrm{s}$ cooling rate with and without a 30-T magnetic field are shown in Fig. 2 . The figure plots temperature versus time for a specimen cooled with an applied magnetic field (solid line) and without a field (dashed line). The recalescence associated with austenite decomposition is observed in both plots. However, the presence of a 30-T magnetic field has clearly shifted the onset of recalescence from approximately $670{ }^{\circ} \mathrm{C}$ without the field to approximately $760{ }^{\circ} \mathrm{C}$ with it. Also, the plot for the $30-\mathrm{T}$ experiment shows a secondary recalescence event at approximately $700{ }^{\circ} \mathrm{C}$. The initial event at $760{ }^{\circ} \mathrm{C}$ is associated with the formation of proeutectoid ferrite and the second event at $700{ }^{\circ} \mathrm{C}$ is transformation of the remaining austenite.

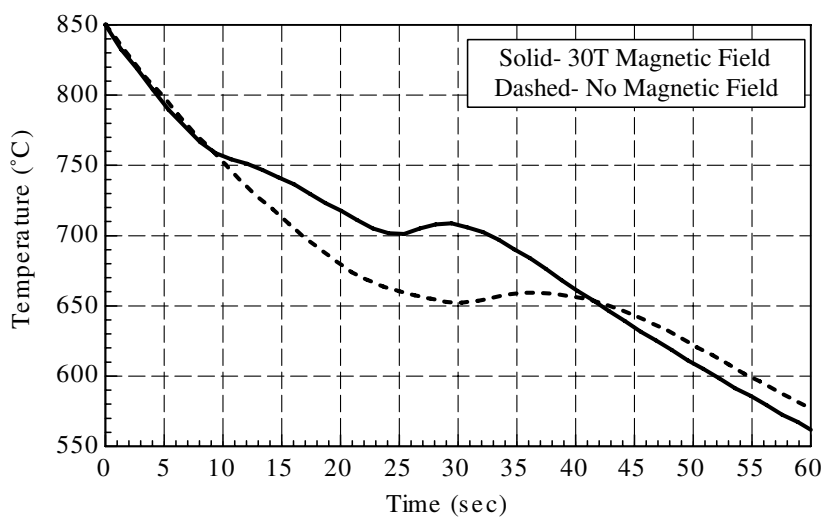

Fig. 2. Cooling curves for cooling at $10{ }^{\circ} \mathrm{C} / \mathrm{s}$. Specimen held at $850{ }^{\circ} \mathrm{C}$ for 5 min prior to cooling. 

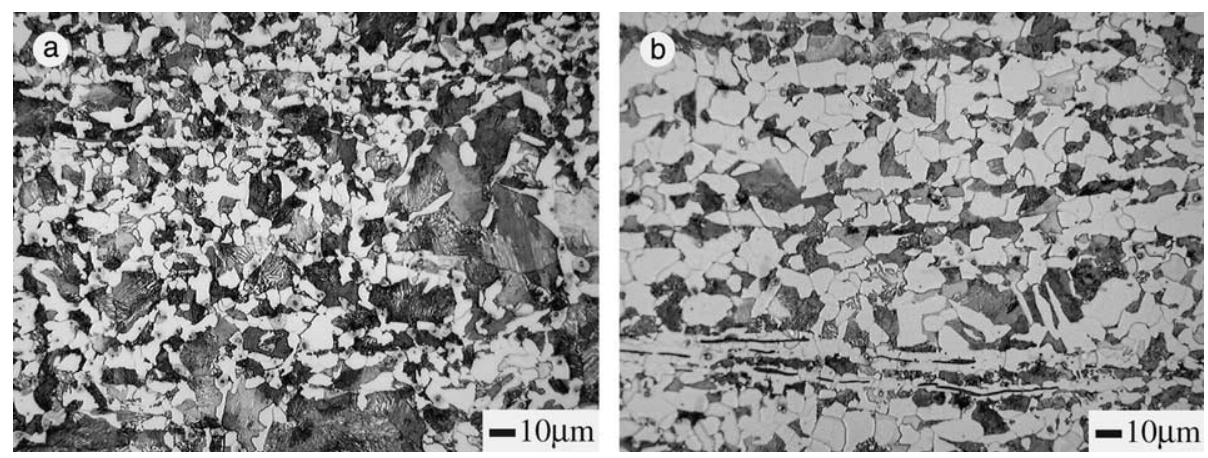

Fig. 3. Microstructure for 1045 steel specimens cooled at $10{ }^{\circ} \mathrm{C} / \mathrm{s}$. For (a) without magnetic field and (b) with $30-\mathrm{T}$ field (light micrograph, $2 \%$ nital).

The formation of proeutectoid ferrite is not apparent in the data without field. It is speculated that the volume of ferrite formed was not enough to create an observable recalescence event.

Fig. $3 \mathrm{a}$ and $\mathrm{b}$ shows microstructures corresponding to the $10{ }^{\circ} \mathrm{C} / \mathrm{s}$ cooling rates plotted in Fig. 2. The figures are light micrographs of the microstructure at the mid length of the longitudinal plane for each specimen. The light grains are ferrite and the dark regions are pearlite. Fig. 3a displays the microstructure obtained for cooling without a magnetic field. A substantial increase in ferrite volume fraction is observed in Fig. 3b, where the 30-T field was applied. An estimate of the phase composition indicates that the 30-T magnetic field increased the ferrite volume fraction from $40 \%$ to $65 \%$ ferrite. The application of the 30-T magnetic field has changed the majority constituent from pearlite to ferrite without significant coarsening of the microstructure. Because the chemistry and cooling rates are unchanged, it is evident that the free energy of the system has been altered by the application of a 30-T magnetic field.

Temperature data for experiments performed using a He gas quench are plotted in Fig. 4. The figure plots temperature versus time for three cooling rates with the 30-T field (solid lines) and without the field (dashed lines). The figure clearly shows a significant and consistent increase in the kinetics of austenite decomposition

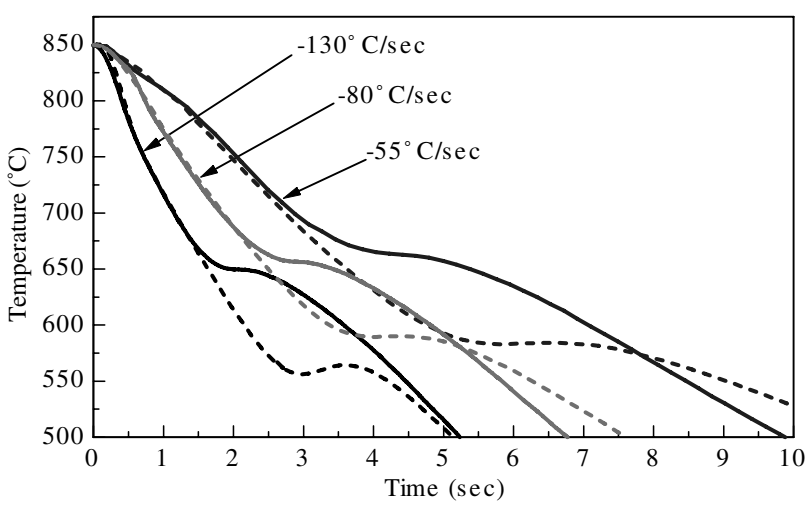

Fig. 4. Cooling curves for various cooling rates with (solid line) and without (dashed line) a 30-T magnetic field. Specimen held at $850{ }^{\circ} \mathrm{C}$ for 5 min prior to cooling.

due to the 30-T magnetic field. If the recalescence seen in the data is employed as a reference, an approximately $70-90{ }^{\circ} \mathrm{C}$ increase in transformation temperature due to the magnetic field is suggested. This increase in transformation temperature decreases the time between transformation start and finish. These results reinforce those shown in Fig. 2 and indicate that the thermodynamic effect is evident over a range of cooling rates.

Microstructures for material cooled at the fastest rate $\left(130{ }^{\circ} \mathrm{C} / \mathrm{s}\right)$ without and with a magnetic field are shown
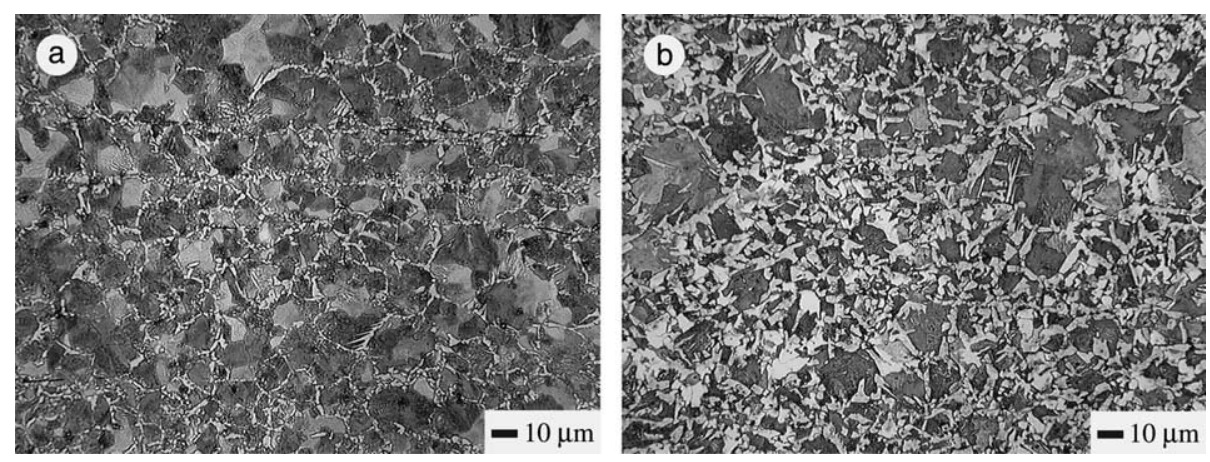

Fig. 5. Microstructures for specimens cooled at $-130{ }^{\circ} \mathrm{C} / \mathrm{s}$ (a) without and (b) with a $30-\mathrm{T}$ field (light micrograph, $2 \%$ nital). 
in Fig. 5a and b, respectively. The effect of the high magnetic field on the resulting ferrite content is readily observed, even at the highest cooling rate. The non-field case in Fig. 5a shows ferrite predominately located along prior austenite grain boundaries with the remaining microstructure composed of pearlite and bainite. Again, a significant increase in ferrite volume fraction is observed for the material cooled with a $30-\mathrm{T}$ magnetic field. Estimates of ferrite volume fraction indicate an increase from $20 \%$ to $50 \%$ ferrite due to a 30 $\mathrm{T}$ magnetic field.

\section{Conclusions}

Continuous cooling experiments were performed with a 1045 steel to investigate the effect of a 30-T magnetic field on the kinetics of austenite decomposition. Specimens were cooled at four different rates with and without the magnetic field. Temperature measurements identify the occurrence of phase transformations because of the release of latent heat and the associated interruption in specimen cooling. By comparing the recalescence for cooling with and without a magnetic field, the shift in the onset of austenite decomposition due to the field is determined.

The results of the experimental work clearly reinforce the postulate that a high magnetic field will alter the thermodynamics and, therefore, the transformation kinetics and microstructure of plain carbon steel during austenite decomposition. Temperature measurements indicate a $70-90{ }^{\circ} \mathrm{C}$ increase in transformation temperature and quantitative metallography suggests a $25-30 \%$ increase in ferrite volume fraction due to a $30-\mathrm{T}$ magnetic field.

\section{Acknowledgements}

The authors would like to acknowledge Mr. Roger D. England of Cummins Inc. for providing material and specimen preparation as well as his valuable input. Dr. Sudarsanam Suresh Babu and Dr. Paul C. Becker of Oak Ridge National Laboratory are thanked for their reviews of this manuscript. Also, Dr. Bruce Brandt, Ms. Merry Ann Johnson and the staff at the National High Magnetic Field Laboratory are acknowledged for their efforts and support. This research was sponsored by the US Department of Energy, under contract DE-AC0500OR22725 with UT-Battelle, LLC.

\section{References}

[1] Choi J-K, Ohtsuka H, Xu Y, Choo W-Y. Scripta Mater 2000;43:221.

[2] Enomoto M, Guo H, Tazuke Y, Abe YR, Shimotomai M. Metall Mater Trans A 2001;32:445.

[3] Liu W, Ou DR, Zhou HH, Tang GY, Wu F. J Mater Res 2001;16:2280.

[4] Joo HD, Kim SU, Shin NS, Koo YM. Mater Lett 2000;43:225.

[5] Lee KJ. Scripta Mater 1999;40:735. 


\title{
Effect of $30 \mathrm{~T}$ magnetic field on transformations in a novel bainitic steel
}

\author{
R.A. Jaramillo ${ }^{\text {a,* }}$, S.S. Babu ${ }^{\text {a }}$, G.M. Ludtka ${ }^{\text {a }}$, R.A. Kisner ${ }^{\text {a }}$, J.B. Wilgen ${ }^{\text {a }}$, \\ G. Mackiewicz-Ludtka ${ }^{\text {a }}$, D.M. Nicholson ${ }^{\text {a }}$, S.M. Kelly ${ }^{\text {b,c }}$, M. Murugananth ${ }^{\mathrm{d}}$, \\ H.K.D.H. Bhadeshia ${ }^{\text {e }}$ \\ ${ }^{a}$ Metals and Ceramics Division, Oak Ridge National Laboratory, P.O. Box 2008 MS6064, Oak Ridge, TN 37831, USA \\ b Joint Institute for Computational Sciences, Oak Ridge National Laboratory, Oak Ridge, TN 37831, USA \\ ${ }^{\mathrm{c}}$ Department of Materials Science and Engineering, Virginia Tech, 213 Holden Hall, Blacksburg, VA 24061-0237, USA \\ ${ }^{\mathrm{d}}$ School of Materials Engineering, Nanyang Technological University, Singapore 639798 \\ e Materials Science and Metallurgy, University of Cambridge, Cambridge, CB2 3QZ, UK
}

Received 23 September 2004; accepted 10 November 2004

\begin{abstract}
The continuous cooling transformation characteristics of novel bainitic steels have been studied, both under ordinary conditions and whilst subjected to a $30 \mathrm{~T}$ magnetic field. The magnetic field has been found to completely change the microstructure obtained, from a mixture of bainite and martensite to one containing an incredibly fine pearlite with an interlamellar spacing of about $50 \mathrm{~nm}$. As a consequence, the pearlite is found to be much harder than any other examples found in the published literature.

(C) 2004 Acta Materialia Inc. Published by Elsevier Ltd. All rights reserved.
\end{abstract}

Keywords: Steel; Transformtions; Magnetic field; Pearlite; Martensite; Bainite; Continuous cooling

\section{Introduction}

Novel bainitic steels have recently been developed with strengths in excess of $2 \mathrm{GPa}$ [1-4]. The distinguishing characteristic of these steels is that they transform at such low temperatures that the bainite plates can be as thin as $20-40 \mathrm{~nm}$; this, combined with the presence of carbon-enriched austenite between the bainite, ensures the impressive combination of strength and toughness [1-4]. This microstructure is generated during isother-

\footnotetext{
3940 .

* Corresponding author. Tel.: +1 865576 3768; fax: +1 865574

E-mail address: jaramillora@ornl.gov (R.A. Jaramillo).
}

mal transformation at $200{ }^{\circ} \mathrm{C}$ for more than $400 \mathrm{~h}$, depending on the alloy composition [1,4]. The rate of transformation can be accelerated without compromising the scale of the microstructure or the mechanical properties. This is done by increasing the magnitude of the free energy change accompanying the decomposition of austenite, with the addition of cobalt and/or aluminum [5]; in this case, the time required is reduced to some $100 \mathrm{~h}$.

A further way of influencing the driving force for the transformation of austenite is to impose a magnetic field; this is because the ferrite is ferromagnetic below about $760{ }^{\circ} \mathrm{C}$ whereas the austenite in low-alloy steels is paramagnetic [6,7]. The subject has been reviewed by Shimizu [8]. Given these differences, it is expected that transformation under the influence of a magnetic 
field will increase the change in free energy as austenite transforms to ferrite. Thus, a $30 \mathrm{~T}$ magnetic field can raise transformation temperatures by $\sim 90{ }^{\circ} \mathrm{C}$ during continuous cooling [9]. It was therefore the purpose of the present study to attempt to accelerate the lowtemperature bainite reaction using strong magnetic fields. Two steels have been studied, one which transforms more rapidly than the other because it has been alloyed with cobalt and aluminum.

\section{Experimental procedure}

The alloy compositions are shown in Table 1. The silicon is at a concentration which inhibits cementite precipitation from austenite, and the other alloying elements are added to control hardenability, the austenite
Table 1

Alloy compositions in $\mathrm{wt}^{\mathrm{t}} \%$

\begin{tabular}{llllllllll}
\hline Alloy & $\mathrm{C}$ & $\mathrm{Si}$ & $\mathrm{Mn}$ & $\mathrm{Mo}$ & $\mathrm{Cr}$ & $\mathrm{Co}$ & $\mathrm{Al}$ & $\mathrm{V}$ & $\mathrm{Fe}$ \\
\hline SK & 0.75 & 1.63 & 1.95 & 0.28 & 1.48 & - & 0.01 & 0.10 & Balance \\
FK & 0.78 & 1.60 & 2.02 & 0.24 & 1.01 & 3.87 & 1.37 & - & Balance \\
\hline
\end{tabular}

grain size and temper embrittlement, as described elsewhere [1-5]. As stated earlier, the sole purpose of the cobalt and aluminum is to accelerate transformation. The terms "FK" and "SK" therefore refer to fast and slow kinetics, respectively. The steels were homogenized for $48 \mathrm{~h}$ at $1200^{\circ} \mathrm{C}$ before the experiments. They were then subjected to austenitization at $1000{ }^{\circ} \mathrm{C}$ and continuous cooling magnetic field processing. Test specimens were rectangular with dimensions of $12 \times 5 \times 2 \mathrm{~mm}$.
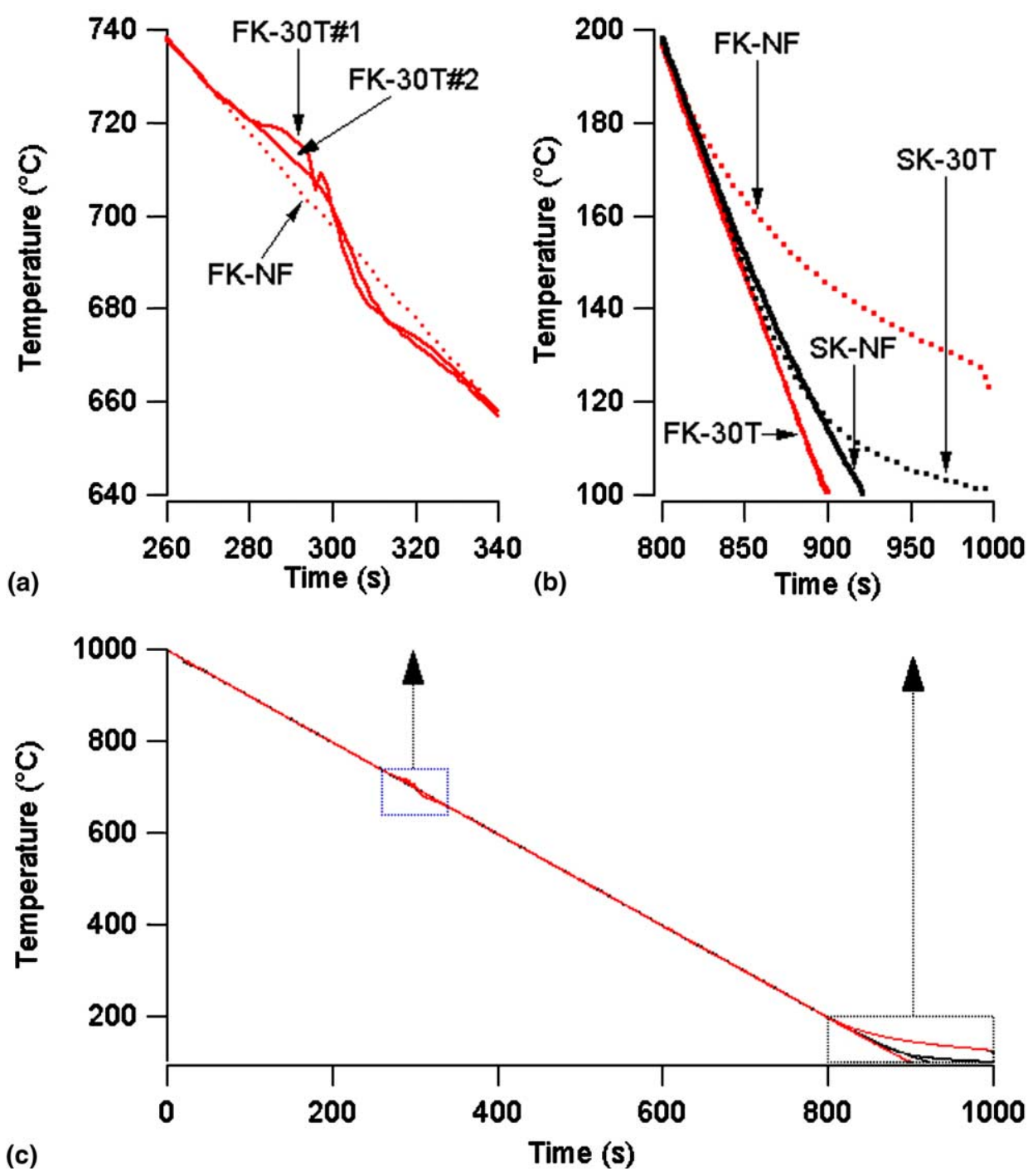

Fig. 1. Measured time-temperature plots. (a) FK-30 T, two runs; (b) FK-NF, SK-NF, SK-30 T; (c) as for (a), but placing the recalescence events in context. 
A $32 \mathrm{~mm}$ bore diameter resistive-magnet with a $33 \mathrm{~T}$ maximum field strength at the National High Magnetic Field Laboratory was used for the experiments. A key component of the experimental work was the ability to heat and cool the specimen while inside the bore of the magnet. A custom designed induction-heating coil coupled with a gas purge system for atmosphere control and specimen cooling was fabricated for this purpose. The system locates the specimen in the center of the bore mid-length and can heat it up to $1100^{\circ} \mathrm{C}$ and maintain the temperature for extended periods of time. The atmosphere is maintained by purging with argon. Rapid cooling is achieved using a helium gas quench. The magnetic field can be imposed at any stage of the heat treatment. Temperature measurements were made using a type " $\mathrm{S}$ " $(\mathrm{Pt}-10 \% \mathrm{Rh})$ thermocouple spot-welded on the surface at the mid-length of the specimen.

In all cases, the samples were heated at $11^{\circ} \mathrm{C} / \mathrm{s}$ to $700{ }^{\circ} \mathrm{C}$, followed by heating at $5^{\circ} \mathrm{C} / \mathrm{s}$ to $1000{ }^{\circ} \mathrm{C}$ and held for $3 \mathrm{~min}$ in order to complete austenitization. The magnetic field was ramped up one minute after reaching $1000{ }^{\circ} \mathrm{C}$ and it took $90 \mathrm{~s}$ to reach $30 \mathrm{~T}$. Specimen cooling was controlled via feedback loop such that by decreasing power to the induction coil, a $1{ }^{\circ} \mathrm{C} / \mathrm{s}$ cooling rate was obtained. The sample temperatures were monitored continuously.

Throughout this paper, the designations SK-NF and SK-30 T refer to experiments conducted without and with a field (30 T), respectively, and the same adjuncts are used for the FK steel.

The microstructures were characterized using optical microscopy applying standard preparation and etching techniques. Vickers hardness distributions were measured with a Buehler Micromet 2001 tester equipped with Omnimet Advantage software, intervals of $200 \mu \mathrm{m}$ with 300-g loads. Samples for transmission electron microscopy were prepared using standard electropolishing techniques and examined using a Philips Tecnai-20 operated at an accelerating voltage of $200 \mathrm{kV}$.

\section{Results and discussions}

The measured cooling curves from $1000{ }^{\circ} \mathrm{C}$ are presented in Fig. 1. The FK-30 T sample reproducibly shows a deviation from the programmed constant cooling rate at approximately $700{ }^{\circ} \mathrm{C}$ (Fig. 1(a)). Previous work $[9,10]$ has shown that this is caused by recalescence, i.e. heating caused by the release of the latent heat of transformation. This unexpected behavior does not occur when the specimen is cooled without the influence of a magnetic field; instead, recalescence is observed at a much lower temperature (about $180^{\circ} \mathrm{C}$ ) due to martensitic transformation (Fig. 1(b)). By contrast, the SK-30 T sample recalesced at $\approx 130{ }^{\circ} \mathrm{C}$, with no such event in the SK-NF condition because the martensite-start
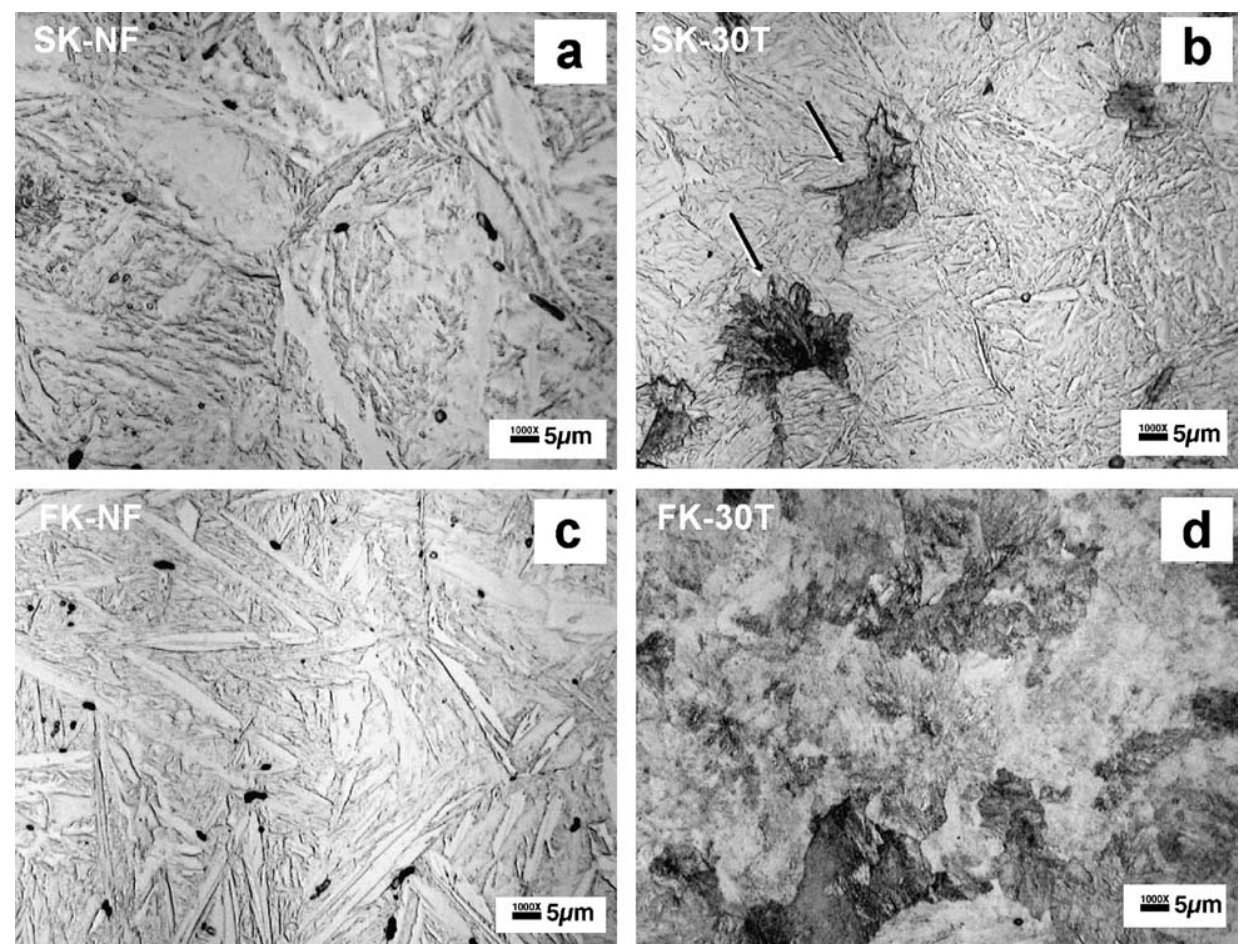

Fig. 2. Optical micrographs (a) SK-NF; (b) SK-30 T; (c) FK-NF; and (d) FK-30 T, the sample used for transmission electron microscopy. 
temperature in this case falls below the temperature where data were collected.

To summarize, the effect of the field is to raise the martensite-start temperature for both alloys. In the case of the faster transformation FK steel, a further transformation at about $700{ }^{\circ} \mathrm{C}$ is promoted by the magnetic field.

The optical micrographs in Fig. 2 confirm this. The microstructures are a mixture of bainite and martensite when the transformation is in the absence of a field, and there are indications of pearlite when a field is imposed. The formation of pearlite would explain the recalescence event at $\sim 700{ }^{\circ} \mathrm{C}$ for FK-30 T.

The clear presence of pearlite was confirmed using transmission electron microscopy on sample FK-30 T (Fig. 3). The interlamellar spacing is incredibly fine, approximately $50 \mathrm{~nm}$. Electron diffraction confirmed that the lamella consist of cementite and ferrite. The cooling data indicate that the pearlite formed over a narrow temperature range of $725-700{ }^{\circ} \mathrm{C}$ so it is not surprising that the microstructure is rather uniform. The perturbations between 700 and $660{ }^{\circ} \mathrm{C}$ are associated with the system re-establishing temperature control.

It is interesting that the lamellar spacing obtained compares with patented wire $(40-150 \mathrm{~nm})$ [11]. The cementite lamellae exhibit frequent interruptions (Fig. $3(b)$ ), perhaps due to changes at the pearlite-colony interface with austenite and because the transformation occurs during continuous cooling. It would be useful in future work to characterize the partitioning of alloying elements between the cementite and ferrite components of the fine pearlite.

All of the samples were evaluated by plotting hardness distributions (Fig. 4). There are clear differences between FK-NF and FK-30 T, the former with an average hardness of $875 \pm 51 \mathrm{HV}$ and the latter showing $484 \pm 13 \mathrm{HV}$. This is expected since the pearlite will be softer than the microstructure containing martensite.

The average hardness of the SK-30 T sample $(859 \pm 51 \mathrm{HV})$ was slightly higher than the SK-NF sample $(801 \pm 54 \mathrm{HV})$, as shown in Fig. 4(a) and (b). The quantitative distributions are in Fig. 4(e) and (f). The huge difference between FK-NF and FK-30 T is clearly because of the fully pearlitic state of FK-30 T. The hardness data are therefore consistent with the microstructural data in Figs. 2 and 3.

Vertical sections of $\mathrm{Fe}-\mathrm{C}$ phase diagrams calculated using the ThermoCalc software [12] and ThermoTech Fe database [13] are shown in Fig. 5; Fig. 5(b) is estimated by decreasing the free energy of ferrite in order to simulate the effect of the magnetic field in stabilizing ferrite and the effect on cementite is neglected. Given the Bohr magneton $\left(\mu=9.3 \times 10^{-24} \mathrm{~J} / \mathrm{T}\right)$, after converting to $\mathrm{J} / \mathrm{mol}$ using Avogadro's number and multiplying by the
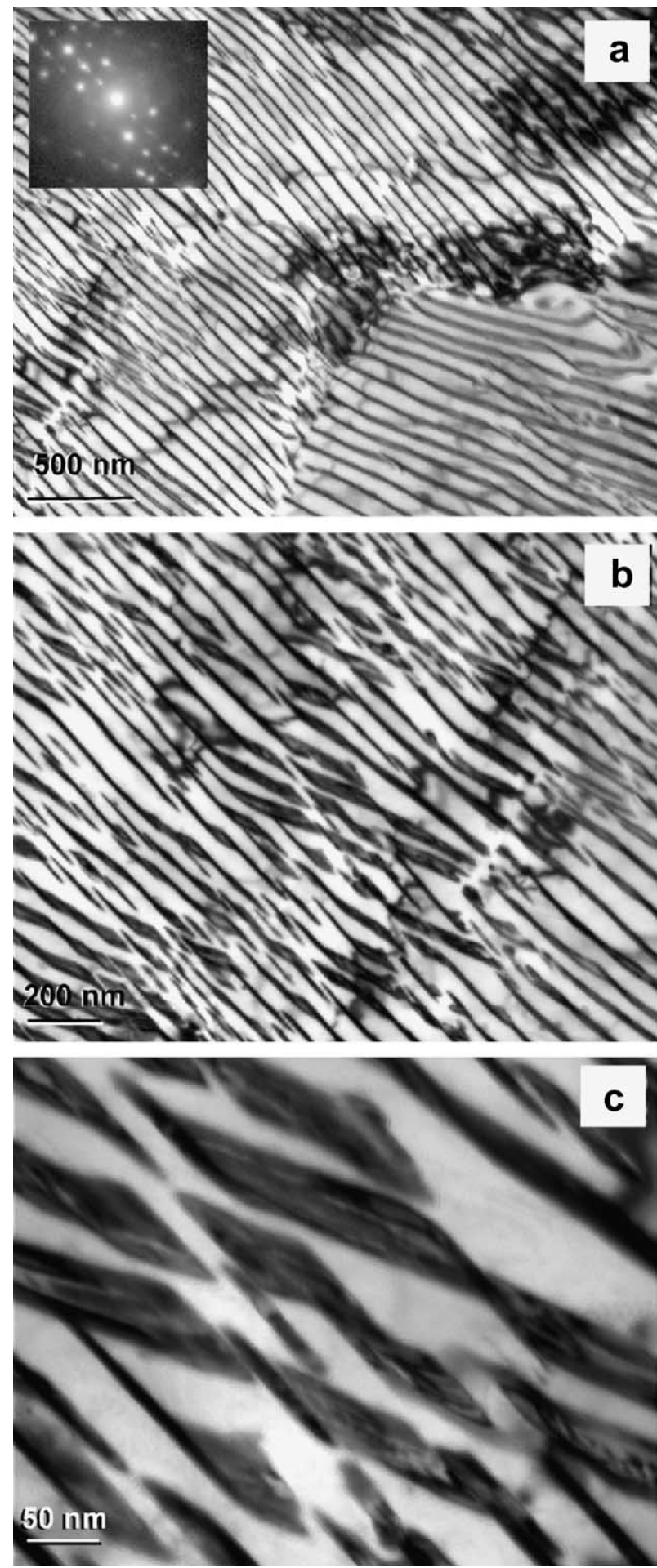

Fig. 3. Transmission electron microscopy images of samples subjected to $30 \mathrm{~T}$ magnetic field: (a) Low-magnification picture showing pearlite colonies with inset diffraction pattern obtained from the same area. High magnification micrographs show (b) the cementite lamellae and (c) fine substructure and morphology of carbides.

magnetic moment per atom of iron in ferrite (2.2) yields a value of $12 \mathrm{~J} / \mathrm{mol} / \mathrm{T}$. Multiplying this factor by $30 \mathrm{~T}$ approximates the free energy change as $360 \mathrm{~J} / \mathrm{mol}$. 


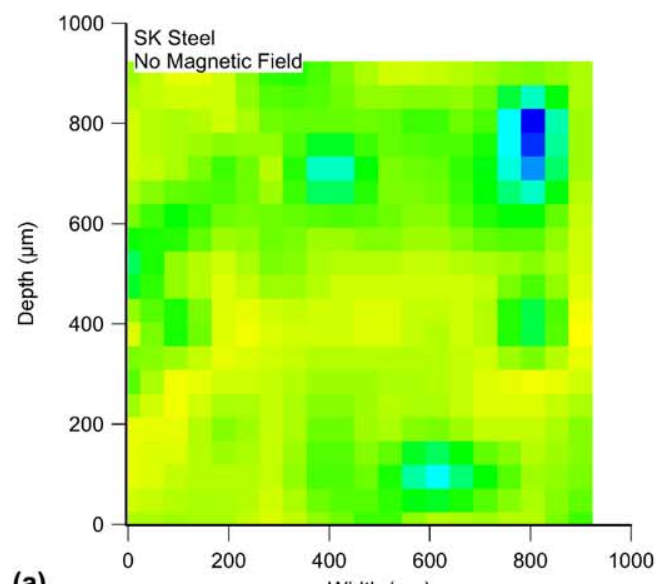

(a)
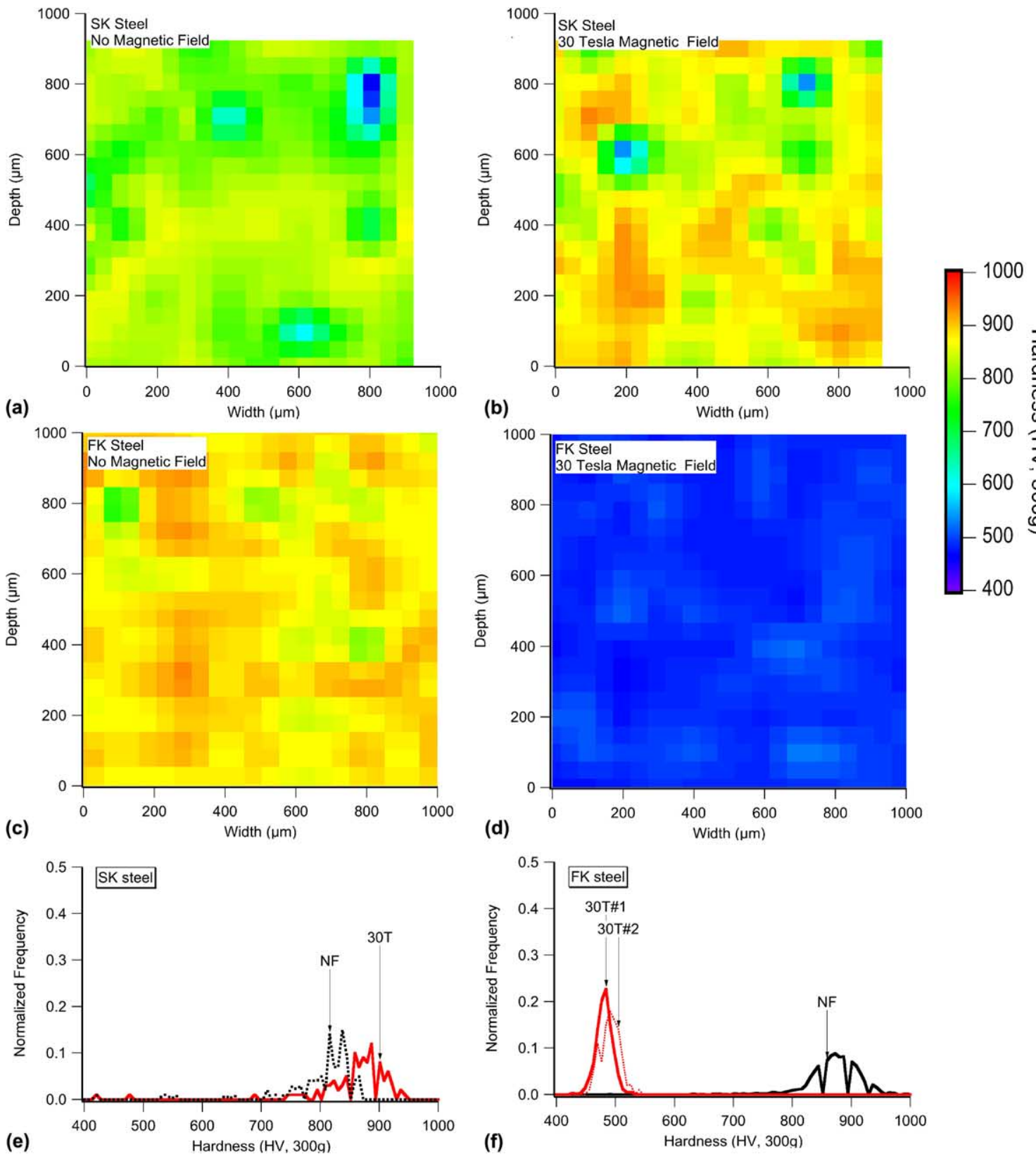

Fig. 4. Interpolated image representations of spatial hardness measurement from all samples are shown. (a) SK sample - continuously cooled at $1{ }^{\circ} \mathrm{C} / \mathrm{s}$ without magnetic field; (b) SK sample - continuously cooled at $1{ }^{\circ} \mathrm{C} / \mathrm{s}$ with $30 \mathrm{~T}$ magnetic field; (c) FK sample continuously cooled at $1{ }^{\circ} \mathrm{C} / \mathrm{s}$ without magnetic field; and (d) FK sample - continuously cooled at $1{ }^{\circ} \mathrm{C} / \mathrm{s}$ with $30 \mathrm{~T}$ magnetic field. Hardness frequency distributions from (e) SK and (f) FK steels are also presented.

Therefore, the ferrite free energy was reduced by $360 \mathrm{~J} /$ $\mathrm{mol}$ in the calculations. It is obvious from these results that the kinetics of the pearlite reaction will be accelerated by the application of a magnetic field.

\section{Summary}

Two novel, high-strength steels designed for a bainitic microstructure have been studied. Continuous cooling transformation experiments both with and without the influence of a magnetic field have been conducted. From recalescence and microstructural observations, it is clear that the effect of the magnetic field is to accelerate the transformation of austenite. The acceleration manifests in two ways, first in promoting the formation of pearlite and secondly in raising the temperature at which martensite forms.

The pearlite that forms has an incredibly fine spacing even though the transformation temperature is quite 

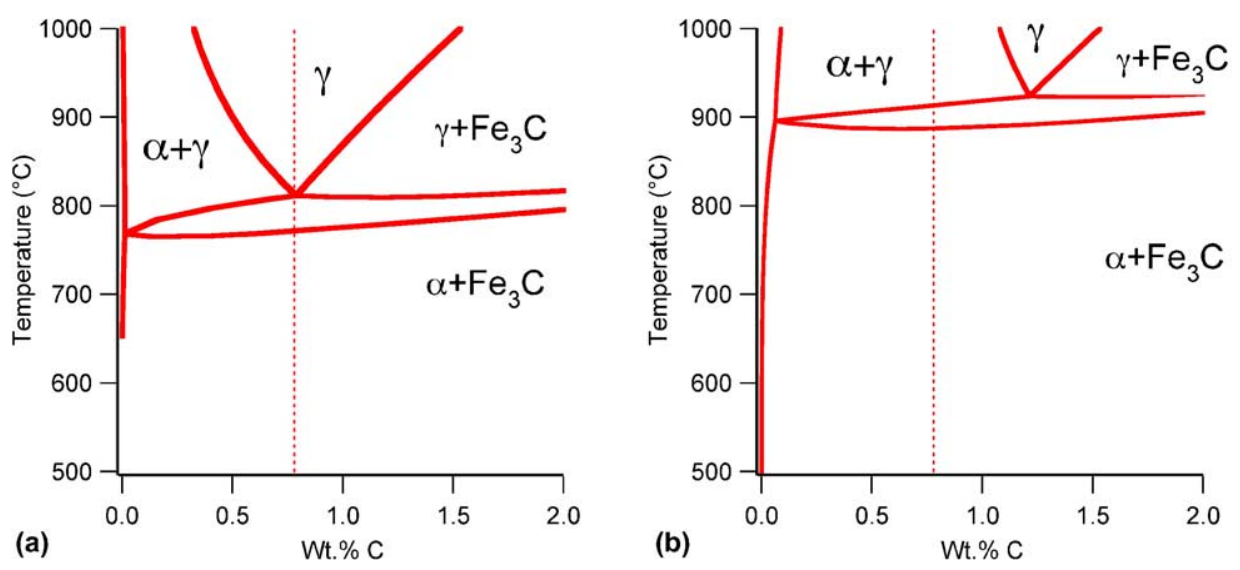

Fig. 5. Calculated quasi-binary Fe-C diagram for FK steel: (a) without modifying the ferrite Gibbs molar free energy, and (b) by reducing the ferrite Gibbs molar free energy by $360 \mathrm{~J}$.

high. In fact, the spacing compares with the best of patented pearlitic wire where transformation temperatures as low as $450{ }^{\circ} \mathrm{C}$ are used. It is suggested that with appropriate alloy design, "magnetic patenting" might become a commercial proposition.

\section{Acknowledgements}

Research sponsored by the Division of Materials Sciences and the Laboratory Directed Research and Development Program of Oak Ridge National Laboratory, managed by UT-Battelle, LLC, for the US Department of Energy under contract no. DE-AC05-00OR22725. Dr. Bruce Brandt and the staff at the National High Magnetic Field Laboratory are acknowledged for their support. The authors also thank Mr. M.A. Pershing and Dr. E.D. Specht of Oak Ridge National Laboratory for helpful discussions on this paper. The authors also thank Mr. M. Peet from University of Cambridge for providing the high-strength bainitic steel samples used in this investigation.

\section{References}

[1] Caballero FG, Bhadeshia HKDH, Mawella KJA, Jones DG, Brown P. Mater Sci Technol 2002;18:279-84.

[2] Garcia-Mateo C, Caballero FG, Bhadeshia HKDH. ISIJ Int 2003;43:1238-43.

[3] Garcia-Mateo C, Caballero FG, Bhadeshia HKDH. J Phys IV 2003;112(part 1):285-8.

[4] Peet M, Babu SS, Miller MK, Bhadeshia HKDH. Scripta Mater 2004;50:1277-81.

[5] Garcia-Mateo C, Caballero FG, Bhadeshia HKDH. ISIJ Int 2003;43:1821-5.

[6] Zener C. Trans Am Inst Min Metall Eng 1955;203:619-30.

[7] Kaufman L, Clougherty EV, Weiss RJ. Acta Metall 1963;11:323-35.

[8] Shimizu K. Mater Trans 2002;45:2050-7.

[9] Ludtka GM, Jaramillo RA, Kisner RA, Nicholson DM, Wilgen JB, Mackiewicz-Ludtka G, et al. Scripta Mater 2004;51:171-4.

[10] Lee KJ. Scripta Mater 1999;40:735-42.

[11] Porter DA, Easterling KE, Smith GDW. Acta Metall 1978;26:1403-22.

[12] Andersson JO, Helander T, Hoglund L, Sundman B. CALPHAD 2002;26:273-312.

[13] Thermotech Fe-Data Thermodynamic Database, Thermotech Ltd./Sente Software Ltd., Surrey Technology Centre, 40 Occam Road, GU2 7YG, United Kingdom. 


\title{
The effect of high magnetic field on phase stability in Fe-Ni
}

\author{
D. M. C. Nicholson, ${ }^{\text {a) }}$ R. A. Kisner, G. M. Ludtka, C. J. Sparks, L. Petit, \\ Roger Jaramillo, G. Mackiewicz-Ludtka, and J. B. Wilgen \\ Oak Ridge National Laboratory, Department of Computer Science and Mathematics, \\ MS6164 Building 5700, One Bethel Valley Road, Oak Ridge, Tennessee 37831
}

Askar Sheikh-Ali and P. N. Kalu

FAMU-FSU, National High Magnetic Field Laboratory, Tallahassee, FL 32310

(Presented on 6 January 2004)

\begin{abstract}
Identically prepared samples of $\mathrm{Fe}_{0.85} \mathrm{Ni}_{0.15}$ were annealed either in the ambient magnetic field or in a field of 29 T. Room temperature x-ray powder diffraction measurements that were performed after magnetic annealing showed that the ratio of the volume of the $\gamma$ to $\alpha$ phase is decreased in the field-annealed sample by a factor of 2. First-principles calculations of the magnetic structure in the presence of a magnetic field are used to compute the resulting change in free energy. Analysis in terms of the phase diagram calculated with and without a magnetic field is in substantial agreement with the measurements. (C) 2004 American Institute of Physics. [DOI: 10.1063/1.1689761]
\end{abstract}

In this article, we emphasize that applied magnetic field should be added to the list of thermodynamic variables, and we give an example where the application of a magnetic field leads to a new temperature composition path. Previous work on the application of high fields to $\mathrm{Ni}-\mathrm{Fe}$ is reviewed by Shimizu and Kakeshita. ${ }^{1}$ In addition, small fields have been used to anneal soft magnetic materials to produce subtle modifications in the local atomic environment that can increase the permeability. ${ }^{2}$ A simple perturbative estimate of the energy change due to the interaction of the atomic moments with the field, $\mathbf{m} \cdot \mathbf{B}$, indicates that a $1 \mathrm{~T}$ field changes the free energy per atom in Fe by about the same amount as changing the temperature by $1 \mathrm{~K}$. By the same token, when applying the highest available fields, $30-40 \mathrm{~T}$ is expected to have impacts similar to temperature changes of 30-40 K.

There are several ways that magnetic fields can influence microstructure. Most directly, it can change the relative stability of phases at zero temperature. Consider a two-phase mixture with different saturation magnetizations. The magnetic induction $\mathbf{B}$ will favor the high magnetization phase by an amount $\left(\mathbf{m}_{\text {high }}-\mathbf{m}_{\text {low }}\right) \cdot \mathbf{B}$, where $\mathbf{m}$ is the atomic moment. At finite temperatures there can be additional mechanisms; thermally occupied extended excitations, such as spin waves and phonons, and localized excitations, such as vacancy facilitated diffusion, will be affected.

Fe alloys are a natural place to look for field-induced modifications of phase equilibrium, because $\mathrm{Fe}$ atoms have large local moments that have strong exchange interactions with their neighbors. Local Fe moments survive to high temperatures and to large percentages of alloy additions. ${ }^{3,4}$ Furthermore, the directional ordering of Fe moments can vary from ferromagnetic to antiferromagnetic depending on the atomic volume. ${ }^{5}$ We chose to look at $\mathrm{Fe}-\mathrm{Ni}$ alloys at compositions in the two-phase region between the bcc and fcc solid solutions ( $\alpha$ and $\gamma$ phases). The temperature was chosen to be $500{ }^{\circ} \mathrm{C}$, a temperature at which diffusion is expected to be

a) Author to whom correspondence should be addressed; electronic mail: nicholsondm@ornl.gov high enough to allow equilibrium to be approached within a few hours. The selected composition was $\mathrm{Fe}_{85} \mathrm{Ni}_{15}$, which lies on the $T_{0}$ line along which the free energies of the $\alpha$ and $\gamma$ phases are equal. ${ }^{6}$ This is also near the Martensite start temperature. ${ }^{7}$ Placing the alloy at this balance point maximizes the local driving force toward phase separation (see Fig. 1). The sample should phase separately even without diffusion into bcc and fcc solid solutions. Phase fractions will proceed toward the value prescribed by the lever rule as shown in Fig. 1. We anticipated that the application of a large magnetic field would tip the balance in favor of the ferromagnetic bcc phase.

An alloy of atomic composition $\mathrm{Fe}_{0.85} \mathrm{Ni}_{0.15}$, prepared from $\mathrm{Ni}$ and Fe stock of $0.999 \%$ purity, was arc melted in a vacuum five times, and then dropcast into a $10 \mathrm{~mm}$ diameter chilled $\mathrm{Cu}$ mold in vacuum. The alloy was homogenized in a vacuum for $100 \mathrm{~h}$ at $1100^{\circ} \mathrm{C}$. A small amount of powder was made by diamond wheel grinding and then encapsulated in $10 \mathrm{~mm}$ diameter stainless steel tubes that were crimped and sealed by electron discharge machining. All powder capsules were annealed together at $700{ }^{\circ} \mathrm{C}$ for $2 \mathrm{~h}$ to obtain the equilibrium $\gamma$ phase, and were quenched in ice salt brine. A powder sample was subjected to a $29 \mathrm{~T}$ field for $245 \mathrm{~min}$ at

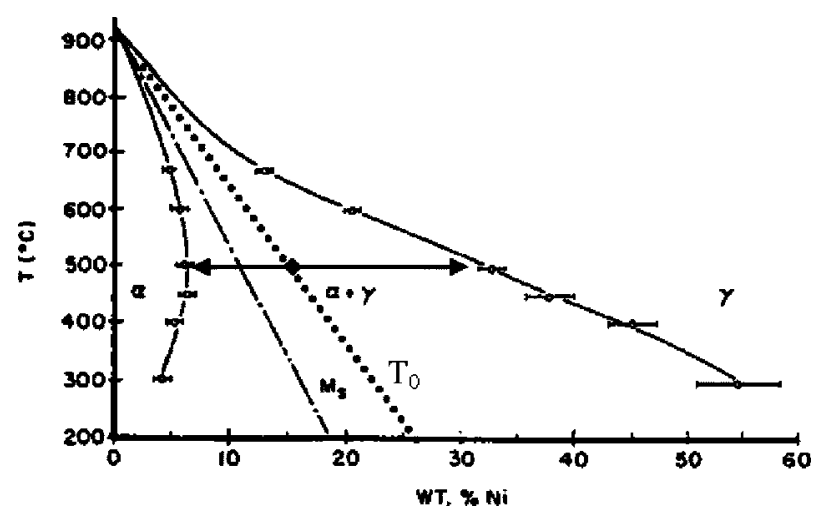

FIG. 1. Fe-rich section of phase diagram showing martensite start temperature, equal free energy line, and decomposition path at $500{ }^{\circ} \mathrm{C}$ (Ref. 8). 
TABLE I. Peak intensities divided by peak multiplicity for the $\alpha$ peaks for anneal with $(B=29 \mathrm{~T})$ and without field $(B=0 \mathrm{~T})$.

\begin{tabular}{lccc}
\hline \hline$h k l$ & 110 & 200 & 211 \\
\hline$P / m(B=0)$ & 1.000 & 0.468 & 0.256 \\
$P / m(B=29)$ & 1.000 & 0.419 & 0.268 \\
$F^{2}$ & 313 & 267 & 178 \\
$\sin (\theta) / \lambda$ & 0.25 & 0.35 & 0.43 \\
\hline \hline
\end{tabular}

$502{ }^{\circ} \mathrm{C}$. As a control, one of the identically prepared samples was annealed for $245 \mathrm{~min}$ at $502^{\circ} \mathrm{C}$ in the ambient field. The samples were rapidly heated from room temperature to $502{ }^{\circ} \mathrm{C}$. They were air cooled at a rate of $100{ }^{\circ} \mathrm{C} / \mathrm{min}$. The field-annealed sample remained in the field until it had cooled $85^{\circ} \mathrm{C}$, at which time the field was turned off.

The volume fractions of the $\alpha$ and $\gamma$ phases were determined using $\mathrm{Cu} K \alpha$ radiation from a Philips defractometer. Several diamond peaks resulting from diamond wheel grinding were seen. The diamond peaks are sufficiently separated from the Fe-Ni peaks that they do not interfere with measurements of the integrated intensities.

In the kinematic approximation to diffraction, and with the use of a compensating slit, the integrated intensity associated with a particular reflection $h k l$ is related to the volume fraction $V_{i}$ of phase $i$ and the scattering angle $2 \theta$ by $^{9}$

$$
P_{h k l, i}=\frac{I_{0}}{16 \pi R} \frac{e^{4} V_{i} m_{h k l} F_{i}^{2}}{m^{2} c^{4} \Omega_{i}^{2}}\left(\frac{1+\cos ^{2}(2 \theta)}{2 \sin ^{2}(\theta)}\right) E\left(\frac{\sin (\theta)}{\lambda}\right) .
$$

Here, $E$ represents absorption effects not present in an infinitely thick powder in the kinematic limit, $I_{0}$ is the beam intensity, $m_{h k l}$ is the reflection multiplicity, $R$ is the distance to the detector, $\lambda$ is the wavelength $(1.54 \AA), \Omega_{i}$ is the atomic volume, and $F_{i}$ is the average atomic scattering factor for the phase $i$. The scattering factor, $F_{i}$ is equal to

$$
\left|c_{i} F_{\mathrm{Fe}}\left(\frac{\sin (\theta)}{\lambda}\right)+\left(1-c_{i}\right) F_{\mathrm{Ni}}\left(\frac{\sin (\theta)}{\lambda}\right)\right|,
$$

where $c_{i}$ is the Fe concentration of phase $i$ and $F_{j}$ is the atomic scattering factor of element $j$. Because $\mathrm{Fe}$ and $\mathrm{Ni}$ have similar atomic numbers, their scattering factors are similar and the average scattering factor at a given $\theta$ varies by less that $10 \%$ for any concentration that can possibly occur in our samples. A further simplifying coincidence is that the scattering factor is independent of concentration near the first $\alpha$ and $\gamma$ peaks, $\sin (\theta) / \lambda=0.24$. Therefore, when the ratio of the first two peak intensities is taken, many of the factors in Eq. (1) cancel and some factors almost cancel. For example, the atomic volumes, scattering amplitudes, and

TABLE II. Same as Table I, but for $\gamma$ peaks.

\begin{tabular}{lccccc}
\hline \hline$h k l$ & 111 & 200 & 220 & 311 & 222 \\
\hline$P / m(B=0)$ & 0.383 & 0.302 & 0.111 & 0.075 & 0.066 \\
$P / m(B=29)$ & 0.207 & 0.135 & 0.067 & 0.041 & 0.041 \\
$F^{2}(\theta) / \lambda$ & 312 & 254 & 172 & 133 & 122 \\
$\sin (\theta)$ & 0.24 & 0.28 & 0.39 & 0.43 & 0.46 \\
\hline \hline
\end{tabular}

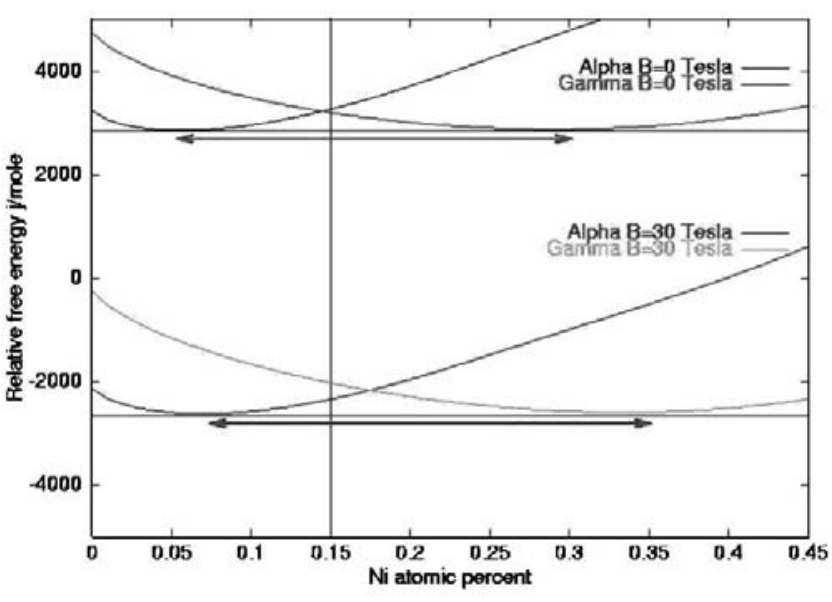

FIG. 2. Free energy with and without applied field. Arrows indicate the phase concentrations.

$\sin (\theta) / \lambda$ are almost equal. When performing these nearly exact cancellations, an extremely simple expression relating $P_{111 \gamma} / P_{110 \alpha}$ to the volume ratio is obtained:

$$
\frac{m_{110}}{m_{111}} \frac{P_{111 \gamma}}{P_{110 \alpha}}=\frac{V_{\gamma}}{V_{\alpha}}=R_{0} .
$$

This simple relation gives the volume fraction $F_{B=0}$ $=V \gamma_{B=0} / V_{B=0 \text { total }}=R_{B=0} /\left(1+R_{B=0}\right)$ to within $1 \%$ of the full expression, Eq. (1).

The integrated intensities under each peak divided by the multiplicity are given in Tables I and II, along with the value of $\sin (\theta) / \lambda$ and the atomic scattering factors. The integrated intensities are in arbitrary units and have been normalized to give $P_{110} / m_{110}=1.0$ for both samples.

The simplicity of Eq. (2) allows us to read $R_{B=0}$ from the data for the 110 and 111 peaks; We find $R_{B=0}=0.383$ and $F_{B=0}=0.28$. The value of 0.28 is smaller than the equilibrium values of $0.355 \pm 0.03$ from application of the lever rule to the phase diagram. ${ }^{8}$ To put this discrepancy into perspective, consider that an uncertainty in our annealing temperature of $10^{\circ} \mathrm{C}$ results in an additional uncertainty in the expected volume fraction of \pm 0.01 ; an uncertainty of $1 \%$ in our alloy composition results in an additional uncertainty in the expected volume fraction of \pm 0.03 . Our uncertainty in temperature and composition should be smaller than $10^{\circ} \mathrm{C}$ and $1 \%$, so our low observed $\gamma$ volume fraction needs explanation. The difference between our value and the measured equilibrium phase diagram could reflect that either our system has not reached equilibrium or that the value of $E$ in Eq. (1) is not the same for the two phases. By using data from all

TABLE III. $S$ calculated from ratios of peak areas for different peak pairs, $($ area $\mathrm{bcc}) /(\operatorname{area~fcc})$.

\begin{tabular}{llllll}
\hline \hline \multirow{2}{\alpha}{$\alpha$} & \multicolumn{5}{c}{$\gamma$} \\
\cline { 2 - 6 } & 111 & 200 & 220 & 311 & 222 \\
\hline 100 & 1.85 & 2.24 & 1.67 & 1.80 & 1.59 \\
200 & 1.65 & 2.00 & 1.49 & 1.60 & 1.42 \\
211 & 1.94 & 2.35 & 1.75 & 1.88 & 1.66 \\
\hline \hline
\end{tabular}


peaks we can approximately account for the combined effects of thermal diffuse scattering, surface roughness, finite sample thickness, preferred orientation, and deviations from the kinematic approximation (extinction). Such an analysis gives an average value of $F_{B=0}=0.30 \pm 0.03$ that is consistent with the value of 0.28 obtained from the simple formula Eq. (1) and compares reasonably to the previously measured value of $0.355 \pm 0.03$ from the data of Fig. $1 .^{8}$
This result gives a baseline from which to measure the effect of the magnetic anneal. If we know the relative reduction, $S=R_{B=0} / R_{B=29}$, in $R$ induced by the field we can determine the resulting phase fraction,

$$
F_{B=29}=\frac{F_{B=0}}{S+S F_{B=0}-F_{B=0}} .
$$

The value of $S$ can be deduced from intensity ratios:

$$
\frac{\left(P_{h k l}^{\gamma} / P_{h^{\prime} k^{\prime} l^{\prime}}^{\alpha}\right)_{B=0 \mathrm{~T}}}{\left(P_{h k l}^{\gamma} / P_{h^{\prime} k^{\prime} l^{\prime}}^{\alpha}\right)_{B=29 \mathrm{~T}}}=S \frac{\left[F^{2}\left(c_{\gamma}, \theta_{h k l}\right) E_{\gamma}\left(\theta_{h k l}\right) / F^{2}\left(c_{\alpha}, \theta_{h^{\prime} k^{\prime} l^{\prime}}\right) E_{\alpha}\left(\theta_{h^{\prime} k^{\prime} l^{\prime}}\right)\right]_{B=0 \mathrm{~T}}}{\left[F^{2}\left(c_{\gamma}, \theta_{h k l}\right) E_{\gamma}\left(\theta_{h k l}\right) / F^{2}\left(c_{\alpha}, \theta_{h^{\prime} k^{\prime} l^{\prime}}\right) E_{\alpha}\left(\theta_{h^{\prime} k^{\prime} l^{\prime}}\right)\right]_{B=29 \mathrm{~T}}},
$$

provided we have an independent determination of the atomic scattering factor and $E$ ratios. For our sample it can be safely assumed that the scattering factor ratios cancel. We find solid evidence that $E$ is independent of the field. Therefore the ratios reduce to 1 . Table III gives $S$ as determined from different $h k l / h^{\prime} k^{\prime} l^{\prime}$ pairs. Averaging all the data, we obtain $1.8 \pm 0.2$. The variability of $S$ with respect to peak pairs is independent of the atomic scattering amplitude ratio but could reflect changes in $E$ due to the field. However, the most likely source of error is the background subtraction which was done by visual interpolation of the intensity between Bragg peaks. The 222 peak has the fewest counts, and is therefore the most sensitive.

Now that $S$ has been determined, we can use Eq. (4) by inserting the volume fraction for the sample annealed in ambient field, $F_{B=0}=0.30 \pm 0.03$, to obtain the $\gamma$ phase fraction of the field-annealed sample; we obtain $F_{B=29}=0.14$ \pm 0.03 . This demonstrates that the field reduces the amount of the $\gamma$ phase by a factor of 2 . The same relative reduction is obtained if the value of $F_{B=0}$ from the measured phase diagram is used in Eq. (1); the only difference being that the reduction is from 0.36 to 0.16 .

For a collinear ferromagnetic material, an applied field shifts the Kohn-Sham potential of the majority electrons to lower energy. This shift results in a slight increase of the saturation magnetic moment. As the temperature is increased, ferromagnetic materials become slightly noncollinear due to thermal excitation of spin waves. Above the Curie temperature the direction of the local moments have no long range correlation and become increasingly random at higher temperatures. The locally self-consistent multiple scattering code ${ }^{10}$ was used to calculate the change in energy due to the application of a $30 \mathrm{~T}$ field. The additional applied magnetic field contributes a shift in the local Kohn-Sham potential along the direction of the magnetic moment and a rotation of the moment toward the direction of the field.

The thermodynamic model of Chuang et al., ${ }^{6}$ based on experimental data, reproduces the phase diagrams in zero field. We calculated the change in the energy resulting from the application of a magnetic field and added this contribution to the existing thermodynamic model. In this way, contributions, which we expect will not be greatly influenced by the magnetic field, such as phonon energy and entropy, can be taken from the existing model. Because we are interested in a temperature well away from the critical temperature, we can approximate the change in the partition function by summing over a small number of spin configurations. Figure 2 shows the calculated modified free energy curves for $\mathrm{Fe}-\mathrm{Ni}$ at $500{ }^{\circ} \mathrm{C}$. The $\alpha$ phase is found to have increased stability due to the field of $30 \mathrm{~T}$. The concentration at which the $\alpha$ and $\gamma$ curves cross is shifted to higher Ni concentration, indicating an increase in the martensite starting temperature. The field-induced change in the volume fraction of $\alpha$ and $\gamma$ is in qualitative agreement with our measurements.

Research was sponsored by the Laboratory Directed Research and Development Program of Oak Ridge National Laboratory (ORNL), managed by UT-Battelle, LLC for the U. S. Department of Energy under Contract No. DE-AC0500OR22725. Calculations were performed at the National Energy Research Computing Center and the Center for Computational Science, Oak Ridge National Laboratory.

\footnotetext{
${ }^{1}$ K. Shimizu and T. Kakeshita, ISIJ Int. 29, 97 (1989).

${ }^{2}$ R. M. Bozorth, Ferromagnetism (Van Nostrand, New York, 1951); J. C. Slonczewski, in Magnetic Ions in Insulators: Their Interactions, Resonances, and Optical Properties, edited by G. T. Rado (Academic, New York, 1963).

${ }^{3}$ Y. Waseda and K. Suzuki, Phys. Status Solidi 39, 669 (1970).

${ }^{4}$ T. Hoshino, R. Zeller, and P. H. Dederichs, J. Magn. Magn. Mater. 140, 113 (1995).

${ }^{5}$ M. Uhl et al., Phys. Rev. B 50, 291 (1994).

${ }^{6}$ Y.-Y. Chuang, Y. A. Chang, R. Schmid, and J.-C. Lin, Metall. Mater. Trans. 17A, 1361 (1986).

${ }^{7}$ Y. E. A. Fokina, L. V. Smirnov, and V. D. Sadovsky, Fiz. Met. Metalloved. 27, 756 (1969).

${ }^{8}$ J. Zhang, D. B. Williams, and J. I. Goldstein, Metall. Mater. Trans. A 25A, 1639 (1994)

${ }^{9}$ B. E. Warren, X-Ray Diffraction (Dover, New York, 1969).

${ }^{10}$ Y. Wang et al., Phys. Rev. Lett. 75, 2867 (1995).
} 